
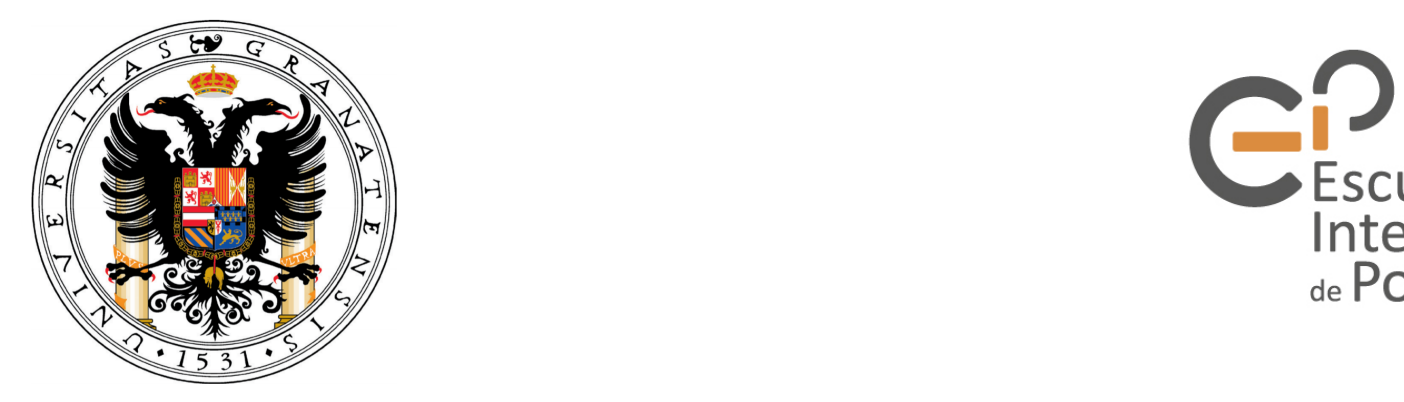

Escuela Internacional de Posgrado

\title{
Propagación de ondas de
}

\section{presión y detección sísmica del meteoroide de Granada 2016}

Máster en Geofísica y Meteorología

Trabajo Fin de Máster

Autor:

Josué Casado Rabasco

Tutores:

Daniel Stich

Juan Luis Guerrero Rascado

UNIVERSIDAD

10 de Septiembre de 2021

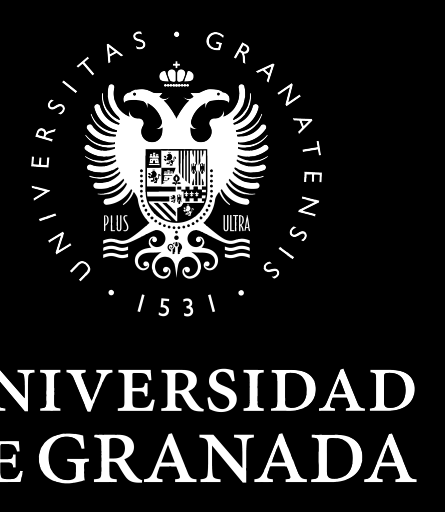





\title{
Propagación de ondas de presión y detección sísmica del meteoroide de Granada 2016
}

\author{
Autor \\ Josué Casado Rabasco \\ Tutores \\ Daniel Stich \\ $I A G$ \\ Juan Luis Guerrero Rascado \\ IISTA-CEAMA

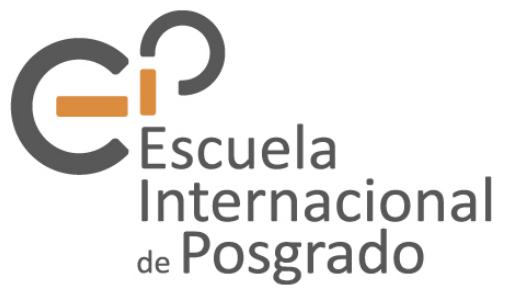

Máster en Geofísica y Meteorología

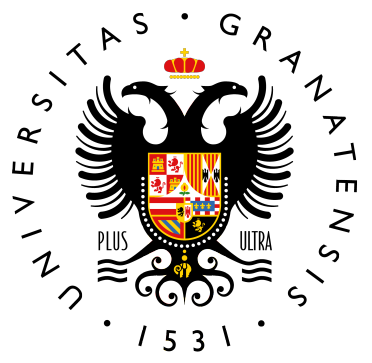

\section{UNIVERSIDAD DE GRANADA}

Granada, 10 de Septiembre de 2021 

¿No ves que los nocturnos meteoros largos surcos de fuego van trazando hacia cualquiera parte do les abre naturaleza misma algún sendero?

Tiembla la tierra por su superficie con motivo de haberse desplomado en su interior grandísimas cavernas, que viene a demoler por fin el tiempo.

Tito Lucrecio Caro. De la naturaleza de las cosas. Siglo I a. C.

I want to thank Luke McFadden for his help and patience with the installation and operation of his program. Thanks, Luke.

Gracias también a José María Madiedo, por sus cálculos de la trayectoria del meteoroide y de los tiempos de los máximos de la curva fotométrica. Agradezco tu dedicación.

Gracias a mis tutores, Daniel Stich y Juan Luis Guerrero Rascado, por su ayuda durante estos meses.

Y gracias a todas las personas que piensen que deberían aparecer aquí. 



\section{Índice general}

$\begin{array}{ll}\text { 1. Introducción } & 1\end{array}$

2. Teoría $\mathbf{5}$

2.1. Meteoroides en la atmósfera . . . . . . . . . . . . . . . . . . . 6

2.1.1. Fragmentación del meteoroide . . . . . . . . . . . . . . . 7

2.1.2. Sonido de meteoros . . . . . . . . . . . . . . . . . . . . 7

2.2. La atmósfera como medio de propagación . . . . . . . . . . . . . . . . . . . 8

2.2.1. De qué depende la propagación . . . . . . . . . . . . . . . 8

2.2.2. Estructura de la atmósfera . . . . . . . . . . . . . . . . . . . 10

2.2.3. Tipos de rayos y zona de sombra . . . . . . . . . . . . . . . . 12

2.3. Propagación de ondas de presión en la atmósfera . . . . . . . . . . . . . . 14

2.3.1. Ecuaciones del trazado de rayos . . . . . . . . . . . . . . . . . 18

3. Datos y Método 23

3.1. Datos sísmicos . . . . . . . . . . . . . . . . . . . 23

3.1.1. Sismogramas y tratamiento . . . . . . . . . . . . . 24

3.1.2. Tiempos de llegada . . . . . . . . . . . . . . . . 26

3.2. Modelo de atmósfera . . . . . . . . . . . . . . . . . . . . 26

3.3. Búsqueda del Supracentro . . . . . . . . . . . . . . . . . . . . 28

3.3.1. Cálculo de los tiempos de viaje y trazado de rayos . . . . . . . . . . . 29

3.3.2. Cálculo del rayo óptimo . . . . . . . . . . . . . . . . . . 31

3.3.3. Cálculo del supracentro. Particle Swarm Optimization . . . . . . . . 32

$\begin{array}{ll}\text { 4. Resultados } & 33\end{array}$

4.1. Tiempo fijo . . . . . . . . . . . . . . . . . 33

4.2. Tiempo como parámetro libre . . . . . . . . . . . . . . . 37

$\begin{array}{lr}\text { 5. Conclusiones } & 39\end{array}$

$\begin{array}{ll}\text { Bibliografía } & 41\end{array}$

$\begin{array}{ll}\text { A. Estaciones sísmicas y sismogramas } & 43\end{array}$

B. Tiempos de llegada $\quad 49$

C. Datos atmosféricos 53

$\begin{array}{ll}\text { D. Transformación vientos } & 55\end{array}$

$\begin{array}{ll}\text { E. Particle Swarm Optimization } & 57\end{array}$

F. Datos astrofísicos $\quad 59$ 



\section{Introducción}

El 11 de diciembre de 2016, alrededor de las 22:25 hora local, los habitantes de varias provincias del sur de España pudieron ver cómo una luz blanca, más brillante que la Luna, iluminaba la noche durante unos instantes. En las redes sociales se hablaba de una bola de fuego. El fenómeno fue acompañado por un temblor y un estallido, que se escuchó en varios pueblos de la provincia de Granada. Algunos vecinos pensaron que se trataba de un terremoto, a los cuales están acostumbrados, cuando vieron vibrar los cristales de las ventanas (Pastor, 2016).

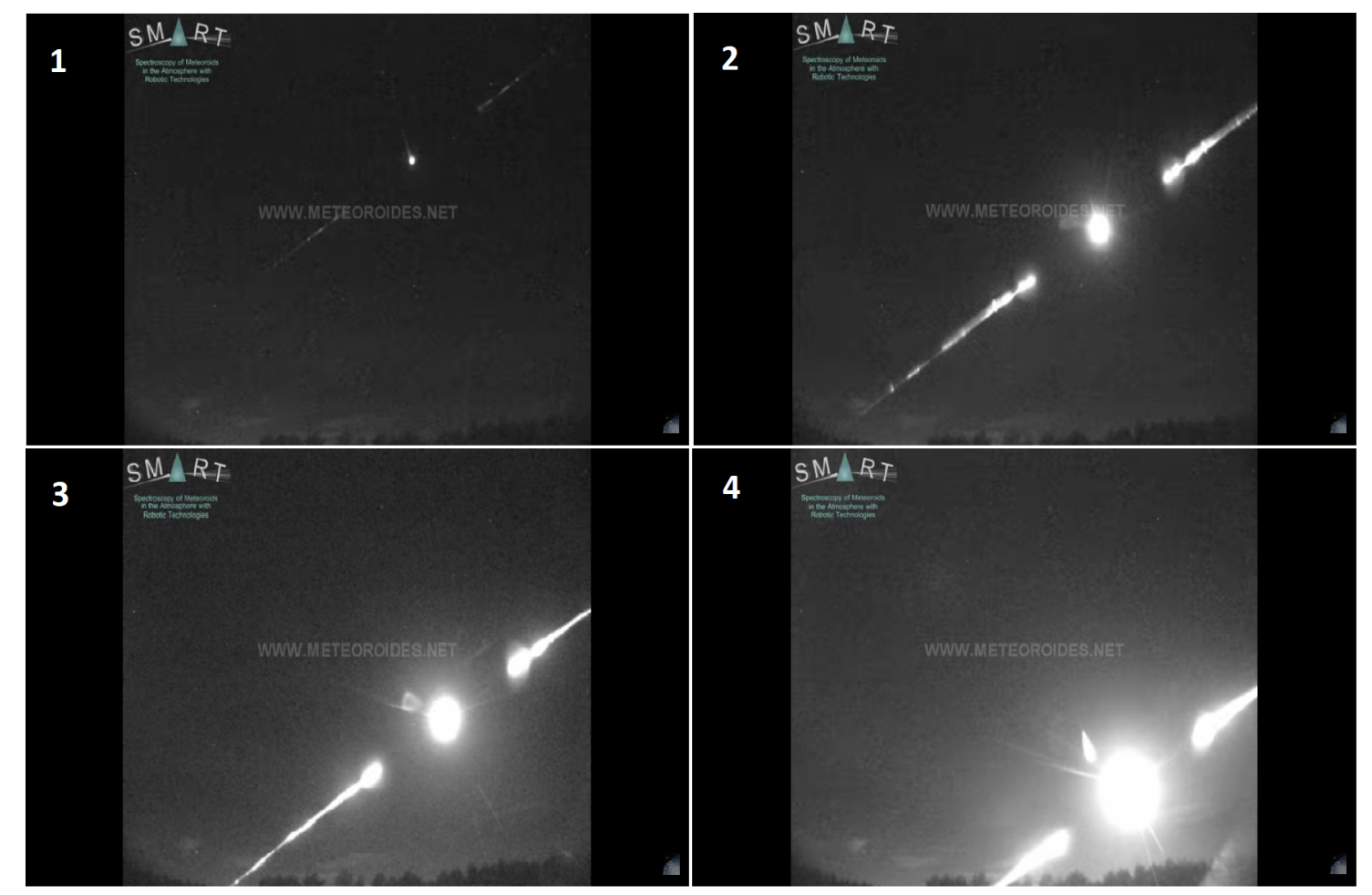

Figura 1.1: Sucesión de fotogramas del evento. Proyecto SMART.

El evento se produjo como consecuencia del impacto contra la atmósfera terrestre de un meteoroide a una velocidad aproximada de $72000 \mathrm{~km} / \mathrm{h}$. Fue registrado por el Proyecto SMART (Spectroscopy of Meteoroids in the Atmosphere by means of Robotic Technologies), que se encarga de detectar y caracterizar los meteoroides que atraviesan la atmósfera terrestre. En concreto, el bólido que sobrevoló Andalucía fue detectado por las estaciones de Calar Alto (Almería), La Hita (Toledo), La Sagra (Granada), Sierra Nevada (Granada) y Sevilla (Madiedo, 2016). En las figuras 1.1 y 1.2 se muestran algunos fotogramas de los vídeos registrados por las cámaras de detección de meteoros que se encuentran ubicadas en esas estaciones ${ }^{1}$.

Como veremos más adelante, cuando un meteoroide entra en la atmósfera puede sufrir

\footnotetext{
${ }^{1}$ Se pueden ver en https://www.youtube.com/watch?v=XXTEAXyXAb4
} 


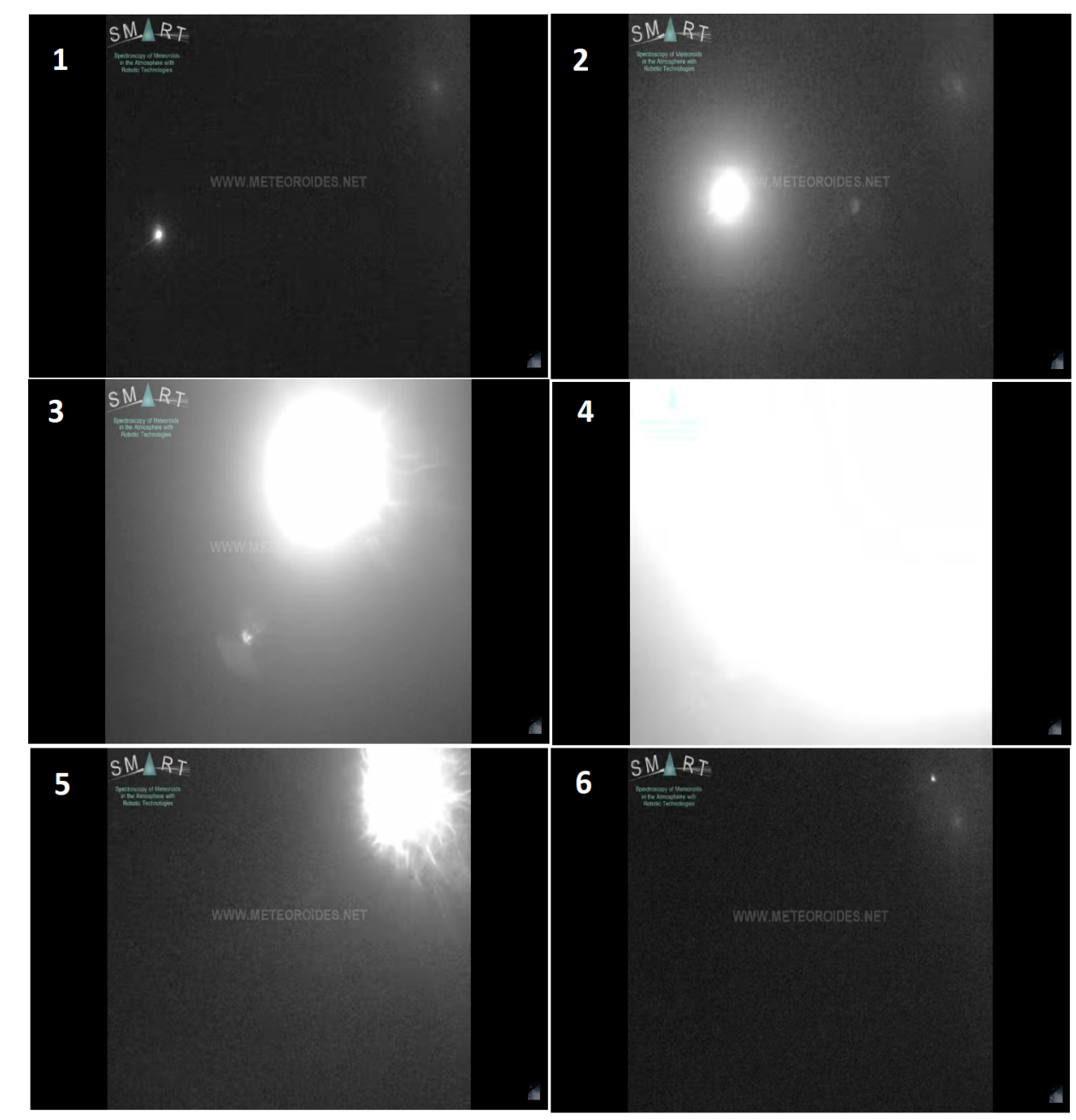

Figura 1.2: Sucesión de fotogramas desde otra perspectiva. Proyecto SMART.

diversas fragmentaciones explosivas que van acompañadas de un aumento de la luminosidad (Edwards et al., 2008). Así, podemos observar en las grabaciones varios momentos de la trayectoria en los que el brillo del meteoro aumenta drásticamente. Por ejemplo, en la figura 1.2.4 tendríamos el momento de máximo brillo, que se correspondería con la explosión de mayor intensidad.

Teniendo en cuenta los testimonios de la gente, es natural que nos preguntemos si los sismómetros de la zona han podido detectar alguna señal procedente del meteoro; y si se han estudiado alguna vez las señales sísmicas con origen en este tipo de fuentes.

Podemos responder a la segunda pregunta recordando un famoso evento que se registró en Rusia hace unos años: el meteoro de Chelyabinsk de 2013. Al igual que ocurre con el meteoro de Granada, el de Chelyabinsk también sufrió una explosión terminal o terminal burst que produjo un temblor y un estallido que fue percibido por los habitantes de la zona. De hecho, la onda de choque generada por la fragmentación explosiva fue lo suficientemente intensa para causar daños severos a personas y edificios, con ventanas rotas en alrededor de 7300 edificios (Heimann et al., 2013). La de Chelyabinsk fue la segunda explosión de un meteoro más grande jamás registrada sísmicamente, después del evento de Tunguska en 1908. Pero el movimiento sísmico causado por el bólido de Chelyabinsk fue detectado en más de 70 estaciones de banda ancha, mientras que el de Tunguska sólo se registró en cuatro estaciones. 
Si se dispone de un modelo suficientemente bueno de la atmósfera en el momento de la explosión del meteoro, se puede modelizar la propagación de la onda de choque atmosférica y su llegada a las estaciones sísmicas, con el objetivo de realizar una inversión de la forma de onda completa (como hace Heimann et al. (2013)) o de los tiempos de llegada a las estaciones (como en McFadden et al. (2021)), y así obtener la localización y altura de la fuente.

Por lo tanto, parece interesante hacer un análisis del bólido de Granada, pues la explosión terminal fue lo suficientemente grande como para ser sentida por las personas. En efecto, si observamos los sismogramas registrados ese día en las estaciones de la zona, podemos observar una llegada clara correspondiente a la onda de choque de la explosión (Figura 1.3).

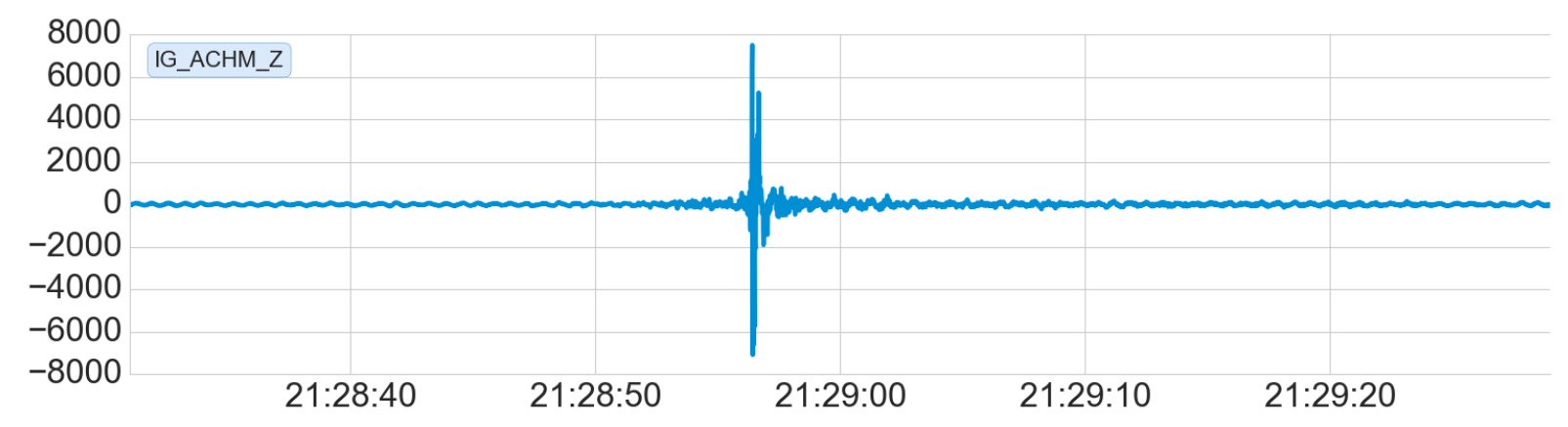

Figura 1.3: Sismograma en la estación sísmica ACHM (Chimeneas) del IAG. Hora UTC.

Por tanto, nuestro objetivo será entender cómo se propaga el sonido a través de una atmósfera realista para establecer un algoritmo de cálculo que permita invertir los tiempos de llegada a las estaciones. De este modo, dado un modelo de atmósfera, la posición de las estaciones y los tiempos de llegada, queremos obtener la localización en el tiempo y en el espacio de la explosión terminal del meteoroide. Con este propósito, comenzaremos introduciendo algunos conceptos básicos acerca del fenómeno meteórico, para entender cómo es la fuente de las ondas. Continuaremos con un estudio general sobre la propagación de ondas de presión en un medio fluido como la atmósfera, para entender cómo afecta la estructura de la atmósfera y de los vientos a las trayectorias que siguen las ondas de sonido. Una vez establecida la teoría formal, se aplicará para establecer un algoritmo de trazado de rayos y de búsqueda de la fuente de ondas, que finalmente aplicaremos al caso particular del meteoroide de Granada de 2016. 



\section{Teoría}

De las diversas fuentes de movimiento sísmico en la Tierra, habitualmente se estudian las que se encuentran en la superficie o por debajo de ésta, como son las explosiones nucleares o los terremotos. Sin embargo, también puede producirse un temblor sísmico debido a fuentes situadas en la atmósfera. La interacción de meteoroides con nuestro planeta pueden generar un movimiento sísmico mediante diversos mecanismos (Heimann et al., 2013).

Un meteoroide es un fragmento de un asteroide que penetra en la atmósfera terrestre. Si consigue impactar contra la tierra sólida, lo que se conoce como meteorito, puede producir ondas sísmicas que se propagarían por el interior terrestre. Por suerte, la atmósfera terrestre actúa como un escudo, reduciendo la energía de los meteoroides y haciendo que muchos no lleguen a la superficie. Esto hace que el movimiento sísmico producido por impactos de meteoritos sea muy poco frecuente. En la mayoría de los casos, el movimiento del suelo es debido a las ondas de choque que llegan hasta la superficie (Heimann et al., 2013).

Cuando el meteoroide atraviesa la atmósfera a una velocidad hipersónica se produce una onda de choque balística cuyo frente de ondas se propaga aproximadamente perpendicular a la trayectoria del meteoroide. En algunos casos, además, el meteoroide puede llegar a fragmentarse, produciendo ondas de choque particularmente fuertes con un frente de ondas aproximadamente esférico. Estas ondas de presión u ondas de sonido son ondas longitudinales que se propagan a través de la atmósfera hasta la superficie terrestre. En general, sólo las ondas con frecuencias en la banda del infrasonido ${ }^{1}$ (inferiores a $20 \mathrm{~Hz}$ ) tienen la suficiente energía para inducir un movimiento medible en el suelo (Edwards et al., 2008). Podemos distinguir tres mecanismos mediante los cuales se pueden producir ondas sísmicas debido a un meteoroide.

1. Acoplamiento directo. Las ondas sísmicas se generan por la carga local en la superficie debido a la presión que ejerce una onda acústica incidente. Son las llegadas directas a las estaciones sísmicas y son las que se miden más frecuentemente.

2. Precursores. El acoplamiento se ha dado en algún lugar de la superficie y se generan ondas superficiales y ondas internas que viajan hacia las estaciones. Dado que su velocidad de propagación es mayor que la del sonido en el aire, estas ondas preceden a las llegadas directas.

3. Acoplamiento por impacto. Generación de ondas internas y superficiales por el impacto de un meteorito contra la superficie. Su observación sísmica es poco común.

En la figura 2.1 se resumen los distintos mecanismos de acoplamiento y generación de ondas comentados hasta ahora. Nuestro interés para este trabajo será la propagación de las ondas de presión generadas por la fragmentación de un meteoroide, así como la detección de las llegadas directas a las estaciones sísmicas.

\footnotetext{
${ }^{1}$ Las ondas de sonido con frecuencias entre 20 y $20000 \mathrm{~Hz}$ son audibles para los humanos. Frecuencias más altas (ultrasonido) y más bajas (infrasonido) son inaudibles.
} 


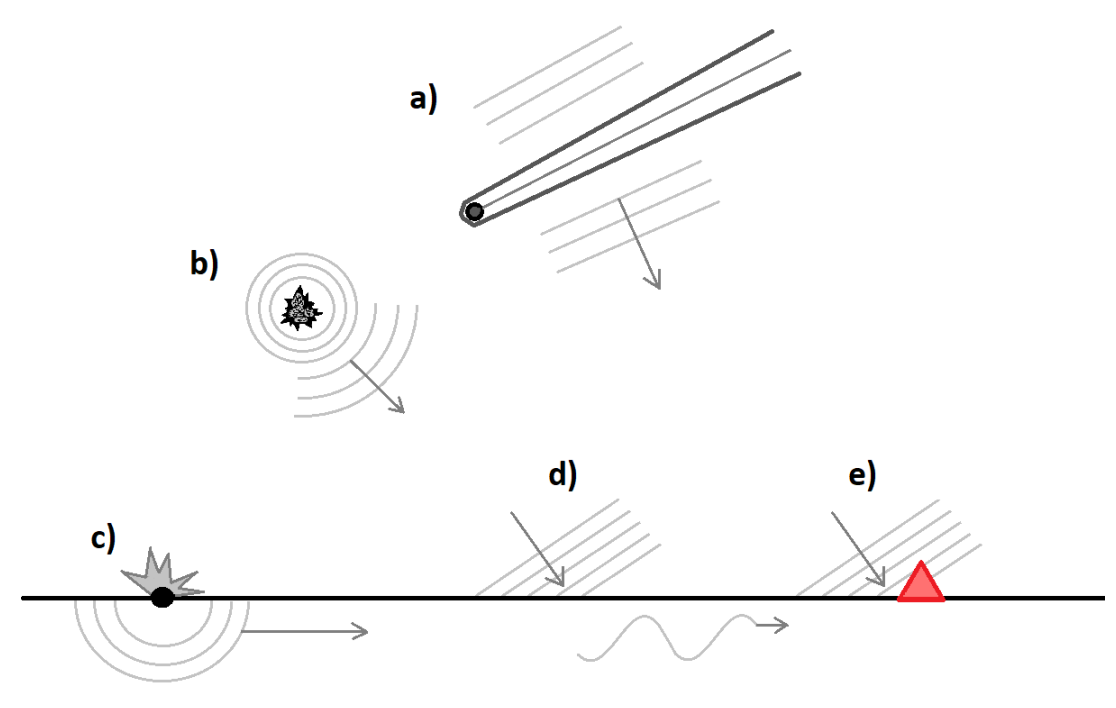

Figura 2.1: Diagrama esquemático que muestra los distintos mecanismos de generación de ondas de choque y de ondas sísmicas debidas a meteoroides. a) Onda de choque balística. b) Fragmentación. c) Impacto de meteorito. d) Precursores sísmicos. e) Llegadas directas por acoplamiento directo. Esta figura está basada en la que aparece en Edwards et al. (2008).

\subsection{Meteoroides en la atmósfera}

Para empezar, vamos a describir brevemente el fenómeno meteórico. Como se ha visto en la introducción, varios procesos físicos ocurren durante el paso de un meteoroide a través de la atmósfera. Además de las ondas de presión producidas en la explosión del meteoroide, que son nuestro principal interés pues es su acoplamiento con el suelo lo que se detecta en las estaciones sísmicas, también se produce un fenómeno luminoso, que permite que el meteoro sea detectado visualmente. Dado que en este trabajo usaremos tanto datos sísmicos como datos obtenidos por cámaras de detección de meteoros, parece interesante dar una breve explicación de los distintos procesos que sufre un meteoroide al atravesar la atmósfera. Para ello, usaremos principalmente la información de Bronshten (1983) y Le Pichon et al. (2010), entre otras a las que se hará referencia.

Como hemos avanzado, la interacción de meteoroides con la atmósfera terrestre produce señales infrasónicas que pueden generar a su vez ondas sísmicas en la Tierra sólida. Esta interacción comienza a alturas en las que la atmósfera es lo suficientemente densa (típicamente entre 60 y $90 \mathrm{~km}$, dependiendo del tamaño del meteoroide), de modo que se pueden dar colisiones entre las moléculas del aire y el meteoroide de forma continua. Debido a la interacción con las moléculas del aire, el meteoroide se caliente a muy altas temperaturas, lo que hace que se funda y se vaporice. Este proceso por el cual el meteoroide pierde masa se conoce como ablación, y consiste en la fusión de la capa más externa del cuerpo, así como la vaporización de la fase sólida o de la capa líquida formada. Los átomos vaporizados del meteoroide y las moléculas del aire se excitan y se ionizan debido a las colisiones inelásticas que sufren entre sí. Se forma así un plasma de átomos, iones y electrones alrededor del meteoroide, llamado coma. A medida que los electrones excitados caen a un estado de menor energía se liberan fotones, produciéndose el fenómeno visual que vemos desde la superficie: una cola brillante que deja el meteoroide a su paso. Esto es lo que llamamos un meteoro, 
y su luminosidad está relacionada con la pérdida de masa del meteoroide (Edwards, 2003; Le Pichon et al., 2010).

En este sentido, las estrellas fugaces son producidas por aquellos meteoroides que son completamente destruidos por el proceso de ablación (ReVelle, 1973). Si son lo suficientemente grandes para sobrevivir a la ablación, los meteoroides pueden llegar a impactar con la superficie terrestre o pueden sufrir una fragmentación explosiva que resulta en la destrucción del meteoroide en micro-partículas y pequeños fragmentos.

Además del fenómeno de ablación, cuando un meteoroide atraviesa la atmósfera a tan altas velocidades se genera una onda de choque balística, al igual que ocurre con los aviones supersónicos. Estas ondas de choque son ondas de presión que se producen cuando un objeto viaja por un medio a una velocidad mayor que la velocidad del sonido en ese medio. La forma de este frente de ondas se conoce como cono de Mach, y corresponde al caso de la figura 2.1.a. Las altas velocidades de estos meteoroides hacen que el ángulo típico del cono de Mach sea lo suficientemente pequeño para que podamos aproximar el frente de ondas como cilíndrico, propagándose perpendicular a la trayectoria (Edwards et al., 2008). Cuando un meteoro va acompañado de un estallido sónico asociado a esta onda de choque (produce ondas acústicas) se le suele conocer como bólido (Edwards, 2003).

\subsubsection{Fragmentación del meteoroide}

Una onda de choque particularmente fuerte puede ser generada por la fragmentación explosiva del meteoroide. En este caso, el meteoroide pierde una gran parte de su energía cinética, que se transmite al frente de onda. Este fenómeno ocurre cuando la presión debida al rozamiento atmosférico es mayor que la que une al propio cuerpo. Al ser sometido a tan altas presiones, la existencia de pequeños defectos en la propia estructura cristalina facilita la aparación de microroturas, que crecen y se acumulan hasta formar macroroturas, en las que finalmente se da la fractura. Normalmente va acompañado de un aumento de la luminosidad del meteoro, ya que se produce un aumento súbito del área superficial que sufre ablación (Heimann et al., 2013). Si tuviéramos una curva fotométrica medida por un radiómetro, las fragmentaciones del meteoroide aparecerían como picos que sobresalen (ver por ejemplo McFadden et al. (2021)). La fragmentación del meteoroide puede darse como una serie de explosiones en cascada o como una sola explosión mayor, llamada terminal burst (Edwards, 2003).

En estos casos, se producen ondas de choque con frentes de onda cuasi-esféricos, como si se tratara de una explosión en la atmósfera. Frente a la onda de choque balística, ésta se conoce como onda de choque ablacional (Edwards et al., 2008). Cuanto más lento viaje el meteoroide, mejor será la aproximación a un fuente puntual con propagación esférica, siendo las velocidades típicas de entrada de un meteoroide de entre 11.2 y $73.2 \mathrm{~km} / \mathrm{s}$ (ReVelle, 1973). En el estudio sísmico de las ondas generadas por meteoroides, la localización espacio-temporal de la fragmentación explosiva se conoce como supracentro, en analogía al hipocentro de un terremoto.

\subsubsection{Sonido de meteoros}

Tanto el viaje supersónico del meteoroide a través de la atmósfera como la fragmentación de éste son capaces de producir ondas de presión asociadas, y por tanto una señal acústica. Estas señales incluyen sonidos audibles por las personas, como el propio estallido sónico (Edwards and Hildebrand, 2004; Le Pichon et al., 2010). Pero nos interesan más las señales 
acústicas dentro del rango del infrasonido, pues pueden propagarse a mayor distancia antes de disiparse completamente, y por tanto, como se ha comentado antes, son estas frecuencias las que llegan a la superficie terrestre con la energía suficiente para inducir movimiento del suelo.

A diferencia de la luminosidad y la ionización, la producción de sonido no está directamente relacionada con el proceso de ablación, sino con la resistencia atmosférica. Esto es porque el sonido generado no es otra cosa que la onda de choque producida cuando el meteoroide atraviesa la atmósfera a velocidades supersónicas. Debido al rozamiento con el aire, el meteoroide pierde su energía cinética, que se transmite al frente de ondas. Inicialmente, la onda de choque balística sigue una propagación altamente no-lineal, que al alejarse de la fuente sufre una transición hacia un estado de débil no-linealidad, antes de pasar a una propagación lineal con menor atenuación (Le Pichon et al., 2010). Lo mismo ocurre para la onda de choque producto de la fragmentación explosiva del meteoroide. En este caso, la energía que se transmite al frente de onda cuasi-esférico es la de los propios enlaces entre partículas del meteoroide, que se han roto, así como parte de la energía cinética del meteoroide.

Como resumen de este apartado, remarcaremos que el paso de cuerpos meteóricos por la atmósfera produce varias señales físicas que pueden ser medidas: el fenómeno luminoso (debido a la ablación) y el fenómeno acústico (debido al rozamiento atmosférico). Y, por otro lado, distinguimos las señales que se han producido en el propio viaje del meteoroide de aquellas relacionadas con la fragmentación. Es en la fragmentación cuando se producen aumentos de la intensidad de la luminosidad y una onda de presión particularmente fuerte que sigue una propagación propia de una fuente puntual.

\subsection{La atmósfera como medio de propagación}

En el apartado anterior hemos explicado brevemente lo que sucede a los meteoroides en la atmósfera y cómo, en ocasiones, pueden convertirse en una fuente de ondas de presión. A partir de ahora, nos proponemos entender cómo se propagan las ondas de presión por un medio fluido como es la atmósfera. Pero antes de entrar en el estudio matemático de la propagación del sonido, vamos a tratar cualitativamente el asunto, para entender qué esperamos observar empíricamente. Dado que el objetivo final de localizar el supracentro se basa predominantemente en conocer cómo se propagan las ondas, necesitamos entender bien los patrones típicos de la propagación.

\subsubsection{De qué depende la propagación}

El sonido es una onda longitudinal de presión que viaja a través de un medio material, perturbando el estado de equilibrio de las moléculas y haciendo que vibren en la dirección de la propagación. Al tratarse de una onda, podemos modelizar su propagación de acuerdo con la ecuación de ondas ${ }^{2}$, que para el campo de presiones $\psi$ se escribe:

$$
\nabla^{2} \psi-\frac{1}{C^{2}} \frac{\partial^{2} \psi}{\partial t^{2}}=0
$$

\footnotetext{
${ }^{2} \mathrm{Y}$, por tanto, también podemos aplicar otras ecuaciones que gobiernan el comportamiento de las ondas, como la Ley de Snell.
} 
como se deduce, por ejemplo, en Feynman et al. (2011). Aquí, $C$ corresponde a la velocidad de la onda de presión.

Al igual que ocurre con cualquier movimiento oscilatorio, las ondas acústicas que se propagan por el medio se caracterizan por sus frecuencias. Los infrasonidos serían las ondas con frecuencias por debajo de $20 \mathrm{~Hz}$, y son las que sufren menor atenuación a lo largo del trayecto, por lo que son las que pueden propagarse a mayor distancia sin disiparse.

Una gran variedad de fenómenos naturales producen señales acústicas dentro del rango de los infrasonidos, como por ejemplo los volcanes, los rayos, el océano, terremotos o avalanchas (Le Pichon et al., 2010; McFadden et al., 2021). Una fuente natural de infrasonidos, como hemos visto, son los cuerpos interplanetarios que atraviesan la atmósfera terrestre a velocidades supersónicas.

Nos preguntamos entonces de qué características de la atmósfera depende la propagación del infrasonido. En este escenario de ondas de presión de baja frecuencia, podemos obtener una expresión para la velocidad de la onda $C$ que aparece en la ecuación de ondas (ecuación 2.1):

$$
C=\sqrt{\frac{\gamma R T}{M_{0}}}
$$

(McFadden et al., 2021). Como vemos, la velocidad del sonido en un medio estacionario (esto es, en ausencia de vientos) depende de la temperatura absoluta $T$ del medio. En el caso de la atmósfera terrestre, las otras constantes ${ }^{3}$ son $\gamma=1.40, M_{0}=28.9644 \mathrm{~g} / \mathrm{mol} \mathrm{y}$ $R \approx 8.31 \mathrm{~J} / \mathrm{K} / \mathrm{mol}$. Existen fórmulas más completas para la velocidad del sonido, teniendo en cuenta la composición química del aire o el contenido de humedad, pero con esta primera aproximación es suficiente para nuestro propósito.

Siguiendo con la aproximación de la ecuación 2.2, para una atmósfera isótropa, en la que $T$ es constante y no hay vientos, la velocidad de las ondas sería la misma en todos los puntos. En este escenario, las ondas no sufren reflexiones ni refracciones, de modo que siguen una propagación rectilínea desde la fuente hasta el receptor. Por tanto, si tenemos una fuente puntual de ondas (como en el caso de la fragmentación de un meteoroide), éstas se propagan como un frente de onda esférico. El patrón que forman las llegadas en la superficie terrestre corresponde entonces a círculos concéntricos, siendo su centro la proyección del supracentro en la superficie, o epicentro (figura 2.2). Sin embargo, este patrón puede ser notablemente modificado si tenemos en cuenta la estructura térmica de la atmósfera y los vientos (McFadden et al., 2021).

Podemos hacer una analogía con el caso de las ondas sísmicas propagadas por el interior de la Tierra. En ese caso, la velocidad de las ondas P (longitudinales) en cada punto se calcula a partir de la densidad del medio, similar a la velocidad que calculamos para el sonido en función de la temperatura (ecuación 2.2). Sin embargo, el interior de la Tierra, el medio por el que se propagan las ondas sísmicas, se mueve a velocidades tan lentas (del orden de unos pocos milímetros por año) que para las ondas sísmicas (con velocidades de varios kilómetros por segundo) se considera inmóvil. Pero éste no es el caso cuando el medio por el que se propagan las ondas es la atmósfera, pues se trata de un medio fluido que se mueve. Y dado que las velocidades de los vientos, típicamente de decenas de metros por segundo, no son despreciables frente a la velocidad del sonido $(\sim 300 \mathrm{~m} / \mathrm{s})$, debemos tener en cuenta el movimiento del medio.

\footnotetext{
${ }^{3}$ Coeficiente adiabático del aire, masa molar promedio del aire seco y constante universal de los gases, respectivamente.
} 


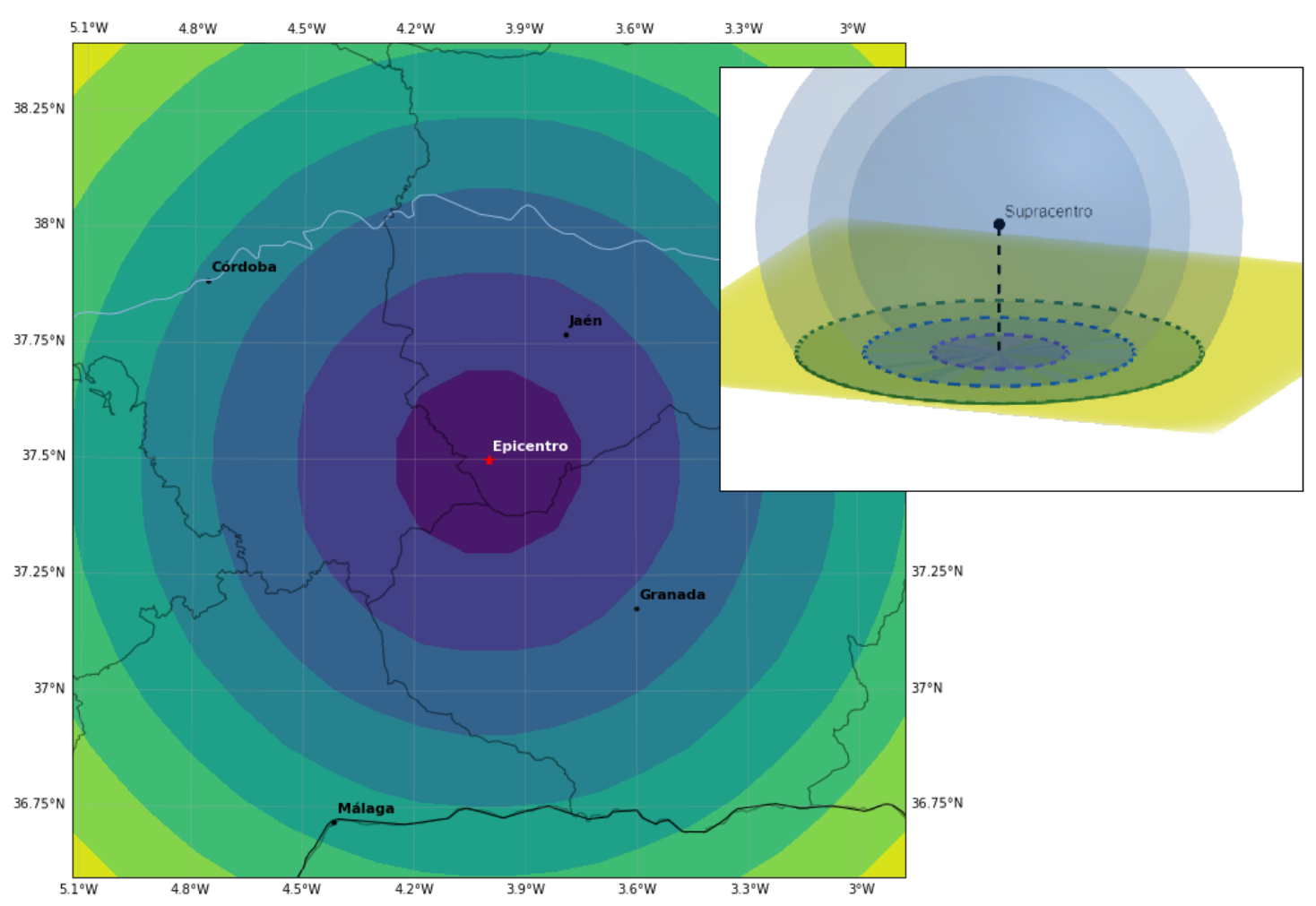

Figura 2.2: Patrón de círculos concéntricos que forman las llegadas de las ondas en superficie en el caso de una atmósfera isótropa. Localización del supracentro y del epicentro. Los colores más claros representan mayor tiempo de viaje.

Por ejemplo, si la velocidad de una onda de presión que viaja por la atmósfera es de $300 \mathrm{~m} / \mathrm{s}$ y además el viento sopla en la misma dirección y sentido con intensidad de $50 \mathrm{~m} / \mathrm{s}$, entonces la velocidad efectiva de la onda (la que mediría alguien desde la superficie estática) sería de $350 \mathrm{~m} / \mathrm{s}$. Pero, si el viento sopla en sentido contrario a la propagación, la velocidad efectiva será de $250 \mathrm{~m} / \mathrm{s}$. Podemos expresar esta relación matemáticamente de la siguiente manera:

$$
C_{\text {eff }}=C+\overrightarrow{\boldsymbol{V}} \cdot \hat{\boldsymbol{n}}
$$

donde $C_{\text {eff }}$ es la velocidad efectiva de la perturbación que mediría un observador en un sistema de referencia inercial; $C$ viene dado por la ecuación $2.2 ; \overrightarrow{\boldsymbol{V}}$ es la velocidad del viento respecto al sistema estacionario; y $\hat{\boldsymbol{n}}$ la dirección de propagación de la onda de presión, es decir, el vector unitario normal al frente de onda. Así, el producto escalar $\overrightarrow{\boldsymbol{V}} \cdot \hat{\boldsymbol{n}}$ no es otra cosa que la componente del viento que es paralela a la dirección de propagación (Le Pichon et al., 2010).

\subsubsection{Estructura de la atmósfera}

La velocidad del sonido y la temperatura de la atmósfera son directamente proporcionales según la ecuación 2.2. Dado que son las variaciones en la velocidad de propagación las que controlan las refracciones y reflexiones (y por tanto la curvatura de las trayectorias) que sufrirán las ondas de sonido (según la Ley de Snell), podemos hacernos una idea cualitativa de cómo puede ser la propagación típica del sonido en la atmósfera si atendemos a su estructura térmica.

La atmósfera está dividida en distintas regiones según las variaciones en el gradiente de 
la temperatura, de la misma manera que la Tierra sólida está dividida en capas, también según el gradiente térmico (figura 2.3). La capa de la atmósfera que está en contacto con la superficie terrestre es la troposfera. En esta capa, la temperatura desciende con la altura hasta llegar a la tropopausa, zona de transición hacia la siguiente capa, la estratosfera. En esta capa, que sube desde la tropopausa hasta los $50 \mathrm{~km}$ aproximadamente, el gradiente térmico es positivo, lo que significa que la temperatura aumenta con la altura. Al pasar la estratopausa, encontramos una capa en la que el gradiente vuelve a ser negativo, la mesosfera, y la temperatura desciende hasta llegar a la mesopausa, a unos $80 \mathrm{~km}$ de altura. Finalmente, en la termosfera, la temperatura vuelve a aumentar con la altura (Garcés et al., 1998).

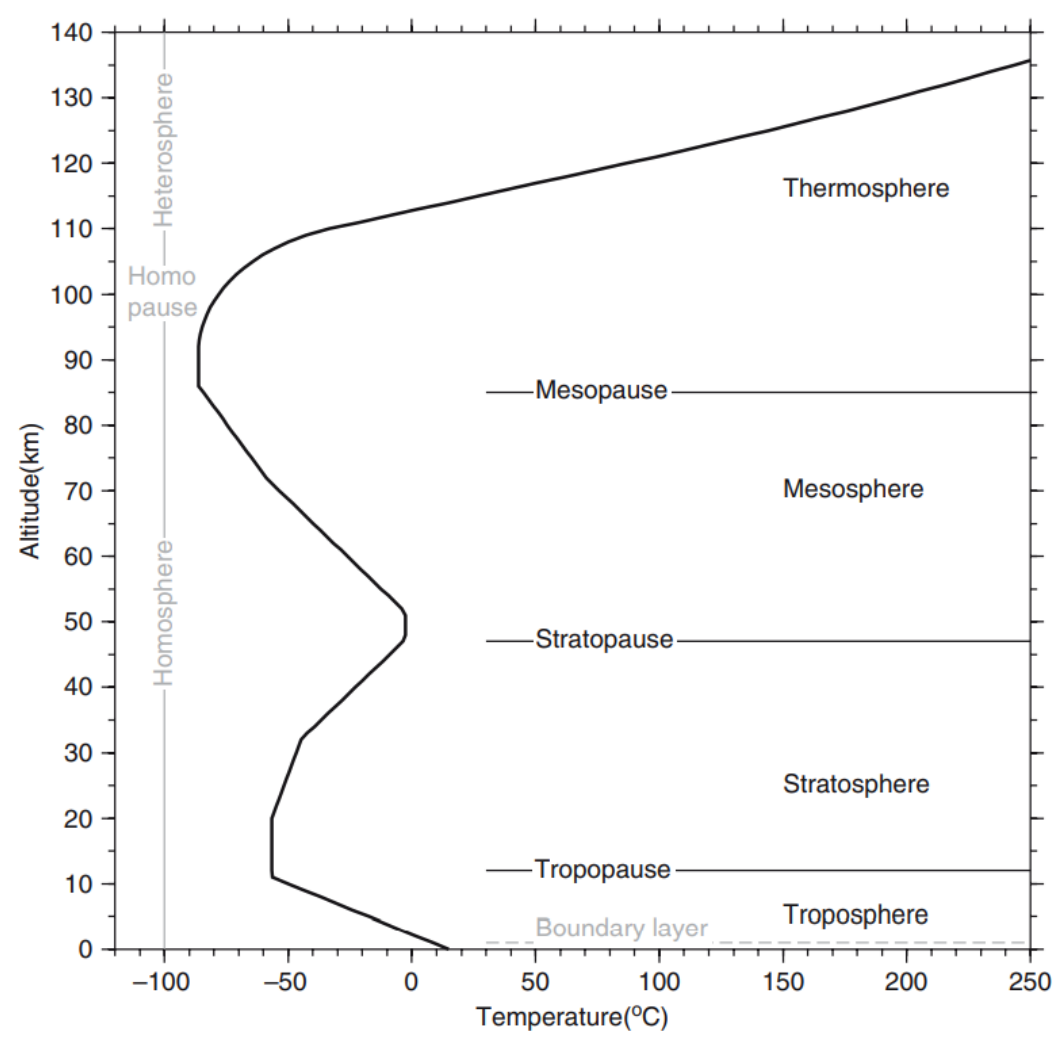

Figura 2.3: Estructura térmica típica de la atmósfera terrestre. Nombres en inglés de las distintas capas. Esta figura aparece en Le Pichon et al. (2010).

Y por tanto, el perfil en altura para la velocidad del sonido tendrá aproximadamente el mismo comportamiento que el perfil de temperatura de la figura anterior. Esto ya es suficiente para deducir que en la troposfera, donde la temperatura disminuye con la altitud, la onda de sonido tenderá a curvarse hacia arriba, según la Ley de Snell:

$$
\frac{\sin \theta_{1}}{\sin \theta_{2}}=\frac{C_{1}}{C_{2}}=\frac{\sqrt{T_{1}}}{\sqrt{T_{2}}}<1 \Rightarrow \theta_{2}>\theta_{1}
$$

Es decir, al pasar de un medio de menor velocidad a uno de mayor velocidad, el ángulo $\theta$ del rayo con respecto a la normal aumenta. 


\subsubsection{Tipos de rayos y zona de sombra}

Conocer la estructura típica de la atmósfera nos permite clasificar los rayos ${ }^{4}$ según los distintos caminos que recorren entre la fuente y el receptor. Es decir, una llegada medida en superficie no tiene porqué ser necesariamente un rayo directo, sino que, debido a la refracción y a la estructura de la atmósfera, puede haber seguido otro camino. A continuación exponemos la clasificación que se expone en Edwards (2003):

a) Llegadas directas. Rayos que viajan directamente desde la fuente al receptor.

b) Llegadas de precursores. Rayos que se acoplan al suelo y generan ondas sísmicas superficiales, llegando al receptor como ground roll.

c) Reflexiones estratosféricas ${ }^{5}$. Rayos que antes de llegar al receptor sufren una refracción de vuelta al suelo desde la estratosfera.

d) Reflexiones termosféricas ${ }^{6}$. Rayos que se refractan hacia el suelo desde la termosfera.

e) Ondas guiadas 7 . Rayos que viajan horizontalmente entre la estratosfera y la troposfera, a través de una guía de ondas atmosférica o conducto atmosférico.

f) Rayos que antes de llegar al receptor han rebotado en la superficie terrestre de vuelta a la atmósfera, para acabar volviendo al suelo.

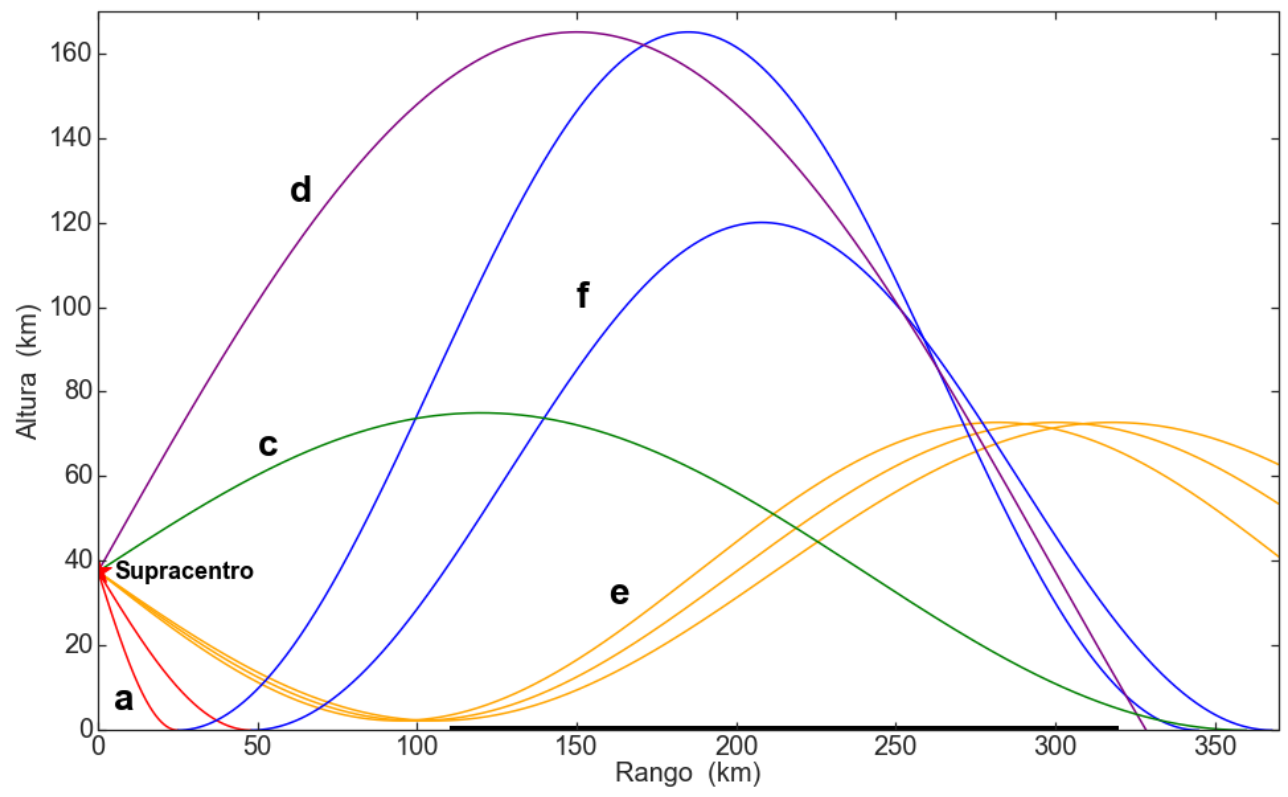

Figura 2.4: Esquema cualitativo con los distintos tipos de llegadas, según la clasificación anterior. Trayectorias no realistas. La línea gruesa del eje horizontal representa la zona de sombra aproximadamente. Esta figura está inspirada en otra que aparece en Edwards (2003).

\footnotetext{
${ }^{4}$ Como es usual cuando se estudia la propagación de ondas, podemos hablar indistintamente de rayos y ondas. Discutiremos esto más adelante.

${ }^{5}$ Del inglés, Stratospheric returns.

${ }^{6}$ Del inglés, Thermospheric returns.

${ }^{7}$ Del inglés, Ducted waves.
} 
Para el propósito de la localización del supracentro, solo las llegadas directas serán calculadas en el trazado de rayos, pues son las más energéticas ya que los efectos de atenuación son menores.

En la figura 2.4 se muestra un diagrama esquemático con los tipos de rayos que hemos comentado. Podemos observar que las llegadas directas alcanzan la superficie sólo hasta distancias de unos $100 \mathrm{~km}$, en el ejemplo de la figura. Después, por efecto de la estructura de la atmósfera, tenemos todo un rango de distancias a las que no llega ningún tipo de rayo, hasta que, a más de $300 \mathrm{~km}$, volvemos a encontrar llegadas. Como hemos visto antes, debido a que en la troposfera la temperatura disminuye con la altura, los rayos que se propagan hacia la superficie con una orientación más horizontal tenderán a refractarse hacia arriba, alejándose del suelo. Esta refracción típica crea una zona de sombra en la superficie, donde no se reciben llegadas directas (Edwards, 2003).

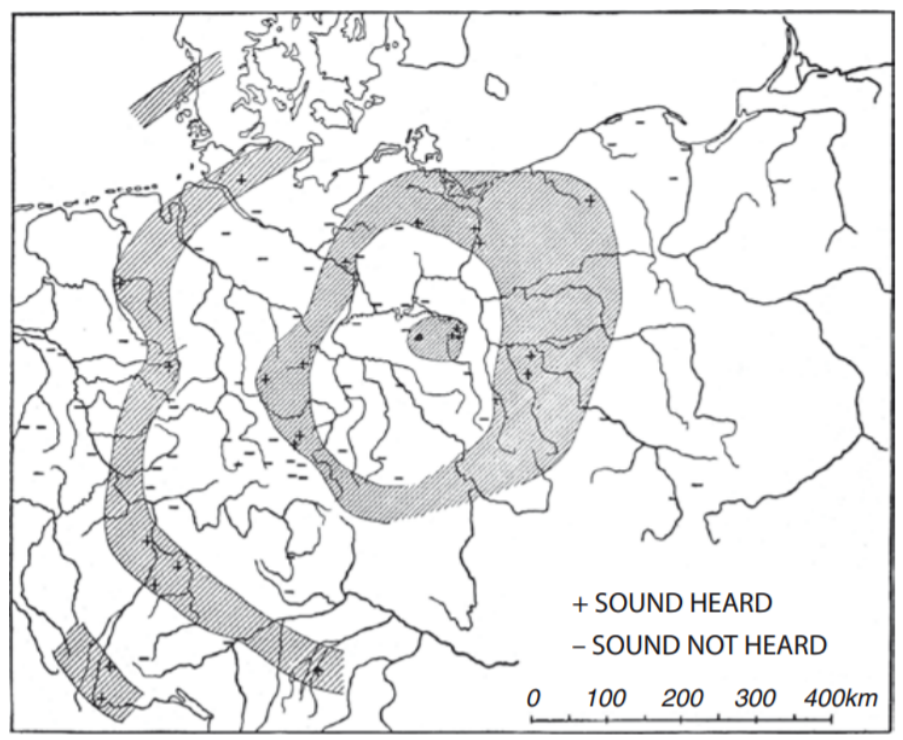

Figura 2.5: Distribución de las zonas en las que se detectó, o no, el sonido de una explosión de 1938. Esta imagen aparece en Le Pichon et al. (2010).

Ya en 1857, Stokes desarrolló el concepto de zona de sombra como el área de la superficie a la que el sonido no llega a propagarse (Edwards, 2003). En el siglo XX, algunos estudios analizaban las observaciones de eventos explosivos, encontrando zonas en las que se podía escuchar la explosión y otras en las que no (figura 2.5). Es decir, a partir de cierta distancia es probable que las ondas de infrasonido no lleguen a alcanzar la superficie terrestre siguiendo un camino directo desde la fuente. Todavía hay debate a la hora de explicar esta zona de sombra, pero se sabe que tanto la estructura térmica como el viento afectan (Le Pichon et al., 2010).

En particular, el efecto del viento puede ser el de acortar o alargar el rango de distancias que pueden alcanzar los rayos directos, según si estos viajan de barlovento o sotavento. En la figura 2.6 tenemos un trazado de rayos en una atmósfera con un perfil típico de temperaturas, con y sin viento. En ambos casos aparece una zona de sombra debido a la refracción de los rayos. Sin embargo, por acción del viento, el rango de distancias que pueden alcanzar los rayos es menor si viajan en contra del viento, y llegan más lejos al viajar en la misma dirección que éste. 

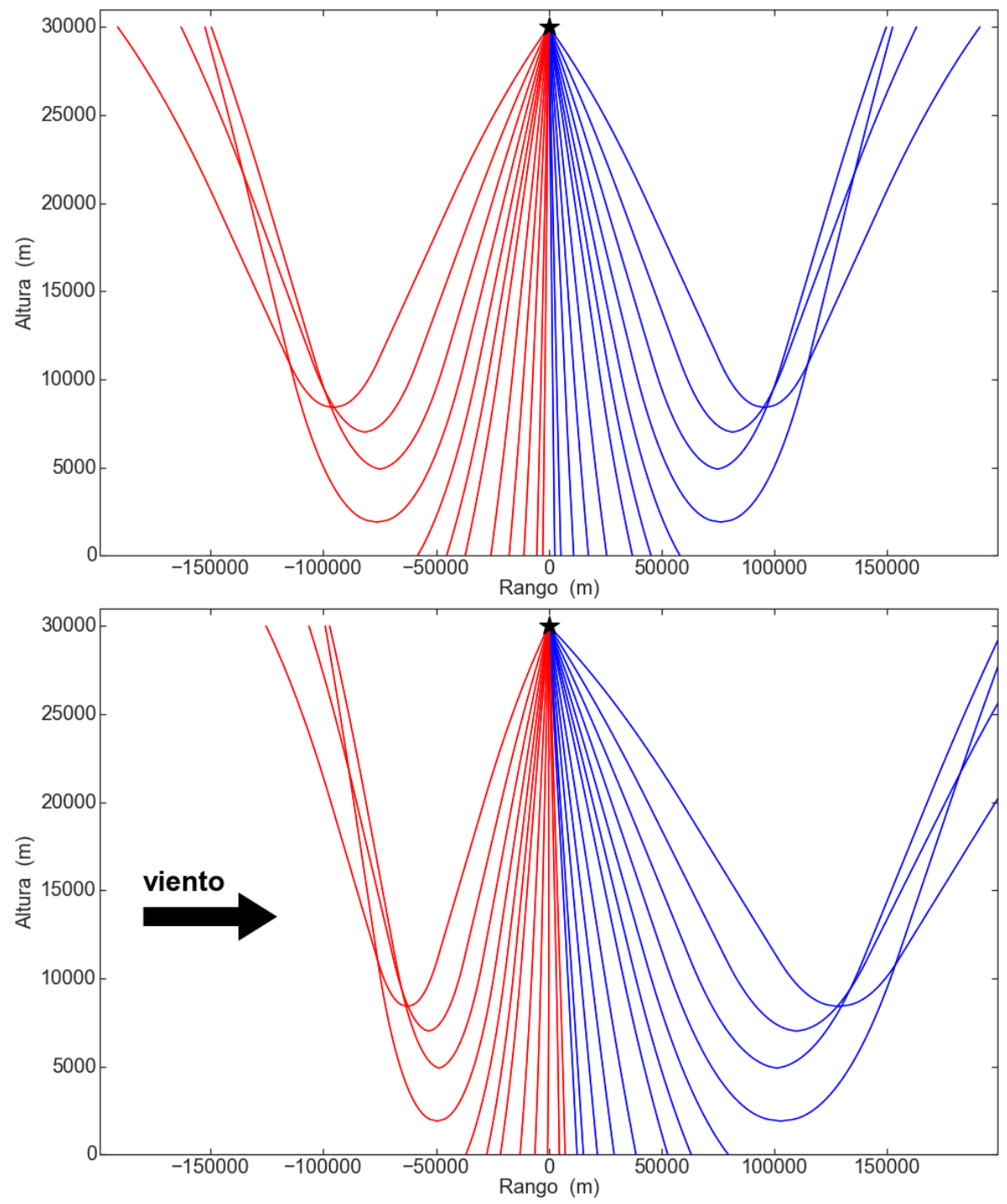

Figura 2.6: Viaje de los rayos en una atmósfera típica (International Standard Atmosphere, 1976), con y sin vientos. Viento de $100 \mathrm{~m} / \mathrm{s}$ en la dirección que marca la flecha negra, en todas las alturas. Trazado de rayos realizado con el método que veremos en el siguiente capítulo.

\subsection{Propagación de ondas de presión en la atmósfera}

Una vez que hemos completado esta breve descripción de la fuente de la onda de presión, así como de las características más importantes del medio de propagación, podemos por fin afrontar la propagación del sonido en un medio fluido. Para estudiar formalmente la propagación de un frente de ondas en un medio en movimiento, como es el caso de la atmósfera si tenemos en cuenta los vientos, usaremos principalmente las referencias Lindsay (1960) y Groves (1955).

El formalismo de la propagación de ondas acústicas es análogo al que se usa para estudiar la propagación de las ondas sísmicas en el interior de la Tierra, pues ambos casos se engloban dentro de uno más general: la propagación de una perturbación mecánica en un medio material. La diferencia crucial, como ya se ha comentado, es la velocidad del propio medio. Para el caso de las ondas sísmicas, podemos despreciar la velocidad del medio. Sin embargo, tendremos que tener en cuenta los vientos al estudiar la propagación del sonido, pues sus 
velocidades no son despreciables.

Comencemos estableciendo la notación que vamos a usar para el desarrollo matemático. Primero adoptaremos un sistema de referencia $S$, estacionario respecto al medio fluido (se corresponde, por ejemplo, con un observador colocado en la superficie de la Tierra). Usamos coordenadas cartesianas $(x, y, z)$ para describir la posición de cualquier punto del medio en el sistema $S$. La velocidad del sonido en el punto $\overrightarrow{\boldsymbol{r}}=(x, y, z)$ será:

$$
C=C(\overrightarrow{\boldsymbol{r}}, t)
$$

Es decir, es una función del espacio y del tiempo, pues las condiciones atmosféricas son variables. Por otro lado, la velocidad del medio en cada punto, es decir, la velocidad del viento, se describe con una magnitud vectorial que también depende de la posición espacial y del instante temporal:

$$
\overrightarrow{\boldsymbol{V}}=\overrightarrow{\boldsymbol{V}}(\overrightarrow{\boldsymbol{r}}, t)
$$

Un resultado bien conocido de la óptica establece que la teoría ondulatoria de la propagación de la luz puede reemplazarse por una teoría geométrica en el caso límite en el que la longitud de onda se hace cero. Es así como se introduce el concepto de rayo. Para un medio cuyas propiedades varían de forma continua, la teoría geométrica sigue siendo una aproximación válida a la teoría ondulatoria. En nuestro caso, si nos centramos en el rango de los infrasonidos, la situación es análoga y podemos estudiar la propagación del sonido usando la teoría geométrica (Groves, 1955). De este modo, igual que se hace en el estudio de la propagación de las ondas sísmicas, pasaremos a hablar de un trazado de rayos para estudiar las trayectorias que siguen las ondas de sonido en la atmósfera.

Definimos el frente de ondas como la superficie geométrica con perturbación constante en magnitud y fase. La propagación de ondas en un medio se estudia entonces considerando el movimiento de estas superficies. Se trata de un problema geométrico que normalmente se simplifica considerando las curvas que son perpendiculares a la superficie en cada punto (Lindsay, 1960). El concepto de rayo antes mencionado hace referencia a estas curvas, y de esta forma convertimos el problema de la propagación de ondas en un problema de trazado de rayos.

Podemos parametrizar el frente de ondas usando unas coordenadas $(\alpha, \beta)$ para cada punto de la superficie, que a su vez definen el rayo que pasa por ese punto (figura 2.7). De este modo, el frente de onda lo conforman los puntos $\overrightarrow{\boldsymbol{r}}(\alpha, \beta, t)$. Y el vector normal al frente de ondas en el punto $(\alpha, \beta)$ será:

$$
\hat{\boldsymbol{n}}=\hat{\boldsymbol{n}}(\alpha, \beta, t)
$$

Este vector normal indica la dirección del rayo descrito por las coordenadas $(\alpha, \beta)$. Que el vector normal sea unitario podemos expresarlo así:

$$
\hat{\boldsymbol{n}}^{2}=1
$$

Y que sea normal a la superficie en cada punto se expresa como:

$$
\hat{\boldsymbol{n}} \cdot \frac{\partial \hat{\boldsymbol{n}}}{\partial \alpha}=\hat{\boldsymbol{n}} \cdot \frac{\partial \hat{\boldsymbol{n}}}{\partial \beta}=0
$$

(Groves, 1955), lo que significa que es perpendicular a las variaciones respecto a las coordenadas paramétricas de la superficie. También las variaciones del vector de posición respecto 


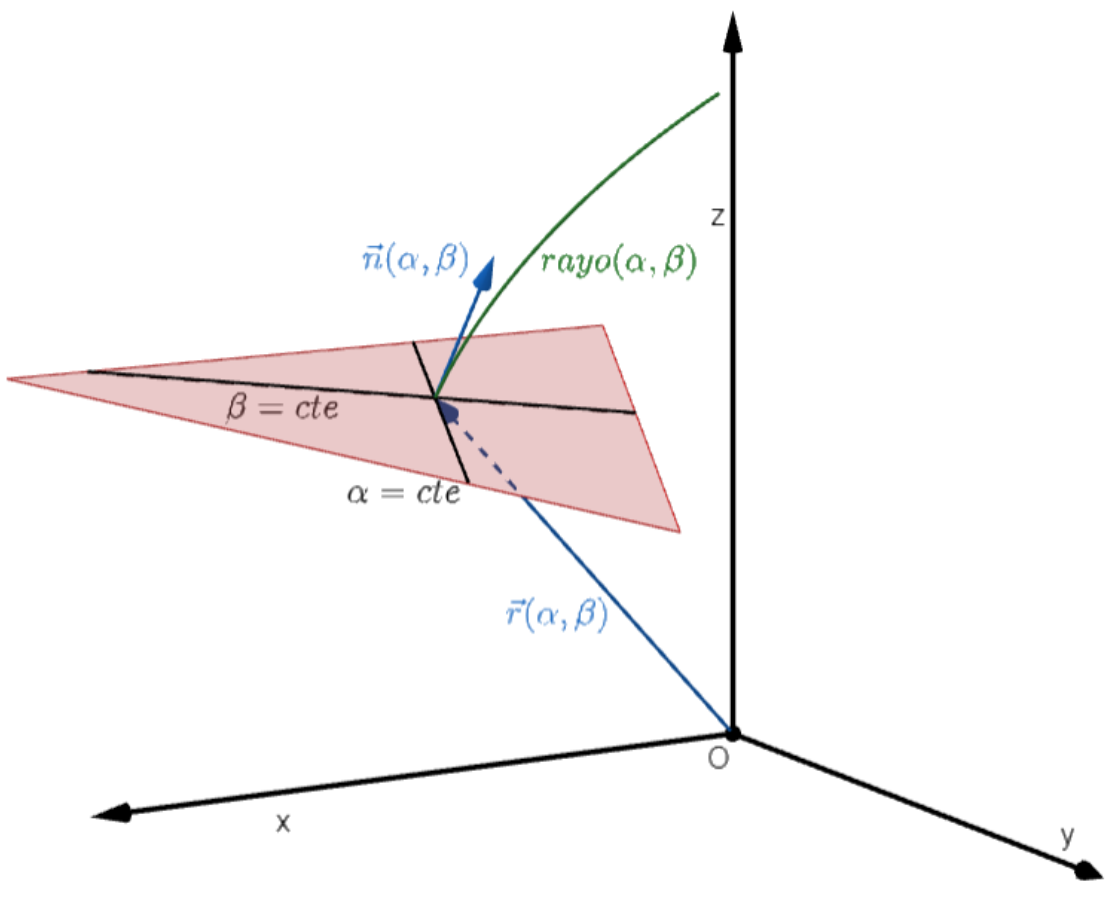

Figura 2.7: Esquema del frente de ondas y el sistema de referencia. Notación. La forma triangular representa una parte de un frente de ondas.

a las coordenadas paramétricas yacen en el plano perpendicular al vector normal en ese punto, es decir:

$$
\hat{\boldsymbol{n}} \cdot \frac{\partial \overrightarrow{\boldsymbol{r}}}{\partial \alpha}=\hat{\boldsymbol{n}} \cdot \frac{\partial \overrightarrow{\boldsymbol{r}}}{\partial \beta}=0
$$

Esta última ecuación la podemos expresar usando la terminología propia del estudio de variaciones de funciones, como hacen en Lindsay (1960), y nos será más fácil manejarla después. De esta forma, denotamos el cambio del vector de posición respecto a cambios en las coordenadas paramétricas como $\delta \overrightarrow{\boldsymbol{r}}$, y la ecuación anterior se expresa como:

$$
\delta \overrightarrow{\boldsymbol{r}} \cdot \hat{\boldsymbol{n}}=0
$$

Y podemos hacer lo mismo para la ecuación 2.9:

$$
\delta \hat{\boldsymbol{n}} \cdot \hat{\boldsymbol{n}}=0
$$

Vamos a asumir que la velocidad de un punto $(\alpha, \beta)$ del frente de ondas es la suma de: (i) la velocidad del sonido en ese punto, $C(\overrightarrow{\boldsymbol{r}}, t)$, en la dirección del vector normal; (ii) la velocidad del viento en ese punto, $\overrightarrow{\boldsymbol{V}}(\overrightarrow{\boldsymbol{r}}, t)$. Es decir:

$$
\frac{d \overrightarrow{\boldsymbol{r}}}{d t}=\overrightarrow{\boldsymbol{V}}(\overrightarrow{\boldsymbol{r}}, t)+C(\overrightarrow{\boldsymbol{r}}, t) \hat{\boldsymbol{n}}
$$

corresponde a la velocidad a la que se traslada el frente de ondas respecto al sistema de referencia estacionario $S$. Por lo tanto, la velocidad efectiva de la perturbación será la proyección en la dirección normal:

$$
C_{e f f} \equiv \frac{d \overrightarrow{\boldsymbol{r}}}{d t} \cdot \hat{\boldsymbol{n}}=\overrightarrow{\boldsymbol{V}}(\overrightarrow{\boldsymbol{r}}, t) \cdot \hat{\boldsymbol{n}}+C(\overrightarrow{\boldsymbol{r}}, t)
$$


que, efectivamente, corresponde a la ecuación 2.3 que ya vimos en el apartado anterior. En Groves (1955) se demuestra que ambas ecuaciones se deducen de la ecuación de la eikonal, que expresa la condición que define la propagación de un frente de ondas en la teoría geométrica, y por tanto satisfacen todas las condiciones necesarias.

Nuestro objetivo es, entonces, derivar una ecuación que nos permita más adelante conseguir un trazado de rayos. Es decir, queremos conocer cómo evoluciona el vector normal en el tiempo. Para ello, vamos a empezar derivando con respecto al tiempo la ecuación 2.11:

$$
\dot{\hat{\boldsymbol{n}}} \cdot \delta \overrightarrow{\boldsymbol{r}}+\hat{\boldsymbol{n}} \cdot \delta \dot{\overrightarrow{\boldsymbol{r}}}=0
$$

donde denotamos la derivada temporal usando la notación de Newton. Podemos desarrollar el término $\delta \dot{\overrightarrow{\boldsymbol{r}}}$ de acuerdo con la definición de variación ${ }^{8}$ aplicándola a la ecuación 2.13:

$$
\delta \dot{\overrightarrow{\boldsymbol{r}}}=\sum_{k} \frac{\partial \dot{\overrightarrow{\boldsymbol{r}}}}{\partial \alpha_{k}} \delta \alpha_{k}=\sum_{k} \delta \alpha_{k} \frac{\partial}{\partial \alpha_{k}}(\overrightarrow{\boldsymbol{V}}(\overrightarrow{\boldsymbol{r}}, t)+C(\overrightarrow{\boldsymbol{r}}, t) \hat{\boldsymbol{n}})=(\delta \overrightarrow{\boldsymbol{r}} \cdot \nabla) \overrightarrow{\boldsymbol{V}}+(\delta \overrightarrow{\boldsymbol{r}} \cdot \nabla C) \hat{\boldsymbol{n}}+C \delta \hat{\boldsymbol{n}}
$$

para lo cual hemos usado algunos conceptos propios del cálculo vectorial y diferencial, que podemos encontrar por ejemplo en Griffiths (2013). Sustituyendo esta expresión en 2.15, y teniendo en cuenta las ecuaciones 2.8 y 2.12 , se obtiene:

$$
\dot{\hat{\boldsymbol{n}}} \cdot \delta \overrightarrow{\boldsymbol{r}}+(\delta \overrightarrow{\boldsymbol{r}} \cdot \nabla) \overrightarrow{\boldsymbol{V}} \cdot \hat{\boldsymbol{n}}+(\delta \overrightarrow{\boldsymbol{r}} \cdot \nabla C)=0
$$

Reordenando los términos y sacando factor común, podemos escribir:

$$
\delta \overrightarrow{\boldsymbol{r}} \cdot[\dot{\hat{\boldsymbol{n}}}+\nabla(\overrightarrow{\boldsymbol{V}} \cdot \hat{\boldsymbol{n}}+C)]=0
$$

Y teniendo en cuenta la definición 2.14 se convierte en:

$$
\delta \overrightarrow{\boldsymbol{r}} \cdot\left[\dot{\hat{\boldsymbol{n}}}+\nabla C_{e f f}\right]=0
$$

Esta última ecuación significa que el vector $\dot{\hat{\boldsymbol{n}}}+\nabla C_{\text {eff }}$ es perpendicular al vector $\delta \overrightarrow{\boldsymbol{r}}$. Y sabemos, por las ecuaciones 2.10 y 2.11 , que $\delta \overrightarrow{\boldsymbol{r}}$ pertenece al plano perpendicular al vector normal. Por lo tanto, el vector $\dot{\hat{\boldsymbol{n}}}+\nabla C_{\text {eff }}$ tiene la misma dirección que $\hat{\boldsymbol{n}}$, y entonces debe ser proporcional a éste. Es decir:

$$
\dot{\hat{\boldsymbol{n}}}+\nabla C_{\text {eff }}=\kappa \hat{\boldsymbol{n}}
$$

Para hallar el valor de $\kappa$, sólo tenemos que multiplicar la expresión anterior por $\hat{\boldsymbol{n}}$ y tener en cuenta que $\hat{\boldsymbol{n}} \cdot \dot{\hat{\boldsymbol{n}}}=0$ (Groves, 1955) y que es unitario. Entonces:

$$
\hat{\boldsymbol{n}} \cdot \nabla C_{e f f}=\kappa
$$

${ }^{8}$ Dada la función $\overrightarrow{\boldsymbol{r}}=\overrightarrow{\boldsymbol{r}}\left(\alpha_{1}, \alpha_{2}, t\right)$, su variación debida a variaciones infinitesimales de $\alpha_{k}$ se escribe:

$$
\delta \overrightarrow{\boldsymbol{r}}=\sum_{k} \frac{\partial \overrightarrow{\boldsymbol{r}}}{\partial \alpha_{k}} \delta \alpha_{k}
$$


Y finalmente, sustituyendo el valor de $\kappa$ en 2.20, obtenemos la relación que buscábamos:

$$
\dot{\hat{\boldsymbol{n}}}=\left(\hat{\boldsymbol{n}} \cdot \nabla C_{e f f}\right) \hat{\boldsymbol{n}}-\nabla C_{e f f}
$$

\subsubsection{Ecuaciones del trazado de rayos}

En este apartado, usaremos las ecuaciones 2.13, 2.14 y 2.22 para obtener las ecuaciones del trazado de rayos y del cálculo de los tiempos de viaje. Esto lo consigue Garcés et al. (1998), extendiendo el método tradicional Tau-p para el caso de un medio en movimiento.

Primero, necesitamos simplificar el problema asumiendo que podemos despreciar la componente vertical de la velocidad del medio. Se trata de una aproximación buena en el caso de que el medio sea la atmósfera, pues los vientos horizontales son mucho mayores que los vientos verticales en condiciones normales (McFadden et al., 2021). También asumimos que el gradiente horizontal de las velocidades de los vientos es despreciable, lo cual supone una aproximación importante. Esto nos permite considerar la atmósfera por capas, y que la velocidad horizontal del viento sea sólo función de la elevación. De este modo, la velocidad del medio en cada punto será el vector de componentes cartesianas:

$$
\overrightarrow{\boldsymbol{V}}=\left(u^{\prime}, v^{\prime}, 0\right)
$$

donde $u^{\prime}$ sea la componente zonal (Oeste a Este) y $v^{\prime}$ sea la componente meridional (Sur a Norte), en el sistema de referencia $S$. Su magnitud y su ángulo azimutal (Norte hacia Este) son, respectivamente:

$$
\begin{aligned}
\|\overrightarrow{\boldsymbol{V}}\| & =\sqrt{u^{\prime 2}+v^{\prime 2}} \\
\omega & =\arctan \frac{u^{\prime}}{v^{\prime}}
\end{aligned}
$$

Ahora, vamos a colocarnos en otro sistema de referencia, $\Sigma$, que se mueve coherente al frente de ondas, de modo que las coordenadas cartesianas del vector normal respecto de este sistema sean $(a, b, c)$ (figura 2.8). En el sistema $\Sigma$, el vector de la velocidad del viento será $\overrightarrow{\boldsymbol{V}}=(u, v, 0)$.

Entonces, vamos a expresar la ecuación 2.13 para cada una de las componentes en este sistema:

$$
\begin{aligned}
& \dot{x}=a C+u \\
& \dot{y}=b C+v \\
& \dot{z}=c C
\end{aligned}
$$

siendo $(\dot{x}, \dot{y}, \dot{z})$ las componentes del vector $\frac{d \vec{r}}{d t}$ en este sistema. De la misma manera, expandimos la ecuación 2.14 y nos queda:

$$
C_{e f f}=C+a u+b v
$$

que será sólo función de la elevación. Y, por último, la ecuación 2.22 expresada en compo- 


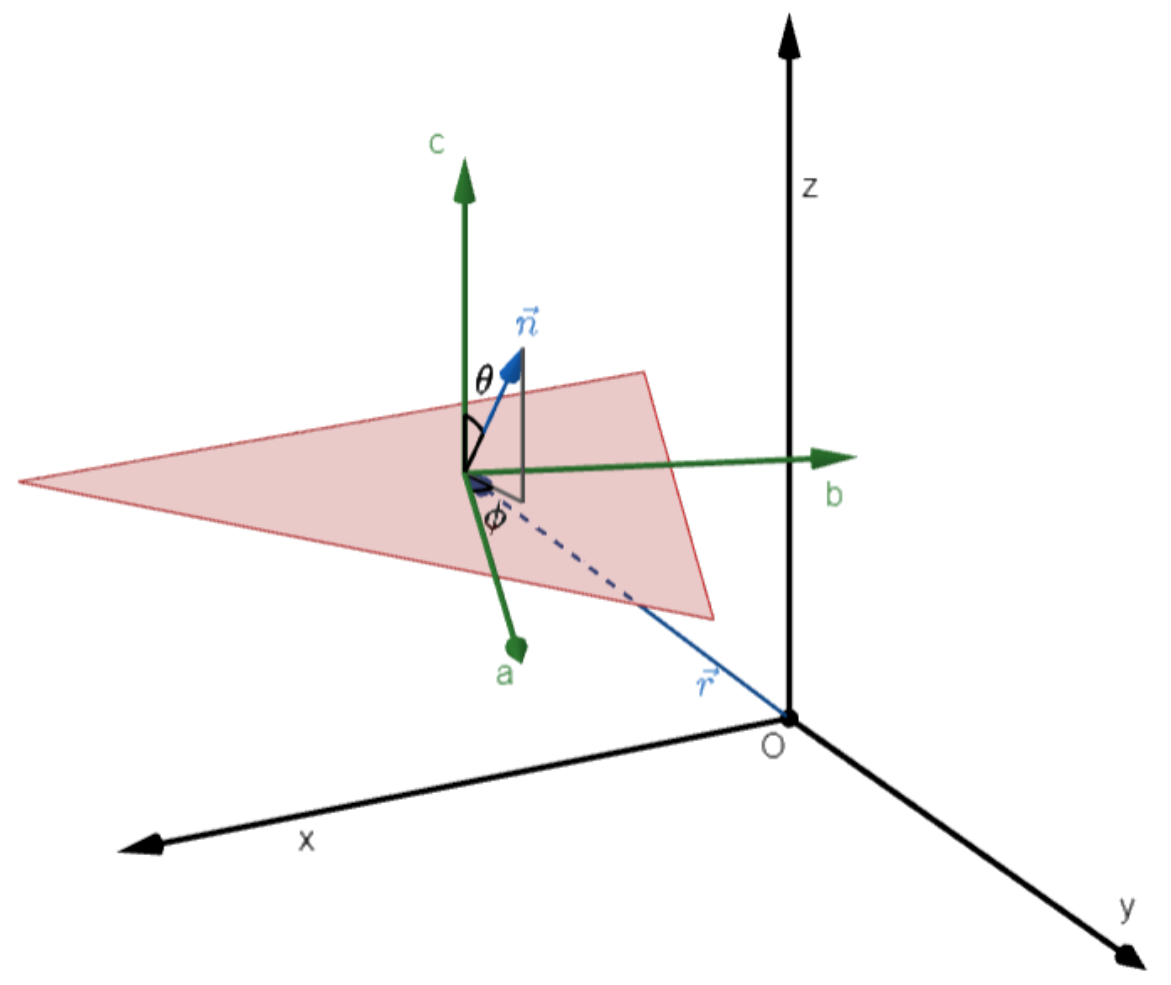

Figura 2.8: Esquema del frente de ondas y el sistema de referencia móvil $\Sigma$ (ejes verdes). Notación.

nentes es:

$$
\begin{aligned}
& \dot{a}=a c \frac{\partial C_{\text {eff }}}{\partial z} \\
& \dot{b}=b c \frac{\partial C_{e f f}}{\partial z} \\
& \dot{c}=\left(c^{2}-1\right) \frac{\partial C_{e f f}}{\partial z}
\end{aligned}
$$

De las dos primeras de estas ecuaciones se obtiene que $\dot{a} / \dot{b}=a / b$. Y la integración inmediata de esta ecuación nos lleva a un resultado fundamental de la teoría acústica:

$$
\frac{a}{b}=c t e
$$

Es decir: La proyección del vector normal en el plano horizontal mantiene una dirección fija. O lo que es lo mismo, el ángulo $\phi$ que aparece en la figura 2.8 es constante a lo largo de la trayectoria. Esto no quiere decir que el rayo no se traslade lateralmente. Sí lo hace. Por efecto del viento, todo el sistema de referencia $\Sigma$ es trasladado, pero con la condición de que la razón $a / b$ permanece constante en ese sistema.

Esto nos permite concretar el sistema $\Sigma$, eligiéndolo de tal modo que el ángulo $\phi$ sea cero. Es decir, alineando el eje $a$ con el vector normal, y que por tanto sea $b=0$. Fijando de esta forma el sistema de referencia $\Sigma$, las componentes $u$ y $v$ del viento son ahora la componente paralela y perpendicular al rayo, respectivamente. Ahora, la ecuación 2.26 se simplifica a:

$$
C_{e f f}=C+a u
$$


De modo que la ecuación 2.27a, calculando la derivada que aparece, se traduce en:

$$
\dot{a}=a c\left(\frac{d C}{d z}+a \frac{d u}{d z}\right)
$$

Dividiendo esta ecuación por la ecuación 2.25c, obtenemos:

$$
\frac{\dot{a}}{\dot{z}}=\frac{d a}{d z}=\frac{a^{2}}{C}\left(\frac{1}{a} \frac{d C}{d z}+\frac{d u}{d z}\right)
$$

Que podemos reescribir para encontrar una cantidad que permanece constante a lo largo de la trayectoria:

$$
\frac{d}{d z}\left(\frac{1}{p}\right) \equiv \frac{d}{d z}\left(\frac{C}{a}+u\right)=0
$$

Recordamos que, en el caso de rayos en un medio estacionario, el parámetro del rayo es $p=a / C$, y es una cantidad que se conserva a lo largo del rayo. Para el caso de un medio en movimiento, vemos que hay que redefinir el parámetro del rayo para que siga siendo una cantidad conservada:

$$
p=\frac{1}{\frac{C}{a}+u}=\frac{a}{C+u a}
$$

De donde se tiene que:

$$
a=\frac{p C}{1-p u}
$$

Teniendo en cuenta que podemos relacionar el ángulo $\theta$ (figura 2.8) con las componentes del vector normal:

$$
\begin{aligned}
& a=\sin \theta \\
& c=\cos \theta=\sqrt{1-a^{2}}
\end{aligned}
$$

Podemos escribir el parámetro del rayo como:

$$
p=\frac{\sin \theta}{C}\left(1+\frac{u \sin \theta}{C}\right)^{-1}
$$

Entonces, usando las ecuaciones 2.25, obtenemos las expresiones que nos permiten computar el tiempo de viaje, $t$; el rango de distancia recorrido a lo largo del azimut constante del rayo, $X$; y la distancia transversal, perpendicular a la dirección del azimut, que se ha desplazado el rayo, $Y$ :

$$
\begin{aligned}
\frac{d t}{d z} & =\frac{1}{c C} \\
\frac{d X}{d z} & =\frac{a C+u}{c C} \\
\frac{d Y}{d z} & =\frac{v}{c C}
\end{aligned}
$$

(Garcés et al., 1998). Integramos estas ecuaciones y las escribimos en función de $p$ y de la 
lentitud, $s=1 / C$, para obtener el resultado final:

$$
\begin{aligned}
t & =\int_{\Gamma} s^{2}\left[s^{2}-\frac{p^{2}}{(1-p u)^{2}}\right]^{-1 / 2} d z \\
X & =\int_{\Gamma}\left[\frac{p}{(1-p u)}+s^{2} u\right]\left[s^{2}-\frac{p^{2}}{(1-p u)^{2}}\right]^{-1 / 2} d z \\
Y & =\int_{\Gamma}\left(s^{2} v\right)\left[s^{2}-\frac{p^{2}}{(1-p u)^{2}}\right]^{-1 / 2} d z
\end{aligned}
$$

Siendo la integral a lo largo del camino $\Gamma$ viajado por el rayo (Garcés et al., 1998). Por supuesto, para el caso sin vientos $(u=v=0)$, estas ecuaciones se reducen a sus formas habituales de un trazado de rayos en un medio estático. La integración numérica de estas integrales nos permite calcular los tiempos de viaje, así como las trayectorias, de un rayo determinado por el parámetro $p$. Esto lo veremos en el siguiente capítulo. 



\section{Datos y Método}

En este capítulo vamos a inspeccionar y procesar los datos que tenemos disponibles, tanto sísmicos como atmosféricos. Después, usando la teoría que hemos estudiado en el capítulo anterior, vamos a ver cómo se construye un método que nos permita calcular la posición del supracentro a partir de los datos que disponemos, en concreto el método desarrollado por Edwards (2003) y McFadden et al. (2021).

\subsection{Datos sísmicos}

Como ya mencionamos en la Introducción, la onda de choque generada por la explosión del meteoroide en la atmósfera fue lo suficientemente fuerte para generar un movimiento sísmico en el suelo, como vimos por ejemplo en el sismograma de la figura 1.3.

Entonces, se han mirado todas las estaciones del sur de España para inspeccionar los sismogramas grabados durante la hora completa tras el fenómeno, y hemos seleccionado todas las estaciones en las que podemos ver algo, y alguna estación cercana adicional. Además, el hecho de usar sólo las llegadas de los rayos directos a las estaciones pone un límite a la distancia a la que pueden estar las estaciones, como vimos cuando hablamos de la zona de sombra. La distribución de las estaciones activas en ese momento se muestra en el mapa de la figura 3.1, y los detalles de cada estación se encuentran en el anexo A. La mayoría de las estaciones pertenecen al Instituto Andaluz de Geofísica (IAG), incluido un perfil de estaciones temporales paralelo a la costa, que estuvo activo desde verano de 2016 hasta otoño de 2018; y otras cinco son de la red de alerta sísmica del Instituto Geográfico Nacional (IGN).

Podemos observar que la distribución de las estaciones respecto a la zona de búsqueda del supracentro $^{1}$ no logra una cobertura azimutal completa, sino que la mayoría de estaciones se encuentran al sur y al sureste del lugar. Para la búsqueda del supracentro, lo bien definida que esté la localización final depende de la distribución de las estaciones. Lo ideal sería encontrar estaciones rodeando completamente la fuente, de forma que se pueda restringir su posición en las dos dimensiones horizontales (Edwards, 2003). Situaciones como la nuestra no son extrañas, pues uno no puede saber dónde ocurrirá el próximo bólido (mientras que sí puedes instalar un array de estaciones alrededor de un volcán), y harán que la incertidumbre en la posición sea mayor a lo largo de determinada dirección. Por ello, nos tenemos que ayudar de otras fuentes de información antes de tomar como válido cualquier resultado.

Respecto a las estaciones, hay que comentar un par de aspectos de algunas de ellas, que nos servirán más adelante. La estación $A N E R$ se encuentra dentro de las Cuevas de Nerja. Algo parecido ocurre con la estación TP12, que se encuentra dentro de la presa de Rules. Tenemos tanto estaciones de banda ancha como de corto periodo, y algunos acelerómetros en la ciudad de Granada ${ }^{2}$.

\footnotetext{
${ }^{1}$ La elección de la zona de búsqueda se explica en el capítulo siguiente.

${ }^{2}$ Se puede consultar en https://wpd.ugr.es/ iag/mapa/redSismica.php.
} 


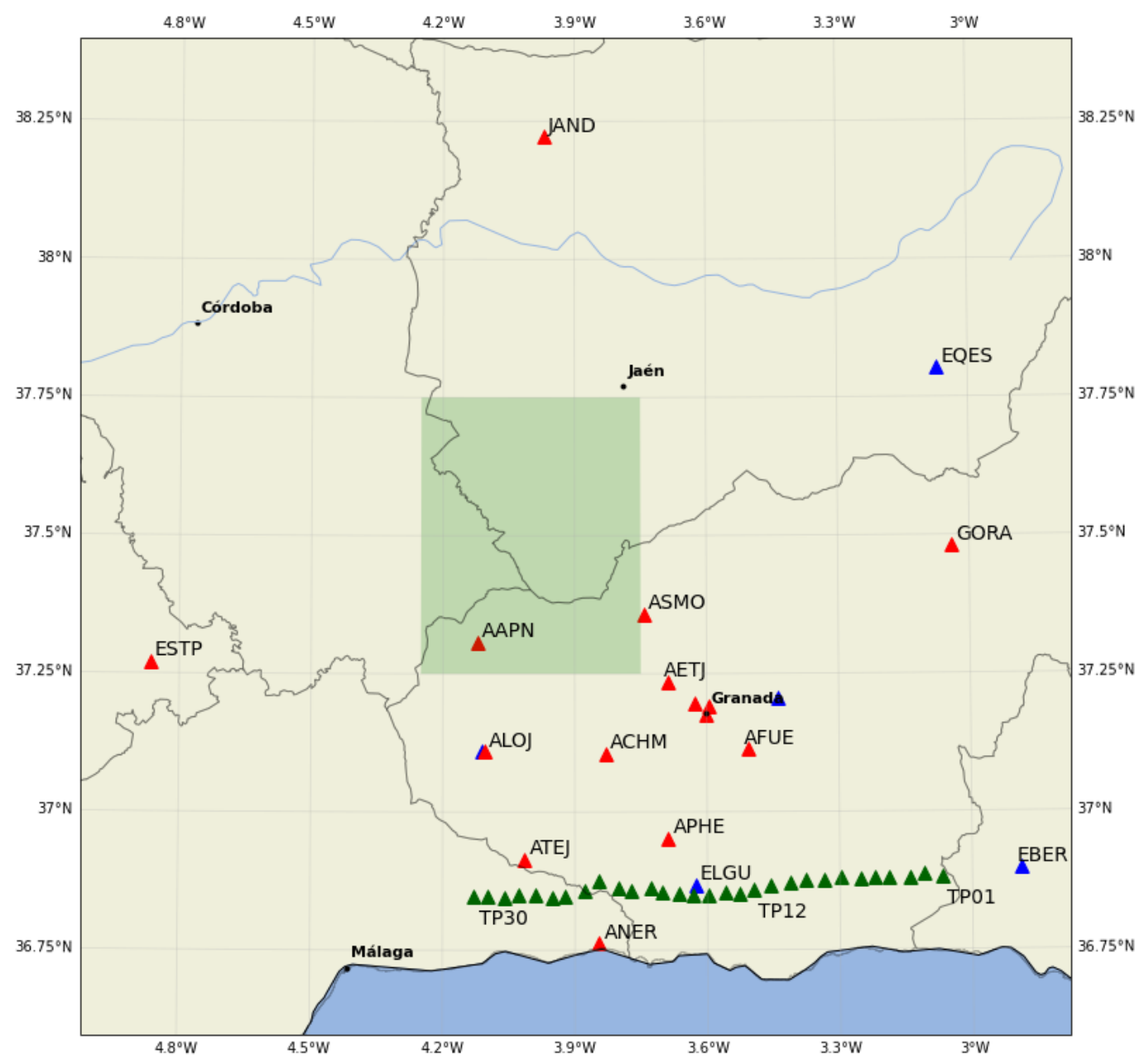

Figura 3.1: Distribución de las estaciones más cercanas a la zona de interés. Triángulos rojos: estaciones del $I A G$; triángulos azules: estaciones del $I G N$; triángulos verdes: perfil temporal. El rectángulo de color verde representa la zona de búsqueda del supracentro.

\subsubsection{Sismogramas y tratamiento}

De cada estación disponible necesitamos obtener un tiempo de llegada para la onda generada en la fragmentación del meteoroide. Algunas de nuestras estaciones son de tres componentes, pero como sólo necesitamos conocer el tiempo de llegada, usaremos sólo la componente vertical para hacer el pick.

No podemos mostrar aquí todos los sismogramas brutos, por falta de espacio, pero se encuentran en el anexo A (figuras A.1 y A.2). Pero mostraremos los pasos del procesado con un ejemplo. Para ello, usaremos el sismograma de la estación $E L G U$ (figura 3.2). Se trata de una estación de banda ancha, por lo que, como vemos en la figura, necesitaremos aplicar algún filtro. Podemos intuir nuestra señal de alta frecuencia escondida entre la señal dominante de menor frecuencia, así que aplicaremos filtros pasa-alta hasta que nuestra señal se aprecie bien. Todo el tratamiento de las señales lo haremos usando el paquete obspy de Python. Con una frecuencia de corte de $1 \mathrm{~Hz}$ es suficiente para poder ver la señal. Antes de eso, se hace un detrend para eliminar la media en todas las series, y se les aplica un taper de 0.05 en ambos extremos. Por tanto, los pasos del procesado consisten en:

1. Detrend de tipo demean. Calcula la media de la serie temporal y la elimina, para 
centrar los datos en cero.

2. Taper del $5 \%$ en ambos extremos del sismograma, para evitar problemas con el filtro.

3. Filtro pasa-alta de $1 \mathrm{~Hz}$. Elimina las frecuencias menores al valor de la frecuencia de corte.

En las estaciones de periodo corto el filtro no es tan imprescindible como en las de banda ancha, pero hemos aplicado el mismo procesado a todos los sismogramas por facilidad. Para el caso del ejemplo, el resultado final de la señal procesada y sobre la que haremos el pick del tiempo de llegada se muestra en la figura 3.2. Ahora, la llegada de la señal acústica se aprecia perfectamente, y nos es más fácil hacer el pick.

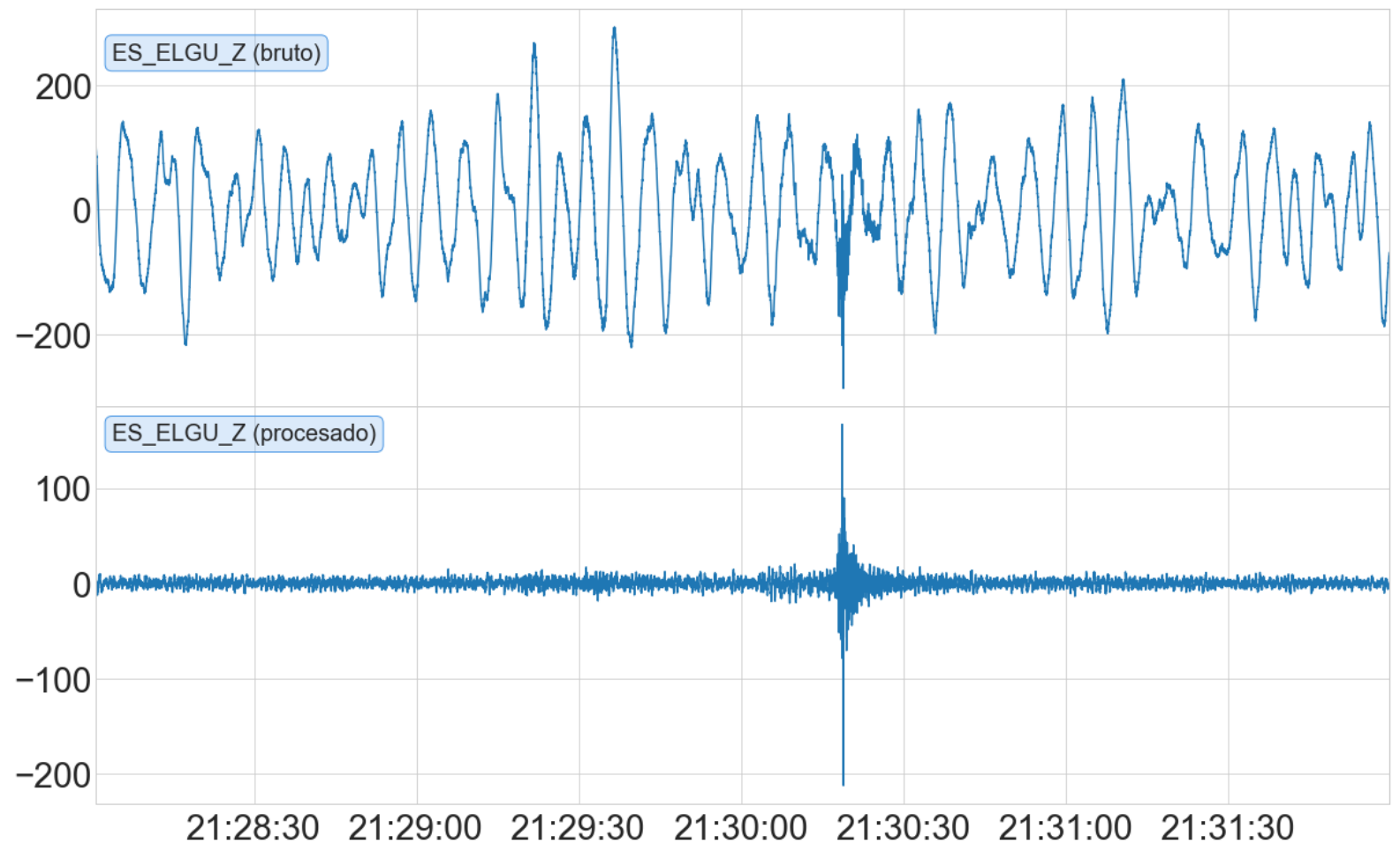

Figura 3.2: Registro en la estación de ELGU (Los Guajares). Sismograma bruto (arriba) y sismograma procesado (abajo). Hora UTC.

Podemos inspeccionar los sismogramas procesados en el anexo A (figuras A.3 y A.4). En la mayoría de ellos somos capaces de identificar una señal, pero hay algunos pocos que no podremos usar para la localización del supracentro. En particular, no observamos ninguna señal clara en las dos estaciones que no se encuentran al aire libre, ANER y TP12. Esto es un hecho significativo que nos indica que lo que detectaron las estaciones sísmicas de este evento fue sólo la llegada directa de infrasonido al lugar de la estación. Por otro lado, las estaciones AAPN (Arroyo Pinares) y ESTP (Estepa) parece que no funcionaban bien en ese momento, pues sólo vemos una señal de ruido. Aunque en AAPN hay una señal de muy pequeña amplitud, que marcaremos aunque se encuentre muy temprana en el sismograma. Lo mismo ocurre en JAND (Jándula-Sierra Morena), donde la amplitud de la respuesta es muy pequeña. Pese a eso, destaca un pico de amplitud dentro del intervalo de tiempo esperado, así que se probará por si fuera una llegada real.

En BBAA (Bellas Artes) sí podemos observar una señal clara, pero en seguida vemos que no puede corresponderse con la llegada que nos interesa, pues ocurre demasiado pronto 
en comparación con otras estaciones cercanas. Por lo tanto, también hay que descartarla. En EBER (Berja) ocurre algo parecido a BBAA, pues la señal llega muy pronto, pero hay otra llegada de menor amplitud que puede ser compatible. En EQES (Quesada) y ACRT (Cartuja) hay dos señales que destacan, por lo que habrá que probar ambas para ver cuál es la correcta.

\subsubsection{Tiempos de llegada}

Finalmente, nos han quedado un total de 46 estaciones de las que vamos a extraer los tiempos de llegada y usarlos para la localización del supracentro. Para realizar correctamente la selección de los tiempos de llegada, nos tenemos que ayudar con un zoom que nos amplifique suficientemente la señal. De nuevo, se muestra como ejemplo el sismograma de ELGU (figura 3.3).

El aumento gradual inicial de la amplitud se debe a la llegada de la onda superficial (ground roll) producto del acoplamiento acústico-sísmico (Edwards, 2003). Se produce debido a que el frente de onda atmosférico va induciendo ondas en la superficie conforme avanza a lo largo del suelo. Sin embargo, esta característica no la vemos en todos los sismogramas.

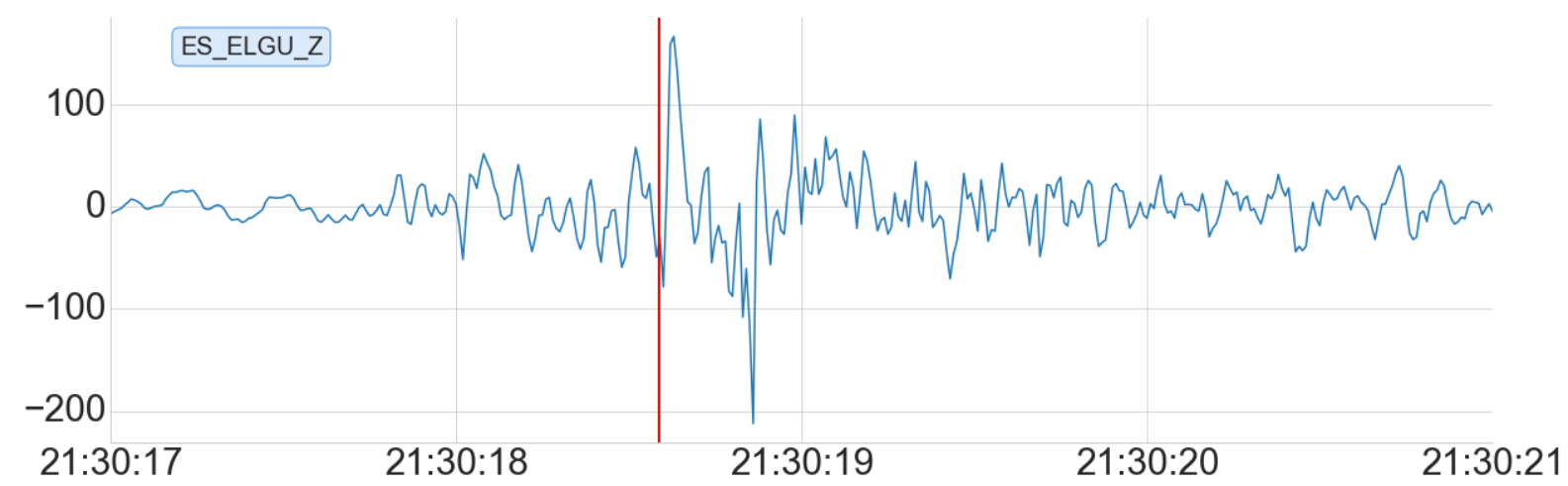

Figura 3.3: Pick (línea roja) del tiempo de llegada en la estación ELGU (Los Guajares). Hora UTC.

En un primer acercamiento, marcaremos los picks en el instante en el que la amplitud crezca de manera abrupta. Como la señal es de alta frecuencia, se encuentra concentrada en un intervalo pequeño de tiempo, y veremos más adelante que los residuos son del orden del segundo, por lo que no corremos ningún riesgo si empezamos con un pickeado de tiempos algo laxo. A la vista de los resultados, podremos analizar si hemos seleccionado los tiempos correctos.

En el anexo B hay una tabla con los tiempos de llegada que hemos marcado en cada estación.

\subsection{Modelo de atmósfera}

En el apartado de Teoría hemos hablado de las variables atmosféricas que más afectan a la propagación del sonido, siendo éstas la temperatura y los vientos horizontales. La estructura térmica y los vientos dependen de la posición geográfica y del momento del día y del año, además de otros factores. Dado que encontrar una solución para la localización del supracentro depende de cómo de bien hagamos el trazado de los rayos, lo ideal sería conocer 
la estructura de la atmósfera en el tiempo exacto y el lugar exacto del evento que estamos estudiando. Como es obvio, normalmente no es posible conocer las condiciones exactas de la atmósfera, por lo que nuestro trazado de rayos siempre contendrá algo de error.

En nuestro caso, y como se sugiere para el propio programa de trazado de rayos que usaremos (McFadden et al., 2021), utilizaremos los datos atmósfericos del European Centre for Medium-Range Weather Forecasts (ECMWF), obtenidos del Copernicus Climate Change Service $^{3}$. La ventaja de estos perfiles atmosféricos es que el modelo que usan los interpola a las regiones cercanas, en lugar de tener sólo el perfil vertical del lugar donde se hicieron las medidas.

En particular, los datos atmosféricos tienen una resolución vertical de 37 niveles de presión que cubren desde los $1000 h P a$ hasta $1 h P a$, a lo largo de un mallado con espaciado horizontal de $0.25^{\circ}$. El programa de trazado de rayos genera una recta entre la fuente y el detector, y combina los datos atmosféricos del punto de la malla más cercano para cada nivel de presión, creando un perfil atmosférico sin discontinuidades mediante un spline cúbico (McFadden et al., 2021).
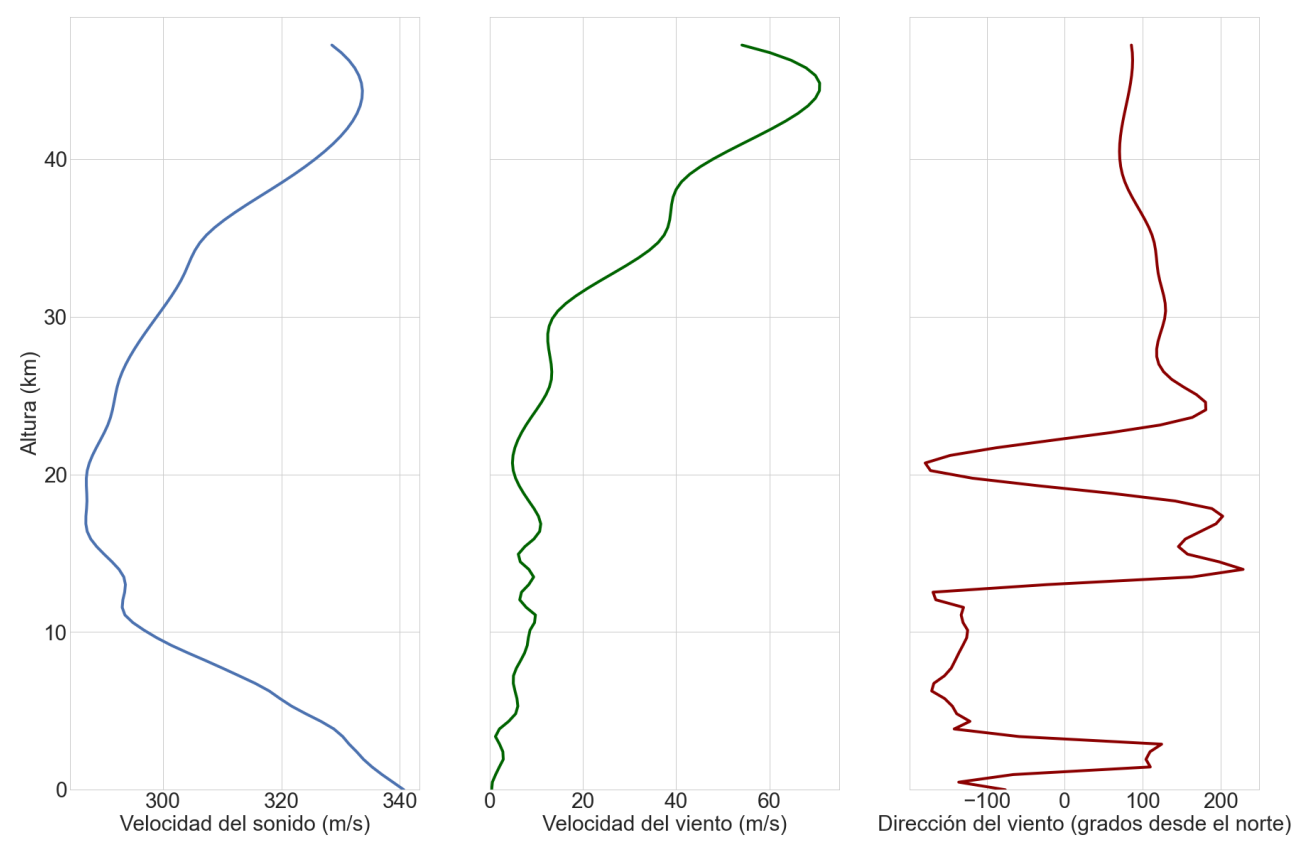

Figura 3.4: Perfiles verticales de la velocidad del sonido, magnitud del viento y dirección, para las coordenadas $37.5^{\circ} \mathrm{N}, 4.0^{\circ} \mathrm{O}$

En nuestro caso, se han empleado los datos para el área que encierran los paralelos $36.5^{\circ} \mathrm{N}$ y $39.0^{\circ} \mathrm{N}$ y $\operatorname{los}$ meridianos $5.5^{\circ} \mathrm{O}$ y $2.5^{\circ} \mathrm{O}$, de forma que todas las estaciones quedan lejos de los bordes del dominio seleccionado. Los datos corresponden a la hora más cercana al evento, las 21:00 UTC. Las variables a descargar son temperatura, velocidad de la componente Este del viento, velocidad de la componente Norte y geopotencial (relacionado con la altura geopotencial). De estos datos podemos extraer la velocidad del sonido usando la ecuación 2.2; y la dirección y magnitud del viento con las ecuaciones 2.24. Por otro lado, la diferencia de altura entre dos valores de geopotencial $\Phi$ viene dada por la siguiente

\footnotetext{
${ }^{3}$ En particular, son los datos de ERA5, quinta generación de reanálisis atmosféricos del clima global, https://cds.climate.copernicus.eu/cdsapp\#!/dataset/reanalysis-era5-pressure-levels? tab=overview
} 
relación:

$$
\Delta z=\frac{\Phi_{2}-\Phi_{1}}{g_{0}}
$$

donde $g_{0}=9.80665 \mathrm{~m} / \mathrm{s}^{2}$, la cual se deduce fácilmente de la relación entre geopotencial y altura (Udías and Mezcua, 1997).

En la figura 3.4 mostramos los perfiles verticales de las variables de interés para las coordenadas $37.5^{\circ} \mathrm{N}, 4.0^{\circ} \mathrm{O}$. Observamos que la velocidad del viento aumenta en altura, con una dirección predominante hacia el sur y hacia el este en algunos niveles. En el anexo C aparecen algunas figuras más.

\subsection{Búsqueda del Supracentro}

Hemos abordado la teoría necesaria y hemos inspeccionado los datos disponibles, de modo que ya estamos listos para buscar el supracentro que mejor ajuste nuestros datos. Sólo falta saber cómo lo haremos exactamente. Como hemos mencionado hasta ahora, el método para localizar el supracentro es análogo al problema de localizar hipocentros de terremotos en el interior de la Tierra, pero en el caso de un medio fluido. Para el caso del supracentro, la implementación de la teoría para desarrollar un algoritmo de cálculo se encuentra en Edwards (2003) y en McFadden et al. (2021). Será el programa de Python desarrollado por este último, Bolide Acoustic Modelling (BAM), el que usaremos nosotros en este trabajo.

El problema a resolver es la localización de una fuente de ondas en el espacio y en el tiempo, dados los tiempos de llegada de esas ondas (emitidas en el mismo instante) a diversos detectores cuya posición es conocida.

Si las ondas se emitieron en un tiempo $t_{0}$ respecto a un tiempo de referencia $t_{R}$, y los tiempos de llegada a las estaciones $\{A, B, C, \ldots\}$ son $\left\{t_{A}, t_{B}, t_{C}, \ldots\right\}$ respecto a $t_{R}$, entonces los tiempos de viaje a cada una de las estaciones serán las cantidades $t_{i}-t_{0}$ para cada estación $i$. Por ejemplo, si el tiempo de referencia son las 21:25:00 UTC y $t_{0}=30 \mathrm{~s}$, significa que la fragmentación ocurrió a las 21:25:30 UTC. Si $t_{A}=300 \mathrm{~s}$, quiere decir que la señal llegó a la estación $A$ a las 21:30:00 UTC, y por tanto el tiempo de viaje es de $270 s$.

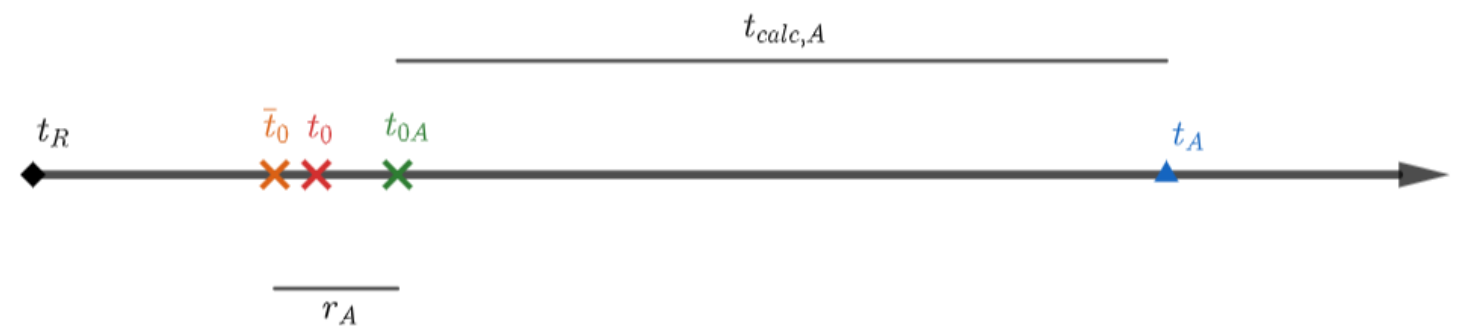

Figura 3.5: Esquema con la notación de los tiempos, residuos y tiempos de viaje.

$\mathrm{Si}$, dado un supracentro, hacemos un trazado de rayos para calcular el tiempo de viaje a una estación, $t_{\text {calc }}$, entonces podemos conocer el momento en el que el rayo salió de la fuente $t_{0 i}=t_{i}-t_{c a l c}$. De esta forma, para cada estación habremos calculado un tiempo correspondiente a la salida del rayo desde la fuente. Dado que la suposición es que todos los rayos partieron de la fuente en el mismo instante, nuestro objetivo es encontrar la 
localización de la fuente para la que todos los tiempos calculados coinciden:

$$
t_{0 A}=t_{0 B}=t_{0 C}=\cdots=t_{0 i} \equiv t_{0}
$$

que debe ser el instante de la fragmentación del meteoroide, $t_{0}$. En casos reales, no conseguiremos que ésto suceda exactamente. Entonces, utilizamos la diferencia entre los tiempos de ocurrencia calculados para dar una estimación de la fiabilidad de la solución. Para ello, se calcula el tiempo de ocurrencia medio, como:

$$
\bar{t}_{0}=\frac{1}{N} \sum_{i}^{N} t_{0 i}=\frac{1}{N} \sum_{i}^{N}\left(t_{i}-t_{c a l c, i}\right)
$$

siendo $N$ el número de estaciones. En la figura 3.5 se aclara la notación. Las desviaciones de cada tiempo de ocurrencia calculado respecto de este tiempo medio serán los residuos de cada estación. Es decir:

$$
r_{i}=t_{0 i}-\bar{t}_{0}=t_{i}-t_{c a l c, i}-\bar{t}_{0}
$$

Por supuesto, el objetivo es encontrar la posición del supracentro que produce un mínimo de residuos, de acuerdo con una norma $L 1$ :

$$
L 1=\frac{1}{N} \sum_{i}^{N}\left|t_{i}-t_{c a l c, i}-\bar{t}_{0}\right|
$$

En el caso en que el tiempo $t_{0}$ de la explosión sea conocido, no necesitamos calcular el tiempo de ocurrencia medio, y calcularemos los residuos respecto de este tiempo conocido. Además, resultará útil añadir pesos a las estaciones, cuando el pick del tiempo no es muy claro o para quitar peso a las más lejanas. En ese caso, la ecuación 3.3 se convierte en:

$$
\bar{t}_{0}=\frac{\sum_{i}^{N} w_{i}\left(t_{i}-t_{c a l c, i}\right)}{\sum_{i} w_{i}}
$$

y la ecuación 3.5 será:

$$
L 1=\frac{\sum_{i}^{N} w_{i}\left|t_{i}-t_{c a l c, i}-\bar{t}_{0}\right|}{\sum_{i} w_{i}}
$$

siendo $w_{i}$ el peso de cada estación (Edwards, 2003).

\subsubsection{Cálculo de los tiempos de viaje y trazado de rayos}

El capítulo de teoría terminó con las ecuaciones 2.38, que nos servían para calcular los tiempos de viaje y hacer el trazado de los rayos. Sin embargo, estas ecuaciones están en forma continua, y para implementarlas en un algoritmo de cálculo es necesario discretizarlas. Para ello, como ya hemos mencionado, se ha considerado la atmósfera como un medio estratificado por capas, de modo que podemos trazar el rayo en cada capa e ir acumulando los resultados (tiempo y desplazamiento). La forma discretizada de las ecuaciones del 


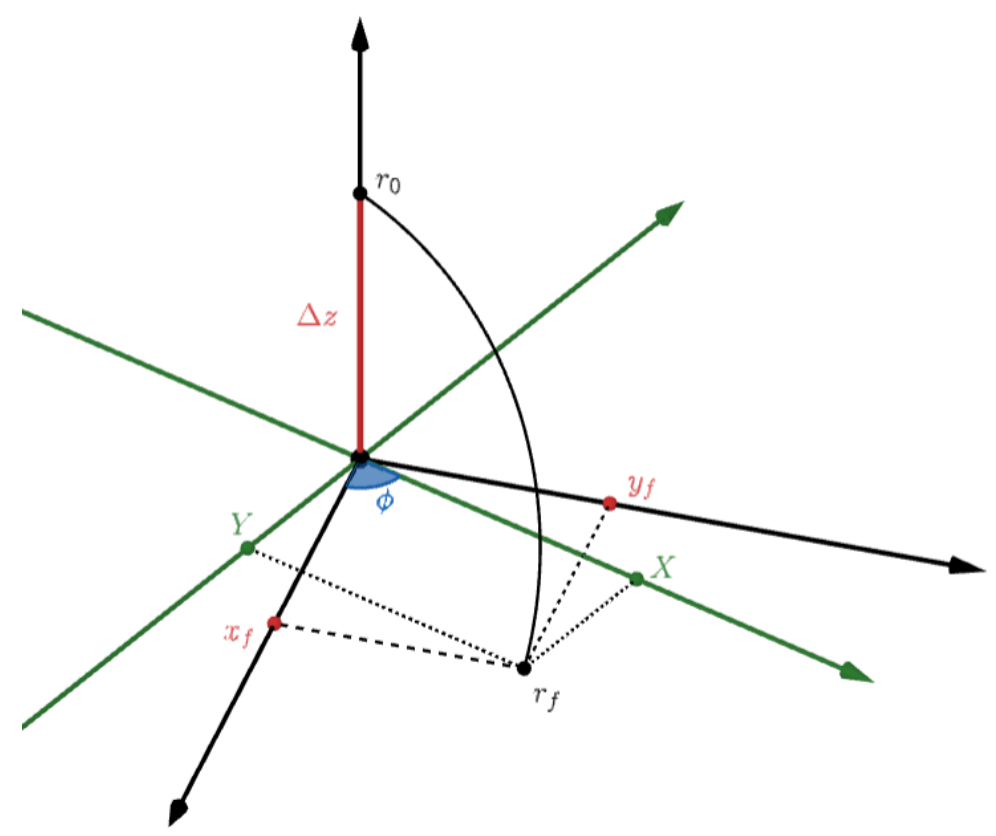

Figura 3.6: Notación del desplazamiento del rayo en los dos sistemas de referencia. Esquema para visualizar la transformación.

trazado de rayos es:

$$
\begin{aligned}
t & =\sum_{i} s_{i}^{2}\left[s_{i}^{2}-\frac{p^{2}}{\left(1-p u_{i}\right)^{2}}\right]^{-1 / 2} \Delta z_{i} \\
X & =\sum_{i}\left[\frac{p}{\left(1-p u_{i}\right)}+s_{i}^{2} u_{i}\right]\left[s_{i}^{2}-\frac{p^{2}}{\left(1-p u_{i}\right)^{2}}\right]^{-1 / 2} \Delta z_{i} \\
Y & =\sum_{i}\left(s_{i}^{2} v_{i}\right)\left[s_{i}^{2}-\frac{p^{2}}{\left(1-p u_{i}\right)^{2}}\right]^{-1 / 2} \Delta z_{i}
\end{aligned}
$$

donde $s_{i}=1 / c_{i}$ es la lentitud de la capa i-ésima; $u_{i}$ es la velocidad del viento en la dirección del rayo caracterizado por el parámetro $p ; v_{i}$ la velocidad del viento en la dirección perpendicular al rayo; $\Delta z_{i}$ es el espesor de la capa i-ésima; $t$ es el tiempo de viaje del rayo, calculado como la suma de tiempos de viaje en cada capa; $X$ es la distancia viajada en la dirección del rayo; e $Y$ es el desplazamiento transversal.

Si un rayo tiene una posición inicial $r_{0}$ al comenzar a atravesar una capa de atmósfera de espesor $\Delta z$, y una posición final $r_{f}, X$ será la distancia recorrida a lo largo de la dirección del azimut inicial $(\phi)$ e $Y$ será la distancia en la dirección perpendicular que ha recorrido por efecto del viento. La transformación a nuestro sistema de referencia será por tanto una rotación, según la figura 3.6:

$$
\left(\begin{array}{l}
x_{f} \\
y_{f}
\end{array}\right)=\left(\begin{array}{cc}
\cos \phi & -\sin \phi \\
\sin \phi & \cos \phi
\end{array}\right)=\left(\begin{array}{l}
X \\
Y
\end{array}\right)
$$

Del mismo modo, los vientos los conocemos en función de su dirección respecto al norte y su magnitud. La transformación a $u$ y $v$ (viento paralelo y perpendicular al rayo) se deduce fácilmente con geometría (Anexo D). 


\subsubsection{Cálculo del rayo óptimo}

Dada la posición del supracentro y una de las estaciones, se necesita saber qué rayo es el óptimo. Es decir, el rayo que sale de la fuente y llega lo más cerca posible a la estación. Cada rayo está caracterizado por un ángulo de despegue $\theta$ (take off angle, el ángulo que forma con la vertical) y el ángulo de azimut $\phi$ (ángulo que forma con el eje $x$ ). El algoritmo de cálculo desarrollado por Edwards (2003) y publicado en Edwards and Hildebrand (2004) calcula los valores de $\theta$ y $\phi$ del rayo óptimo para cada estación. Para ello, se construye una malla de valores posibles para los ángulos de esta forma (figura 3.7):

- Se calcula el azimut de la recta que une el supracentro y la estación, $\varphi$.

- Los posibles valores de azimut a explorar serán $\varphi-90^{\circ}<\phi<\varphi+90^{\circ}$, con un intervalo de $2^{\circ}$. Este valor puede cambiar.

- Los posibles valores para el ángulo de take off serán $90^{\circ}<\theta<180^{\circ}$, con intervalo de $2^{\circ}$. Es decir, rayos que salgan hacia abajo.

Para cada punto se traza el rayo correspondiente, de acuerdo con las ecuaciones del apartado anterior, y guardaremos aquel cuya posición final sea la más cercana a la posición de la estación. Entonces, construiremos de nuevo la malla alrededor del mejor valor (punto $P$ en la figura $3.7 \mathrm{~B}$ ), esta vez con un espaciado de $0.055^{\circ}$. Este proceso se repetirá hasta encontrar

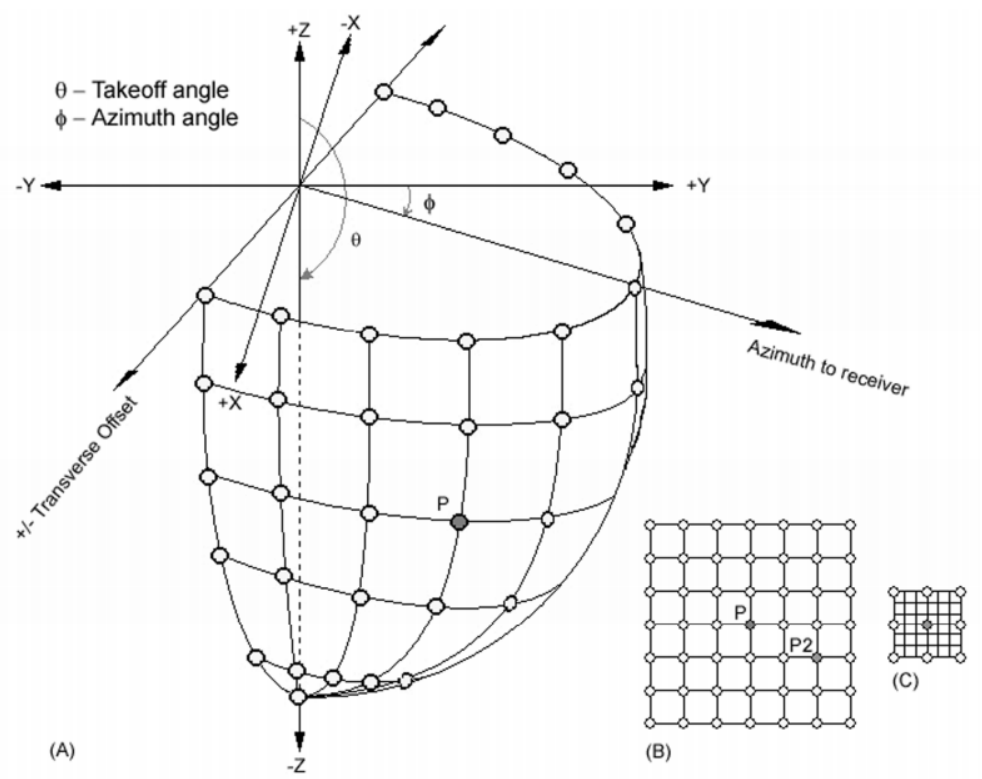

Figura 3.7: Cálculo del rayo óptimo a una estación. Malla de valores para $\theta$ y $\phi$. Figura obtenida de Edwards and Hildebrand (2004).

los parámetros del rayo óptimo dentro de unos valores de aceptación de resolución. En nuestro caso, se considerará que un rayo ha alcanzado la estación cuando la diferencia entre la posición final del rayo y la de la estación sea de menos de $3000 \mathrm{~m}$ verticalmente y de $660 \mathrm{~m}$ horizontalmente. La resolución vertical de $3000 \mathrm{~m}$ es la que se recomienda en McFadden et al. (2021). Esto es para tener en cuenta que en la atmósfera real, aunque el rayo no llegue directamente a la estación, se puede medir una llegada por efectos de scattering o difracción.

Aun así, puede que no se encuentre ningún rayo que alcance la estación. Puede haber varias razones para que esto ocurra, empezando por que la estación se encuentre en una 
zona de sombra para el supracentro dado. Otras razones pueden deberse al propio algoritmo de cálculo, como que todos los rayos correspondientes a los valores de la malla se refracten hacia arriba.

\subsubsection{Cálculo del supracentro. Particle Swarm Optimization}

Para calcular la posición del supracentro necesitamos explorar un gran volumen de posibilidades. En concreto, el volumen de búsqueda usado va desde los $20000 \mathrm{~m}$ hasta los $45000 \mathrm{~m}$ para la altura; longitud entre $4.25^{\circ} \mathrm{O}$ y $3.75^{\circ} \mathrm{O}$; y latitud entre $37.25^{\circ} \mathrm{N}$ y $37.75^{\circ} \mathrm{N}$. Para cada posición del supracentro dentro de este volumen, se calcula el rayo óptimo para cada una de las estaciones siguiendo el proceso descrito en las dos secciones anteriores. Una vez tenemos los rayos óptimos, hay que calcular los tiempos de viaje de cada rayo y computar los residuos en cada estación. Repetimos esto hasta encontrar la posición del supracentro que suponga un mínimo en el valor de $L 1$ de la ecuación 3.7.

Sin embargo, repetir este proceso sistemáticamente para todas las posibles posiciones para el supracentro costaría un gran tiempo de cómputo. El programa desarrollado por McFadden et al. (2021) sustituye el método sistemático por un algoritmo más eficiente y moderno, una búsqueda por optimización de enjambre de partículas (Particle Swarm Optimization, PSO). Este método de búsqueda hace que no sea necesario explorar todo el espacio de posiciones para encontrar el mínimo de residuos. Se trata de un tipo de algoritmo genético que busca el valor mínimo de una función usando una población (enjambre) de soluciones candidatas que se mueven semi-aleatoriamente por el espacio de soluciones (se suele decir que recuerda a una bandada de pájaros) y acaban convergiendo a la posición del mínimo. La explicación del funcionamiento de este algoritmo se encuentra en el anexo E. 


\section{Resultados}

Aplicamos el método de búsqueda del supracentro a nuestras estaciones y tiempos de llegada, usando el paquete BAM de Python desarrollado por McFadden et al. (2021). Como se ha indicado en el capítulo anterior, podemos considerar el tiempo de ocurrencia de la fragmentación explosiva como una variable más a tener en cuenta en la minimización de los residuos, o podemos considerar que es un tiempo conocido y calcular solamente la localización espacial del supracentro.

La diferencia entre fijar o no el tiempo será la mayor o menor incertidumbre en la altura del supracentro (Heimann et al., 2013).

Es gracias a que el fenómeno de la fragmentación viene acompañado de un aumento abrupto de la luminosidad, como ya vimos en el capítulo 2, que podemos obtener el momento de ocurrencia por medios visuales, así como la trayectoria aproximada del meteoroide por triangulación. En concreto, el meteoroide de Granada fue grabado por las cámaras de detección de meteoros del proyecto SMART (Madiedo, 2016), y el investigador principal, el profesor José María Madiedo, ha calculado la trayectoria del meteoroide y los tiempos de los picos de la curva fotométrica. Esta información se encuentra en el anexo F.

En concreto, el instante de mayor luminosidad ocurre a las 21:25:47.3 UTC (precisión en las décimas de segundo), y supondremos que se corresponde al inicio de la propagación de las ondas de presión.

\subsection{Tiempo fijo}

Comenzamos, entonces, fijando el tiempo de ocurrencia a las 21:25:47.3 UTC. Es decir, si el tiempo de referencia son las 21:25:00.0 UTC, entonces no hace falta calcular el tiempo de ocurrencia medio de la ecuación 3.6 ya que lo fijaremos en $\bar{t}_{0}=47.3 \mathrm{~s}$, y calcularemos los residuos de los tiempos de viaje respecto de este tiempo. Tenemos que asignar un peso $w_{i}$ a cada estación, que es un valor entre 0 y 1 . Para elegir el peso nos fijaremos en la confianza que tengamos en el pick del tiempo de llegada, pero también en si queremos establecer menos peso a las estaciones más lejanas.

Primero, hemos realizado pruebas con pocas estaciones y hemos visto así cuales no pueden tener mucho peso en el trazado por encontrarse en zonas en las que el programa no llega a trazar ningún rayo. Se comenzó con una amplia zona de búsqueda, que hemos ido reduciendo a la vista de los resultados típicos, hasta la que observamos en la figura 3.1. También hemos probado a reducir los valores recomendados de tolerancia a la hora de calcular el rayo óptimo. Sin embargo, esto provoca que en muchas estaciones deje de recibirse un rayo directo. Esto cambiaría si, a la misma vez que reducimos el volumen de tolerancia alrededor de las estaciones, reducimos también el espaciado del mallado de búsqueda de los ángulos de los rayos, esto es, densificando el trazado de rayos. Para una resolución vertical de $3 \mathrm{~km}$ en las estaciones, el espaciado inicial del mallado se ha fijado en $0.75^{\circ}$ para el take off y $1.5^{\circ}$ para el azimut. Reducir aún más este valor supone aumentar considerablemente el tiempo de cálculo del programa. 
En la tabla 4.1 aparecen los pesos que hemos usado para cada estación, que se han ido modificando de acuerdo con las pruebas previas que se han hecho. El peso 1 se ha reservado para las estaciones más cercanas y con un pick más fiable, y hemos puesto peso 0.8 a las que se encuentran más lejos de las soluciones típicas. El caso de ASMO es distinto, pues el rayo óptimo llega muy vertical a esta estación, haciendo que su residuo sea siempre del orden de $10 \mathrm{~s}$. ALOJ y EGOR siempre tienen un residuo un poco mayor que el resto de las estaciones cercanas, por lo que su peso se ha dejado en 0.7. Las estaciones de peso 0 son aquellas en las que no teníamos señal clara, como ya comentamos en el capítulo anterior. También se ha puesto un peso menor o nulo en aquellas estaciones que se encuentran en zonas donde en las pruebas previas se ha visto que no siempre se llegan a trazar rayos.

\begin{tabular}{|c|c|c|c|c|c|c|c|c|}
\hline & & & ESTP & nan & 0.0 & TP14 & -3.9 & 0.8 \\
\hline Estación & Residuo (s) & Peso & GORA & -5.3 & 0.01 & TP15 & -2.5 & 0.8 \\
\hline AAPN & -33.2 & 0.0 & JAND & -29.3 & 0.0 & TP16 & -2.6 & 0.8 \\
\hline ACHM & -2.7 & 1.0 & TRAD & 1.6 & 1.0 & TP17 & 0.5 & 0.8 \\
\hline ACRT & 3.1 & 0.0 & TP01 & nan & 0.0 & TP18 & -0.5 & 0.8 \\
\hline AETJ & 0.0 & 1.0 & $\mathrm{TP} 02$ & -10.0 & 0.0 & TP19 & 0.8 & 0.8 \\
\hline AFUE & 0.9 & 1.0 & TP03 & -9.6 & 0.1 & $\mathrm{TP} 20$ & 1.3 & 0.8 \\
\hline ALOJ & -16.5 & 0.7 & TP04 & -12.2 & 0.1 & TP21 & -0.5 & 0.8 \\
\hline ANER & -27.4 & 0.0 & TP05 & -7.0 & 0.1 & TP22 & 0.0 & 0.5 \\
\hline APHE & -2.5 & 0.8 & TP06 & -6.6 & 0.1 & TP23 & -1.1 & 0.5 \\
\hline ASMO & -9.1 & 0.01 & TP07 & -5.7 & 0.1 & TP24 & -1.0 & 0.5 \\
\hline ATEJ & -6.6 & 0.8 & TP08 & -7.2 & 0.1 & TP25 & -2.9 & 0.8 \\
\hline BBAA & -37.0 & 0.0 & ТР09 & -1.0 & 0.8 & TP26 & -1.1 & 0.8 \\
\hline EBER & -4.6 & 0.0 & $\mathrm{TP} 10$ & -5.8 & 0.8 & $\mathrm{TP} 27$ & -3.8 & 0.0 \\
\hline EGOR & -17.1 & 0.7 & TP11 & -5.6 & 0.5 & TP28 & -4.5 & 0.8 \\
\hline ELGU & -1.0 & 0.8 & $\mathrm{TP} 12$ & -3.0 & 0.0 & TP29 & -3.6 & 0.8 \\
\hline EQES & nan & 0.0 & $\mathrm{TP} 13$ & -5.1 & 0.5 & TP30 & nan & 0.0 \\
\hline EQTA & 0.3 & 1.0 & & & & & & \\
\hline
\end{tabular}

Tabla 4.1: Pesos y residuos de cada estación. Tiempo fijo.

La localización del supracentro, dados los anteriores pesos para las estaciones, ha resultado ser aproximadamente $37.4939^{\circ} \mathrm{N}, 3.9083^{\circ} \mathrm{O}$, a una altitud de aproximadamente $38.3 \mathrm{~km}$ sobre el nivel del mar. El epicentro se encuentra en el municipio de Alcalá la Real, en el sur de la provincia de Jaén.

Los residuos de los tiempos de viaje calculados para esta posición del supracentro se muestran también en la tabla 4.1. Aparecen los residuos para las 50 estaciones, pero sólo nos tenemos que fijar en aquellas que tenemos en la tabla del anexo B. Los otros residuos se han calculado para ver cuándo debería haber llegado la señal a las estaciones en las que no hicimos pick. Los altos residuos en JAND y AAPN nos indican que los tiempos de llegada que marcamos no eran correctos, y por tanto no se correspondían con la señal de la onda directa. Lo mismo ocurre en BBAA, donde ya adelantamos que la señal del sismograma no podía tener el mismo origen que las demás.

En algunas estaciones aparece nan en el valor del residuo, lo que significa que el programa no ha conseguido trazar ningún rayo a esa estación desde la posición del supracentro óptimo. Los valores que observamos para los residuos son valores típicos, y podemos esperar residuos de hasta $10 s$ dado el volumen de tolerancia que establecimos para los rayos óptimos, pues un rayo que pasa a $3 \mathrm{~km}$ de altura sobre una estación se considera una llegada por efectos 


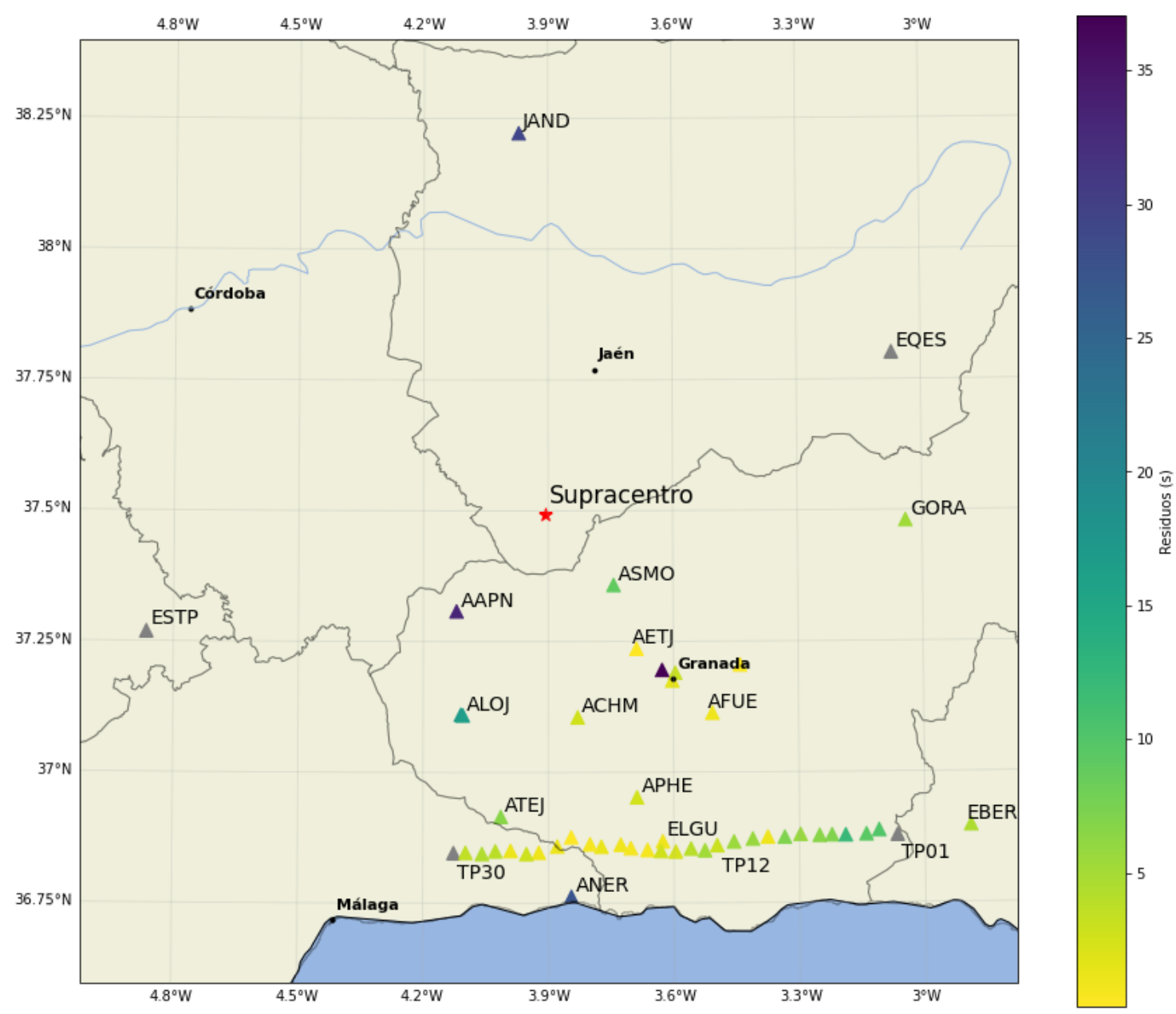

Figura 4.1: Localización del supracentro (proyección en superficie) y residuos en las estaciones. No aparece el código de todas las estaciones.

de scattering, como ya se explicó.

Los resultados se encuentran resumidos en la figura 4.1, y también mostramos un trazado de los rayos óptimos a cada estación en la figura 4.2.

Dada la localización del supracentro y la estructura de la atmósfera, podemos generar una figura como la 2.2, que muestra los tiempos de llegada a la superficie para el caso de una atmósfera isótropa. En la figura 4.3 podemos ver cuánto varía para el caso de una atmósfera realista ese patrón de círculos concéntricos. Vemos que ese patrón característico se ha descentrado hacia el sur-sureste debido a la presencia de los vientos del norte y del oeste que vimos en la figura 3.4.

La zona de sombra que vemos en la figura 4.3, es decir, aquellas zonas a las que no se consigue trazar un rayo directo, no solo depende de la estructura térmica y de los vientos, como vimos en el capítulo de teoría. En este caso, también hay que tener en cuenta un factor computacional, por las propias limitaciones del algoritmo de trazado de rayos. Podemos observar algunas estaciones que se encuentran claramente en la zona de sombra, como ESTP y EQES; y otras que se encuentran en la frontera de esta zona, que son aquellas estaciones a las que se les ha otorgado menos peso.

La incertidumbre en la localización del supracentro tiene su origen, principalmente, en 

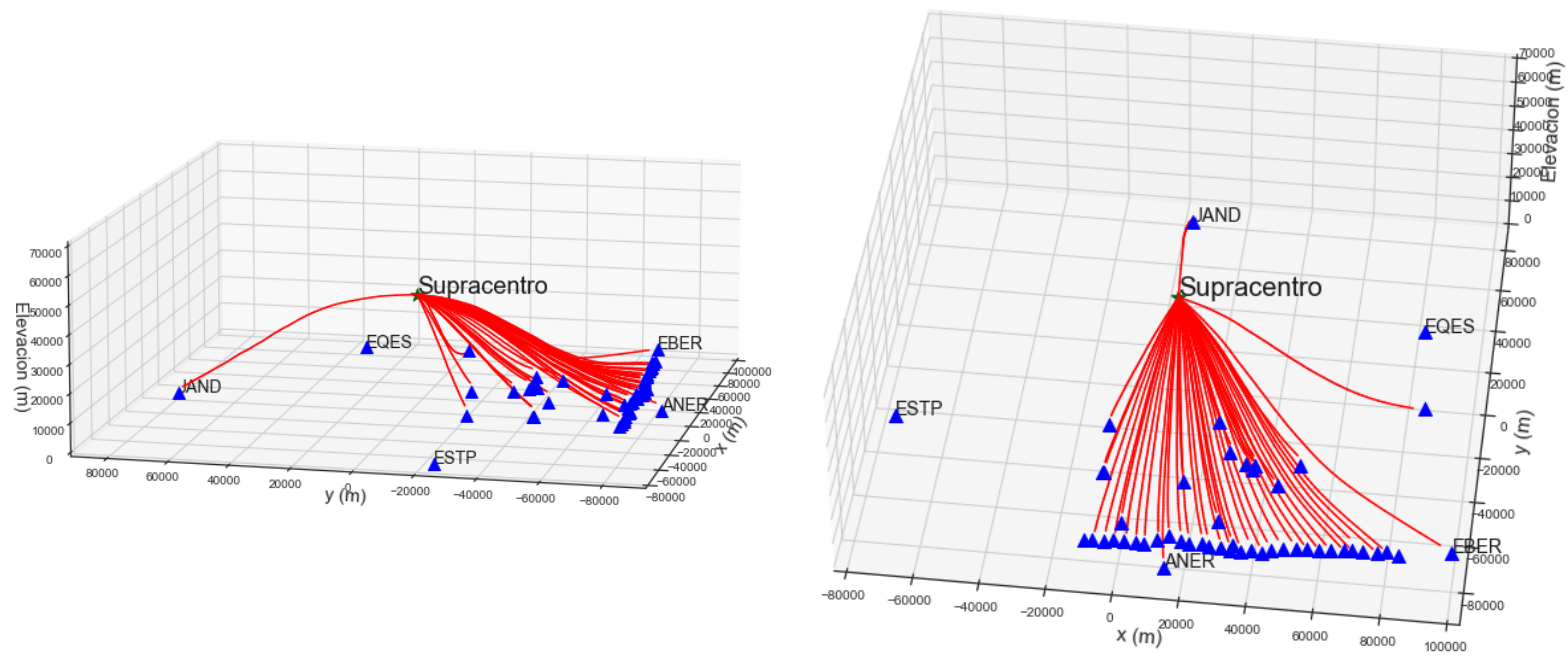

Figura 4.2: Trazado de los rayos óptimos a cada estación. Se muestran dos perspectivas distintas para mejor apreciación. El punto $(0,0)$ del plano corresponde a las coordenadas $37.5^{\circ} \mathrm{N}, 4.0^{\circ} \mathrm{O}$.

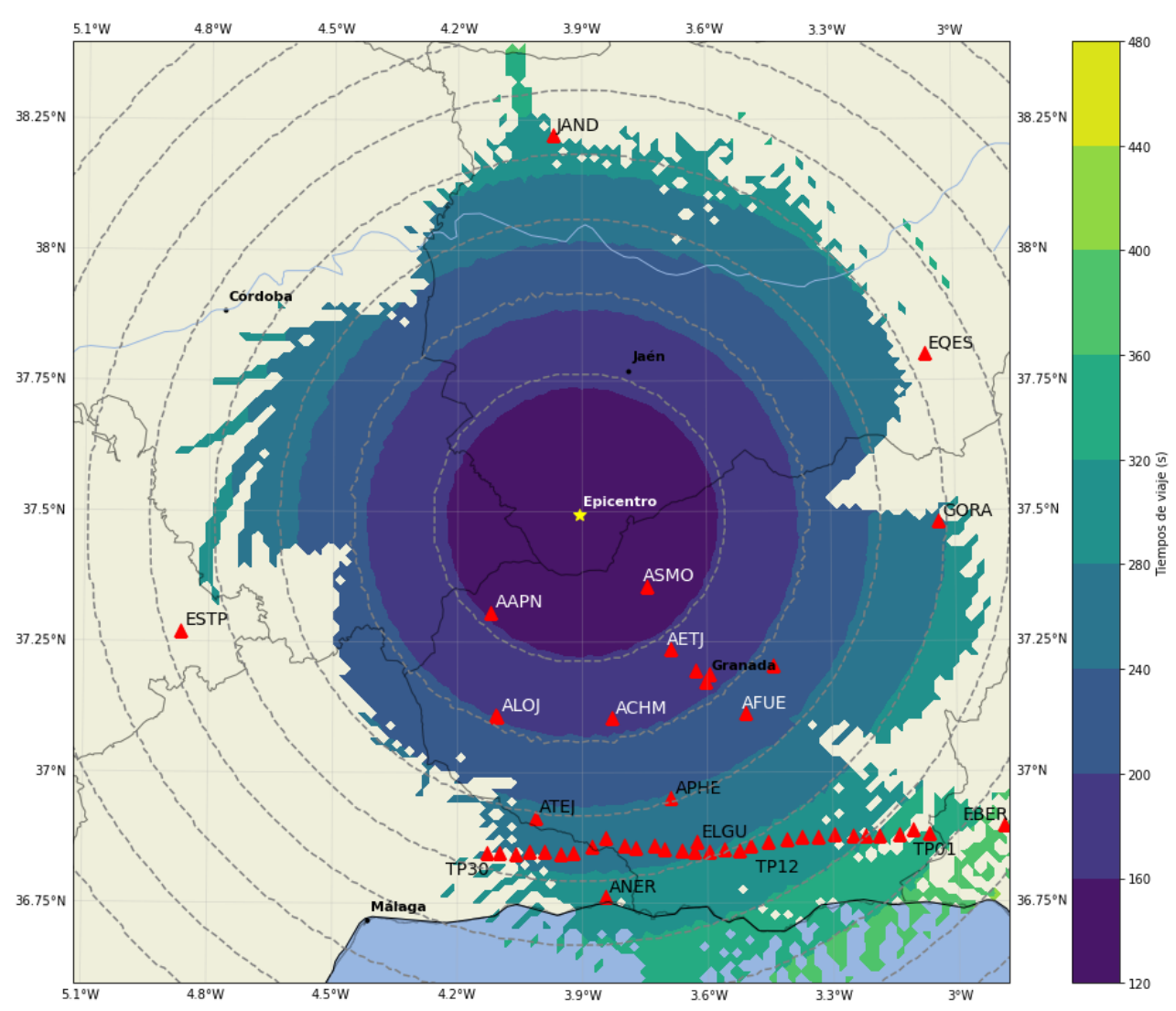

Figura 4.3: Tiempos de llegada a la superficie desde el supracentro óptimo. Las líneas punteadas muestran los contornos correspondientes al caso de atmósfera isótropa.

las aproximaciones que hemos tomado para el modelo de atmósfera, así como en la tolerancia que establecemos para los rayos óptimos. En particular, la incertidumbre en la altitud del supracentro será de al menos $\pm 3 \mathrm{~km}$ debido a la tolerancia vertical (McFadden 
et al., 2021). Respecto al trazado de los rayos, este algoritmo no tiene en cuenta el régimen no-lineal de la onda de choque al comienzo de su propagación, lo que provoca que las soluciones tiendan a estar a menor altitud de lo que se esperaría (Edwards and Hildebrand, 2004). En resumen, el resultado para la altura sobre el nivel del mar del supracentro lo establecemos en el rango $[35.3,41.3] \mathrm{km}$.

\subsection{Tiempo como parámetro libre}

Si, por otro lado, dejamos el tiempo de ocurrencia como un parámetro libre, entonces debemos calcular los residuos respecto al tiempo de ocurrencia medio que nos da la ecuación 3.6. En la tabla 4.2 aparecen los pesos que hemos establecido a cada estación. Hay algunas diferencias respecto al caso con el tiempo fijo, ya que al no fijar el tiempo damos más posibilidades a la solución.

\begin{tabular}{|c|c|c|c|c|c|c|c|c|}
\hline & & & ESTP & nan & 0.0 & TP14 & 2.24 & 0.9 \\
\hline Estación & Residuo (s) & Peso & GORA & -41.48 & 0.01 & TP15 & 3.48 & 0.8 \\
\hline AAPN & -63.57 & 0.0 & JAND & nan & 0.0 & TP16 & 6.57 & 0.8 \\
\hline $\mathrm{ACHM}$ & 1.26 & 1.0 & TRAD & 2.17 & 1.0 & TP17 & 7.02 & 0.9 \\
\hline ACRT & 0.61 & 0.01 & TP01 & nan & 0.0 & TP18 & 9.51 & 0.8 \\
\hline AETJ & -3.74 & 1.0 & TP02 & -19.35 & 0.0 & TP19 & 9.55 & 0.8 \\
\hline AFUE & -0.13 & 1.0 & TP03 & -14.96 & 0.1 & TP20 & 8.53 & 0.8 \\
\hline ALOJ & -26.03 & 0.6 & TP04 & -14.11 & 0.2 & TP21 & 7.28 & 0.8 \\
\hline ANER & -19.16 & 0.0 & TP05 & -10.70 & 0.2 & ТP22 & 4.68 & 0.8 \\
\hline APHE & 6.23 & 0.9 & TP06 & -6.91 & 0.2 & TP23 & 4.42 & 0.8 \\
\hline ASMO & -28.19 & 0.01 & TP07 & -4.93 & 0.8 & TP24 & 5.63 & 0.8 \\
\hline ATEJ & -3.45 & 0.9 & TP08 & -6.44 & 0.8 & TP25 & 1.39 & 0.9 \\
\hline BBAA & -38.80 & 0.0 & TP09 & -1.78 & 0.8 & TP26 & 0.49 & 0.9 \\
\hline EBER & nan & 0.0 & TP10 & -3.25 & 0.8 & TP27 & -0.87 & 0.9 \\
\hline EGOR & -26.60 & 0.6 & TP11 & 0.47 & 0.9 & TP28 & -3.19 & 0.9 \\
\hline ELGU & 6.42 & 0.9 & TP12 & 2.31 & 0.0 & ТP29 & -2.68 & 0.9 \\
\hline EQES & nan & 0.0 & TP13 & 1.24 & 0.8 & TP30 & -6.08 & 0.2 \\
\hline EQTA & -6.48 & 1.0 & & & & & & \\
\hline
\end{tabular}

Tabla 4.2: Pesos y residuos de cada estación. Tiempo libre.

En este caso, la solución para el supracentro óptimo ha sido aproximadamente $37.3415^{\circ} \mathrm{N}$, $3.8462^{\circ} \mathrm{O}$, a una altitud de aproximadamente $33.6 \mathrm{~km}$ sobre el nivel del mar. Los residuos de los tiempos de viaje para esta solución se encuentran en la tabla 4.2. Al dejar el tiempo como un parámetro libre, la incertidumbre en la altura de la fuente será aún mayor, pues aumentar la altura se traduce en retrasar el tiempo de ocurrencia, y lo contrario. Los resultados calculados con el tiempo fijo serán siempre más fiables.

El tiempo de ocurrencia calculado ha resultado ser $\bar{t}_{0}=95.7 \mathrm{~s}$, lo que corresponde a las 21:26:35.7 UTC. Por supuesto, no es un resultado verosímil, ya que según los datos astrofísicos, el fenómeno visual terminó a las 21:25:47.6 UTC.

El resultado para la localización del supracentro para el caso de dejar el tiempo de ocurrencia como un parámetro libre se puede visualizar en la figura 4.4. También mostramos 
ahí la solución del supracentro para el caso de tiempo fijo. Además, se han señalado también otras soluciones de entre las calculadas, tanto con tiempo fijo como libre. Estas otras soluciones fueron cálculos previos con menos estaciones, probando distintos pesos, cambiando las variables que usa el algoritmo PSO, la densificación del trazado de rayos o la tolerancia en la búsqueda de los rayos óptimos.

A la vista de los resultados que se obtienen en los cálculos con tiempo fijo, la mayoría de las soluciones se encuentran en una superficie de unos $100 \mathrm{~km}^{2}$ en el sur de la provincia de Jaén, en el municipio de Alcalá la Real. Podemos ver que la mayoría de las soluciones son coherentes con la trayectoria del meteoroide dentro de cierto margen de tolerancia, de modo que según nuestra solución para el supracentro, éste ocurriría en la segunda mitad del recorrido, lo que concuerda con los registros en vídeo.

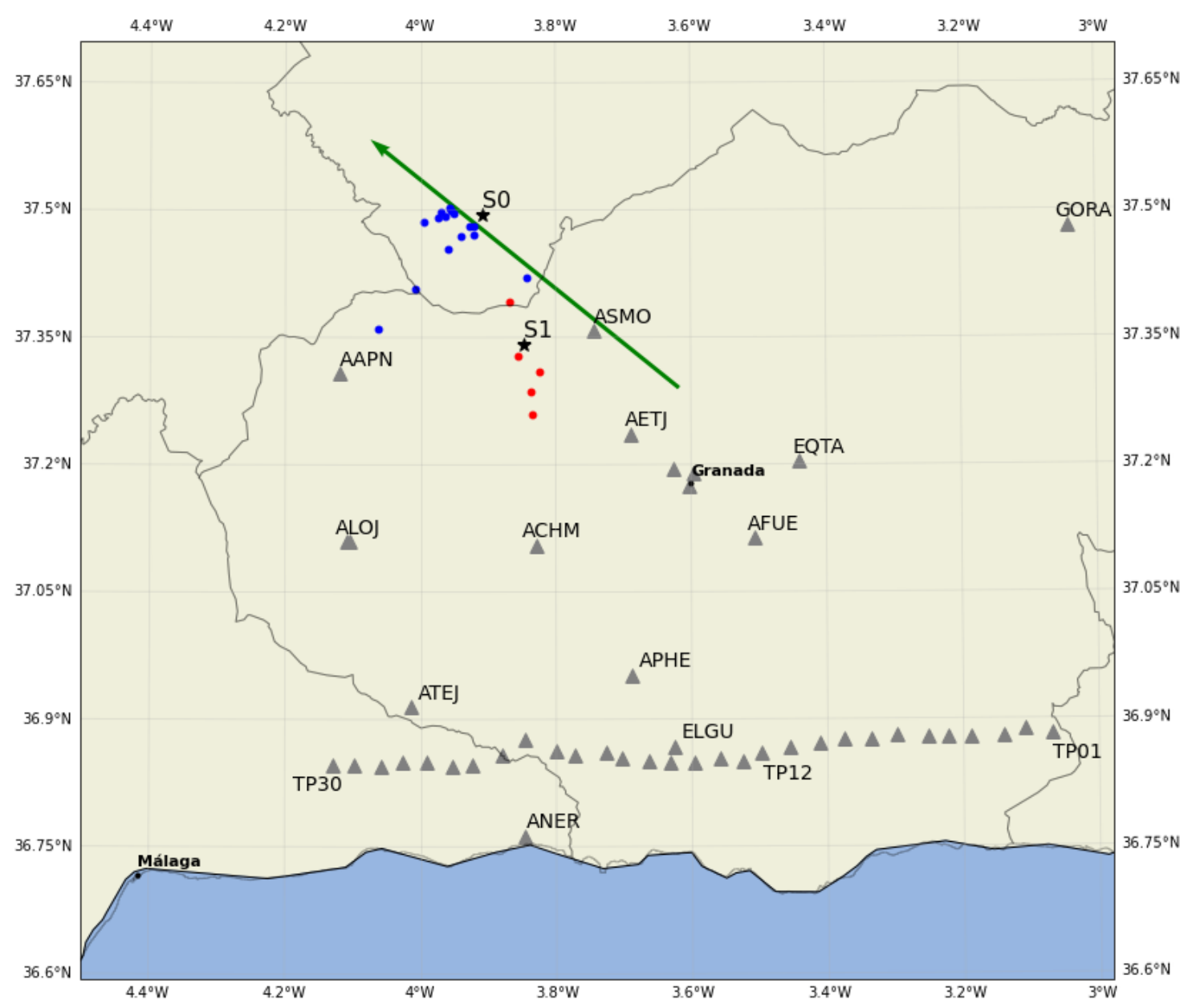

Figura 4.4: Mapa donde se muestra la solución para el supracentro usando tiempo fijo (estrella negra, $S 0$ ) y dejando el tiempo libre (estrella negra, $S 1$ ). Otras soluciones dejando el tiempo fijo se muestran con puntos azules. Otras soluciones dejando el tiempo libre se muestran con puntos rojos. 


\section{Conclusiones}

En esta memoria hemos estudiado un método de cálculo que permite conocer la localización aproximada de una fuente puntual de ondas en la atmósfera, a partir de los tiempos de llegada de la onda de presión a las estaciones sísmicas de la superficie y usando un modelo de atmósfera realista. El algoritmo de cálculo se encuentra en el módulo de Python llamado $B A M$, que está desarrollando Luke McFadden (McFadden et al., 2021). Sin embargo, este programa se encuentra en fase de desarrollo todavía, por lo que algunas características no están disponibles. En este sentido, aunque no se ha mencionado en el trabajo, he añadido al algoritmo la posibilidad de elegir los pesos que tendrá cada estación, pues este aspecto aún no estaba disponible. El módulo $B A M$ utiliza un algoritmo genético, llamado $P S O$, para explorar el espacio de soluciones posibles, y hace un trazado de rayos para encontrar los rayos óptimos a cada estación desde cada posible posición del supracentro, y para calcular los tiempos de viaje.

Este método se ha aplicado al caso particular del meteoroide que sobrevoló las provincias de Granada y Jaén en 2016. Se recopilaron un total de 50 registros sísmicos de estaciones de banda ancha y corto periodo del sur de España, incluyendo un perfil de estaciones temporales del $I A G$. Con un tratamiento adecuado de los sismogramas, específicamente un filtrado de las frecuencias menores a $1 \mathrm{~Hz}$ para eliminar las ondulaciones del ruido oceánico y preservar las frecuencias del acoplamiento acústico-sísmico, podemos identificar claramente la señal procedente de la fragmentación explosiva del meteoroide en la mayoría de los registros sísmicos. En concreto, hemos extraído datos de los tiempos de llegada de la señal en un total de 46 estaciones, aunque en 2 de ellas se eligió una señal incompatible (AAPN y JAND). Las cuatro estaciones en las que no se midió tiempo de llegada fueron ANER, TP12, ESTP y BBAA. De las 44 estaciones que quedan, la más cercana a la solución que hemos dado para el supracentro es ASMO, a $21 \mathrm{~km}$, y la más lejana es EBER, a $112 \mathrm{~km}$.

Se trata de un caso de aplicación real, lo que quiere decir que no se van a cumplir unas condiciones de idealidad para la aplicación del método. Es decir, no tenemos una cobertura azimutal completa, ni tampoco podemos conocer las condiciones atmosféricas exactas. Afortunadamente, gracias al gran número de registros sísmicos debido al perfil temporal de estaciones y a la red sísmica local de la cuenca de Granada, este evento se convierte en uno de los eventos de este tipo con mayor número de registros sísmicos. Los datos disponibles abren puerta a estudios de efectos locales y del acoplamiento acústicosísmico. Por otro lado, una forma de reducir los errores provenientes del modelo atmosférico es aplicar a los sondeos perturbaciones en forma de ruido gaussiano, de forma que simulen la varianza real que esperaríamos en los datos atmosféricos, y así se podría estudiar cuánta incertidumbre provocan en los tiempos de viaje calculados, como ya indican en McFadden et al. (2021). Aunque los datos atmosférico utilizados tienen la resolución suficiente para el ejercicio del método, pues es un modelo realista de atmósfera, en el sentido de que se tienen en cuenta los vientos. Se utilizan los datos atmósfericos del European Centre for MediumRange Weather Forecasts (ECMWF), obtenidos del Copernicus Climate Change Service. La ventaja de estos perfiles atmosféricos es que el modelo que usan los interpola a las regiones cercanas, en lugar de tener sólo el perfil vertical del lugar donde se hicieron las medidas. En 
particular, los datos atmosféricos tienen una resolución vertical de 37 niveles de presión que cubren desde los $1000 \mathrm{hPa}$ hasta $1 \mathrm{hPa}$, a lo largo de un mallado con espaciado horizontal de $0.25^{\circ}$. Las variables que obtenemos de este servicio son: temperatura, componente zonal del viento, componente meridional y geopotencial (relacionado con la altura geopotencial).

Para su aplicación, se ha optado por las dos vías posibles. Por un lado, usando el tiempo de ocurrencia que nos proporcionan los registros en videocámaras y, por otro lado, calculando también este tiempo junto con la localización espacial.

A la vista de los resultados podemos ver que este método de cálculo, aplicado a un problema real, sí nos ha permitido dar una localización para el supracentro, pero dentro de un intervalo grande de incertidumbre y solamente para el caso en el que conocemos el tiempo de ocurrencia de la fragmentación explosiva, obtenido por otros medios. Los resultados dejando el tiempo como parámetro libre no han sido verosímiles, en el sentido de que el tiempo calculado de la explosión no concuerda con lo que sabemos por datos externos. Esto nos sirve para advertir, de nuevo, que sólo podemos admitir los resultados proporcionados por este método como válidos cuando los hayamos podido contrastar con otro tipo de datos y soluciones antes. Los resultados con el tiempo fijo sí son aceptables en cierto grado, ya que la localización del epicentro se encuentra dentro de la proyección de la trayectoria del meteoroide en superficie, calculada por triangulación por José María Madiedo usando los registros de las estaciones de detección de meteoros de Calar Alto (Almería), La Hita (Toledo), La Sagra (Granada), Sierra Nevada (Granada) y Sevilla. En particular, el supracentro calculado de esta forma se encuentra a una altura de $38.3 \pm 3 \mathrm{~km}$ sobre el municipio de Alcalá la Real en la provincia de Jaén, en $37.4939^{\circ} \mathrm{N}, 3.9083^{\circ} \mathrm{O}$. Los parámetros específicos usados para obtener este resultado con tiempo de ocurrencia fijo a las 21:25:47.3 UTC han sido: tamaño de enjambre para el algoritmo PSO, $n=200$; tolerancia vertical para la búsqueda del rayo óptimo, $3000 \mathrm{~m}$; tolerancia horizontal, $660 \mathrm{~m}$; espaciado inicial para el trazado de los rayos, $0.75^{\circ}$ para el ángulo de despegue y $1.5^{\circ}$ para el ángulo de azimut; el volumen de búsqueda usado va desde los $20000 \mathrm{~m}$ hasta los $45000 \mathrm{~m}$ para la altura, longitud entre $4.25^{\circ} \mathrm{O}$ y $3.75^{\circ} \mathrm{O}$, y latitud entre $37.25^{\circ} \mathrm{N}$ y $37.75^{\circ} \mathrm{N}$.

Tanto el hecho de no poder conocer las condiciones atmosféricas, como las aproximaciones que se toman en el desarrollo del método, como las tolerancias que hay que aplicar a la búsqueda de los rayos óptimos, implican que el método puede usarse para localizar el supracentro, pero no podemos ir más allá. En particular, no consigue una precisión suficiente para poder utilizarlo para validar modelos atmosféricos o identificar llegadas en los registros sísmicos. Los residuos obtenidos son mucho mayores que los errores que podemos cometer al medir los tiempos de llegada en los sismogramas, por lo que no hay suficiente precisión como para discernir entre la llegada de la onda directa y otras llegadas de precursores o de ondas reflejadas. Para ello habría que estudiar cómo se produce el acoplamiento sísmicoacústico, y como se traducen los distintos caminos de las ondas en el sismograma, lo cual podría ser el rumbo de futuras investigaciones en este campo, con el objetivo de añadir al método las llegadas de precursores y reflexiones atmosféricas. Ni tampoco se consigue una precisión suficiente como para resolver anomalías locales en parámetros atmosféricos respecto al modelo de atmósfera usado.

A pesar de sus limitaciones, el trazado de rayos atmosférico es un paso imprescindible si queremos estudiar las detecciones sísmicas de meteoroides o de otras fuentes acústicas en la atmósfera. Los resultados de un trazado de rayos nos proporcionan algunos parámetros básicos si queremos estudiar el acoplamiento acústico-sismico, el patrón de radiación de la fuente o la complejidad de la forma de onda registrada, como por ejemplo la distancia viajada por los rayos, los ángulos de incidencia o la dirección de procedencia. 


\section{Bibliografía}

Blokhintzev, D. (1946). The propagation of sound in an inhomogeneous and moving medium I. The Journal of the Acoustical Society of America, 18(2):322-328.

Bronshten, V. A. (1983). Physics of Meteoric Phenomena. Springer Netherlands.

Edwards, W. N. (2003). SUPRACENTER: Determining locations of fireball terminal bursts using seismic arrival times of acoustic waves. Master of Science, University of Calgary, Alberta.

Edwards, W. N., Eaton, D. W., and Brown, P. G. (2008). Seismic observations of meteors: Coupling theory and observations. Rev. Geophys., 46(4):RG4007.

Edwards, W. N. and Hildebrand, A. R. (2004). SUPRACENTER: Locating fireball terminal bursts in the atmosphere using seismic arrivals. Meteoritics $\&$ Planetary Science, 39(9):1449-1460.

Feynman, R. P., Leighton, R. B., and Sands, M. (2011). The Feynman lectures on physics, Vol. I: The new millennium edition: mainly mechanics, radiation, and heat, volume 1. Basic books.

Garcés, M. A., Hansen, R. A., and Lindquist, K. G. (1998). Traveltimes for infrasonic waves propagating in a stratified atmosphere. Geophys. J. Int., 135(1):255-263.

Griffiths, D. J. (2013). Introduction to electrodynamics. Pearson, 4th edition.

Groves, G. (1955). Geometrical theory of sound propagation in the atmosphere. Journal of Atmospheric and Terrestrial Physics, 7:113-127.

Heimann, S., Gonzalez, A., Wang, R., Cesca, S., and Dahm, T. (2013). Seismic Characterization of the Chelyabinsk Meteor's Terminal Explosion. Seismological Research Letters, 84(6):1021-1025.

Le Pichon, A., Blanc, E., and Hauchecorne, A. (2010). Infrasound monitoring for atmospheric studies. Springer Science \& Business Media.

Lindsay, R. B. (1960). Mechanical Radiation. McGraw-Hill.

Lucrecio Caro, T. (1999). De la naturaleza de las cosas: poema en seis cantos. Alicante: Biblioteca Virtual Miguel de Cervantes, 1999.

Madiedo, J. M. (2016). Información sobre la bola de fuego. http://meteoroides.net/ metobs_fireball_11DIC2016.html\#infobolido.

McFadden, L., Brown, P., Vida, D., and Spurný, P. (2021). Fireball characteristics derivable from acoustic data. Journal of Atmospheric and Solar-Terrestrial Physics, 216:105587. 
Mirjalili, S. (2021). Simulation of particles in Particle Swarm Optimization. https://au.mathworks.com/matlabcentral/fileexchange/ 69027-simulation-of-particles-in-particle-swarm-optimization.

Pastor, J. (2016). Una bola de fuego se deja ver en Granada y asusta a la población. https://www.ideal.es/granada/provincia-granada/201612/12/ bola-fuego-deja-granada-20161212001408. html?ref=https $\% 3 \mathrm{~A} \% 2 \mathrm{~F} \% 2 \mathrm{Fwww}$. google. com\%2F.

ReVelle, D. O. (1973). Acoustics of meteors. Effects of the atmospheric temperature and wind structure on the sound produced by meteors. Part 1. Meteors as Sound Producers. Technical Report, University of Michigan.

Udías, A. and Mezcua, J. (1997). Fundamentos de geofísica. Alianza. 


\section{A. Estaciones sísmicas y sismogramas}

Información sobre las estaciones sísmicas que aparecen en la figura 3.1.

\begin{tabular}{|c|c|c|c|c|c|}
\hline Código & Latitud $\left(^{\circ}\right)$ & Longitud $\left(^{\circ}\right)$ & Elevación (m) & Network & Nombre \\
\hline AAPN & 37.307667 & -4.120167 & 1160 & IG & Arroyo Pinares \\
\hline $\mathrm{ACHM}$ & 37.105000 & -3.829667 & 860 & IG & Chimeneas \\
\hline ACRT & 37.189999 & -3.595600 & 770 & IG & Cartuja \\
\hline AETJ & 37.236099 & -3.688300 & 794 & IG & Sierra Elvira \\
\hline AFUE & 37.113335 & -3.506833 & 1586 & IG & Fuente Fría \\
\hline ALOJ & 37.109001 & -4.105000 & 1340 & IG & Sierra de Loja \\
\hline ANER & 36.762333 & -3.845333 & 170 & IG & Cuevas de Nerja \\
\hline APHE & 36.952000 & -3.688000 & 1360 & IG & Pico Herrero \\
\hline ASMO & 37.358002 & -3.743000 & 1170 & IG & Sierra Morrones \\
\hline ATEJ & 36.915001 & -4.014000 & 1480 & IG & Sierra Tejeda \\
\hline BBAA & 37.195400 & -3.627000 & 660 & IG & Bellas Artes \\
\hline EBER & 36.897900 & -2.889600 & 1690 & ES & Berja \\
\hline EGOR & 37.110100 & -4.109600 & 1386 & ES & Sierra Gorda \\
\hline ELGU & 36.867802 & -3.626600 & 874 & ES & Los Guajares \\
\hline EQES & 37.802799 & -3.071100 & 1140 & ES & Quesada \\
\hline EQTA & 37.205002 & -3.439900 & 1100 & ES & Presa de Quéntar \\
\hline ESTP & 37.271332 & -4.866167 & 893 & IG & Estepa \\
\hline GORA & 37.480499 & -3.039833 & 895 & IG & Gorafe \\
\hline JAND & 38.221584 & -3.970483 & 484 & IG & Jándula-Sierra Morena \\
\hline TRAD & 37.175201 & -3.602700 & 684 & IG & Traductores \\
\hline TP01 & 36.882176 & -3.068611 & 665 & IG & TP01 \\
\hline TP02 & 36.888634 & -3.109529 & 1183 & IG & TP02 \\
\hline TP03 & 36.880755 & -3.139966 & 1225 & IG & TP03 \\
\hline TP04 & 36.879106 & -3.189494 & 1303 & IG & TP04 \\
\hline TP05 & 36.879361 & -3.222236 & 1190 & IG & TP05 \\
\hline TP06 & 36.878578 & -3.251819 & 1291 & IG & TP06 \\
\hline TP07 & 36.880576 & -3.297624 & 735 & IG & TP07 \\
\hline TP08 & 36.875523 & -3.335132 & 841 & IG & TP08 \\
\hline TP09 & 36.875988 & -3.375582 & 721 & IG & TP09 \\
\hline TP10 & 36.872190 & -3.411597 & 719 & IG & TP10 \\
\hline TP11 & 36.866946 & -3.456604 & 682 & IG & TP11 \\
\hline TP12 & 36.859954 & -3.496747 & 777 & IG & TP12 \\
\hline TP13 & 36.850350 & -3.526000 & 563 & IG & TP13 \\
\hline TP14 & 36.853787 & -3.559288 & 695 & IG & TP14 \\
\hline TP15 & 36.848228 & -3.595832 & 477 & IG & TP15 \\
\hline TP16 & 36.849354 & -3.631293 & 570 & IG & TP16 \\
\hline TP17 & 36.851312 & -3.663272 & 1117 & IG & TP17 \\
\hline TP18 & 36.854762 & -3.703148 & 921 & IG & TP18 \\
\hline TP19 & 36.861639 & -3.727192 & 1026 & IG & TP19 \\
\hline
\end{tabular}




\begin{tabular}{|c|c|c|c|c|c|}
\hline Código & Latitud $\left(^{\circ}\right)$ & Longitud $\left(^{\circ}\right)$ & Elevación $(\mathrm{m})$ & Network & Nombre \\
\hline TP20 & 36.857684 & -3.773485 & 1125 & IG & TP20 \\
TP21 & 36.862450 & -3.800632 & 1267 & IG & TP21 \\
TP22 & 36.875853 & -3.845605 & 1325 & IG & TP22 \\
TP23 & 36.858219 & -3.879071 & 1271 & IG & TP23 \\
TP24 & 36.846475 & -3.923061 & 791 & IG & TP24 \\
TP25 & 36.843853 & -3.952675 & 1074 & IG & TP25 \\
TP26 & 36.849952 & -3.990660 & 578 & IG & TP26 \\
TP27 & 36.849167 & -4.026998 & 545 & IG & TP27 \\
TP28 & 36.843958 & -4.059058 & 531 & IG & TP28 \\
TP29 & 36.846278 & -4.098463 & 323 & IG & TP29 \\
TP30 & 36.846750 & -4.128586 & 99 & IG & TP30 \\
\hline
\end{tabular}

Tabla A.1: Información de las estaciones.

A partir de aquí se muestran los sismogramas brutos y los ya procesados de todas las estaciones. 


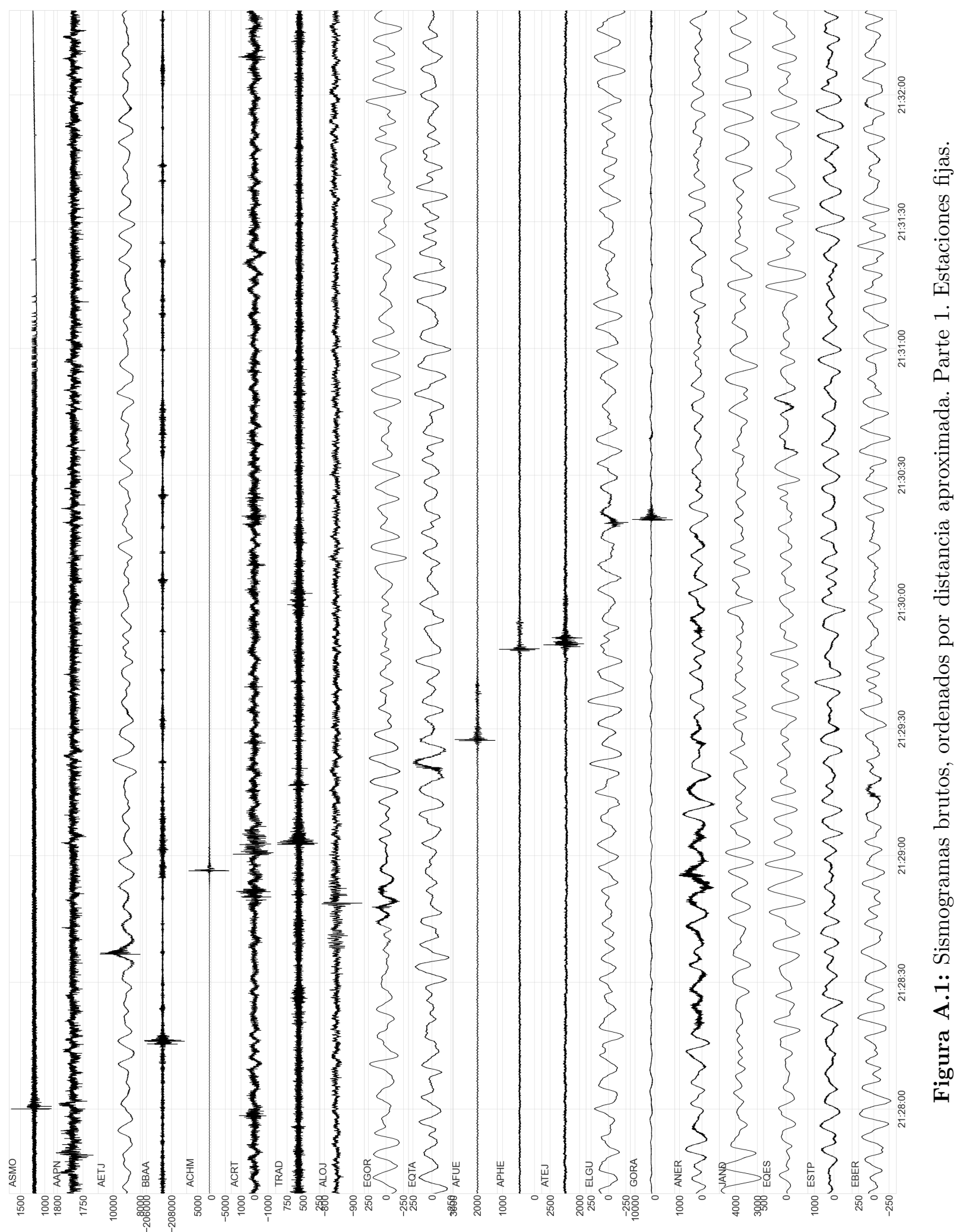




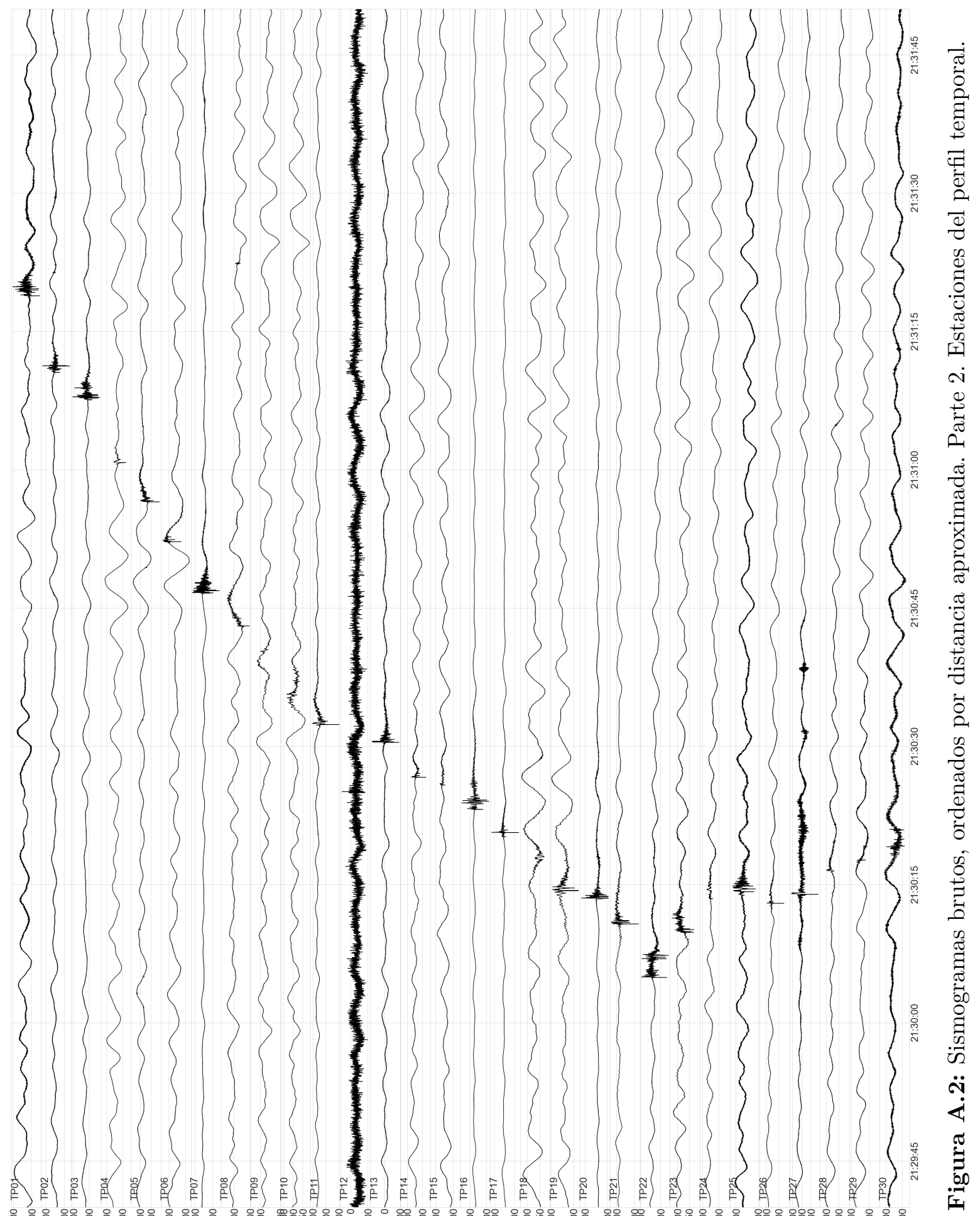

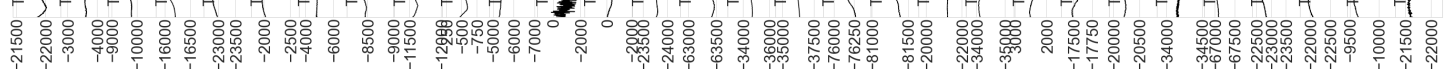




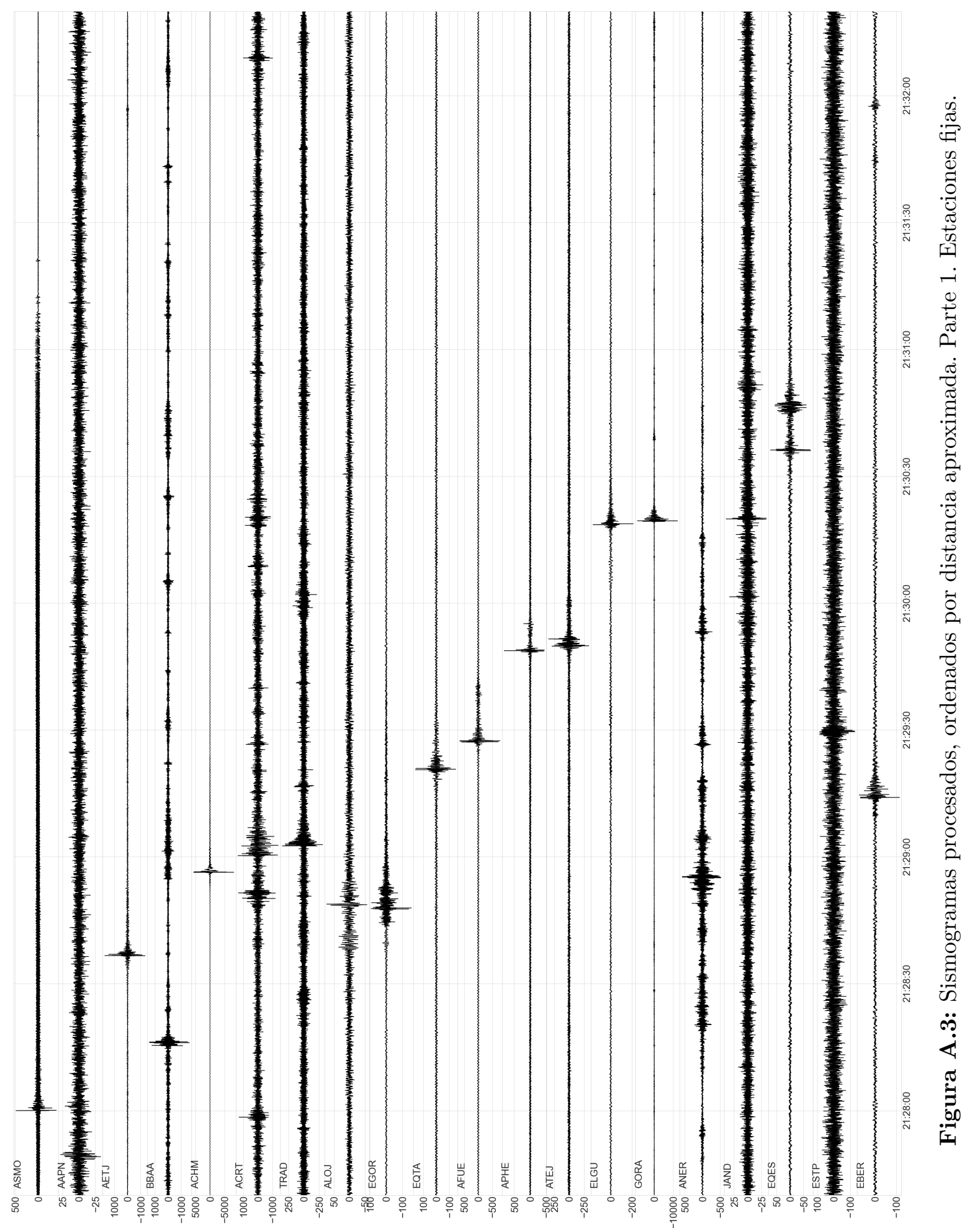




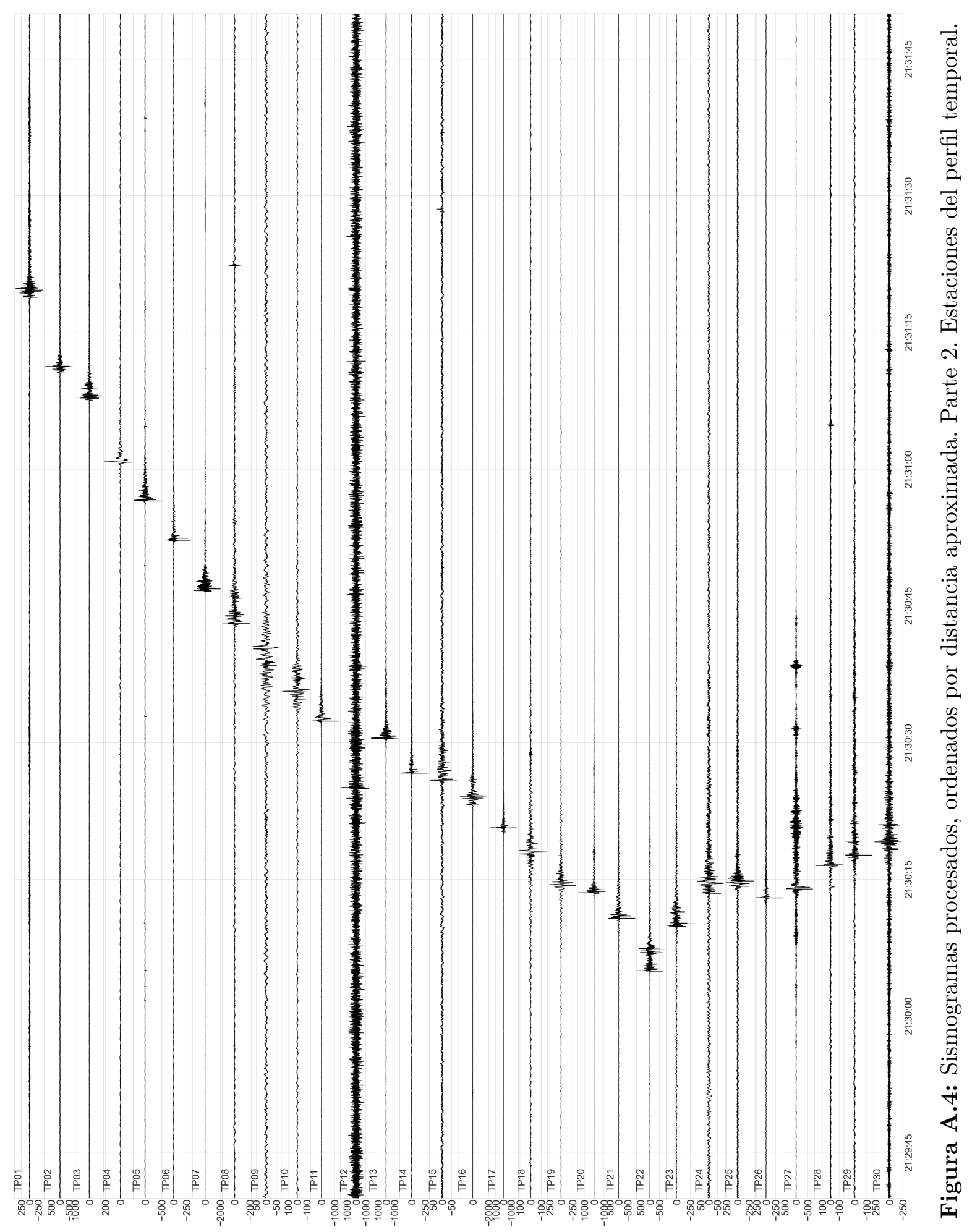




\section{B. Tiempos de llegada}

En la tabla aparecen los tiempos de llegada que hemos marcado en cada uno de los sismogramas de las 46 estaciones sísmicas. Es el tiempo en segundos que ha transcurrido desde el tiempo de referencia, las 21:25:00 UTC. Como se ha explicado, se ha elegido el instante en que la amplitud crece de manera abrupta en el registro de la estación. No podemos afirmar que estos sean los tiempos reales de la llegada de la onda de presión, y los residuos son demasiado altos como para poder corregir estos tiempos.

\begin{tabular}{|c|c|}
\hline Código & Tiempo de llegada (s) \\
\hline AAPN & 169.38 \\
ASMO & 180.01 \\
AETJ & 216.62 \\
EGOR & 227.71 \\
ALOJ & 228.51 \\
ACHM & 236.39 \\
ACRT & 240.29 \\
TRAD & 242.64 \\
EQTA & 260.66 \\
AFUE & 267.19 \\
APHE & 288.77 \\
ATEJ & 289.88 \\
TP22 & 304.94 \\
TP23 & 309.82 \\
TP21 & 310.73 \\
TP26 & 312.98 \\
TP20 & 313.51 \\
TP27 & 313.97 \\
TP25 & 314.27 \\
TP19 & 314.40 \\
TP24 & 314.43 \\
TP28 & 316.52 \\
TP29 & 317.64 \\
\hline
\end{tabular}

\begin{tabular}{|c|c|}
\hline Código & Tiempo de llegada (s) \\
\hline TP18 & 317.97 \\
ELGU & 318.59 \\
TP30 & 319.11 \\
GORA & 319.52 \\
JAND & 319.88 \\
TP17 & 320.66 \\
TP16 & 324.01 \\
TP15 & 325.82 \\
TP14 & 326.65 \\
TP13 & 330.46 \\
TP11 & 332.36 \\
TP10 & 335.67 \\
EQES & 336.23 \\
TP09 & 340.32 \\
TP08 & 343.07 \\
TP07 & 346.69 \\
TP06 & 352.21 \\
TP05 & 356.53 \\
TP04 & 360.70 \\
TP03 & 367.90 \\
TP02 & 371.29 \\
TP01 & 379.85 \\
EBER & 417.49 \\
\hline
\end{tabular}

Tabla B.1: Tiempos de llegada marcados en los registros.

En las páginas siguientes se muestran en los sismogramas los picks de los tiempos de llegada y las llegadas calculadas por el programa de trazado de rayos para el supracentro óptimo. 


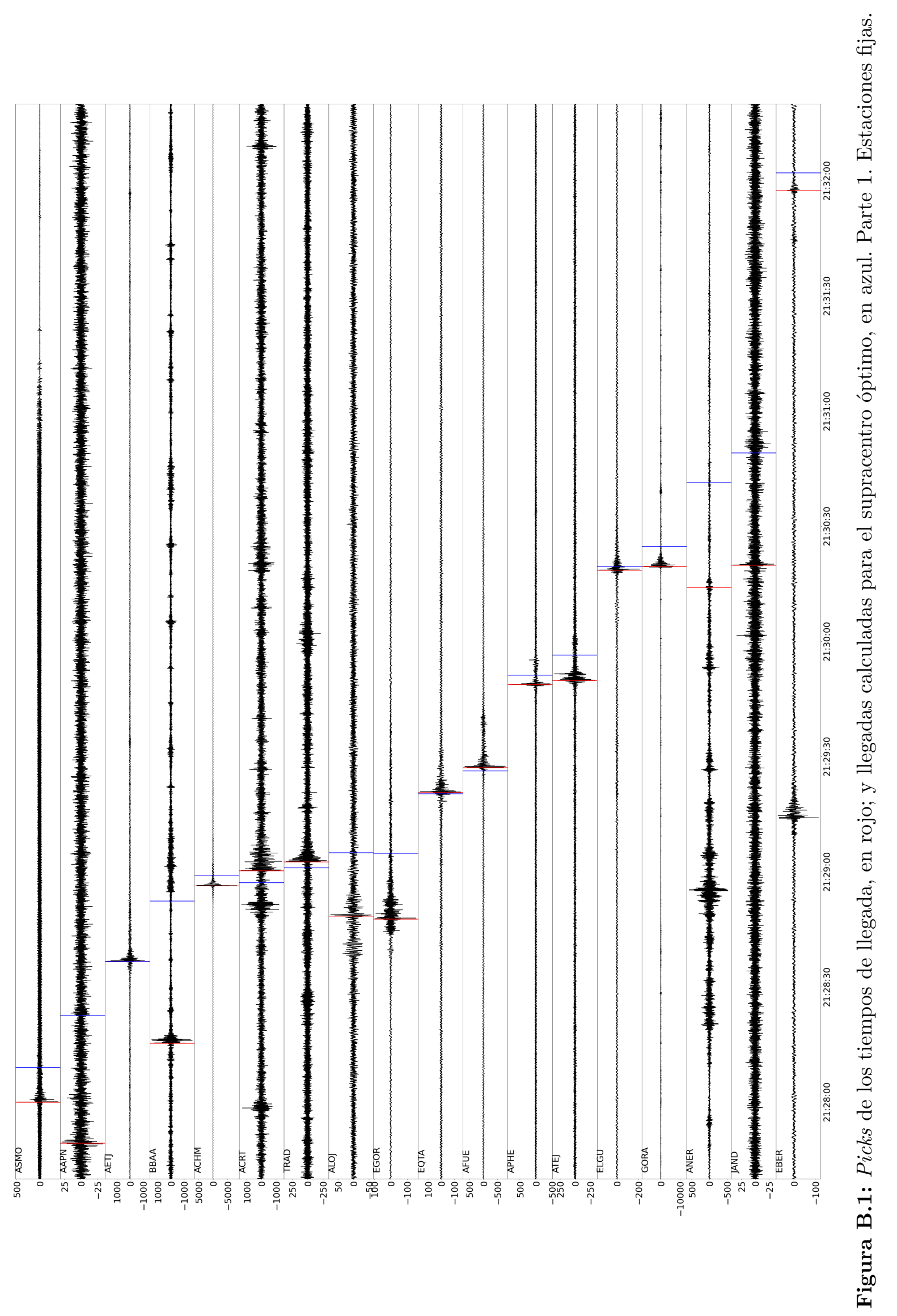




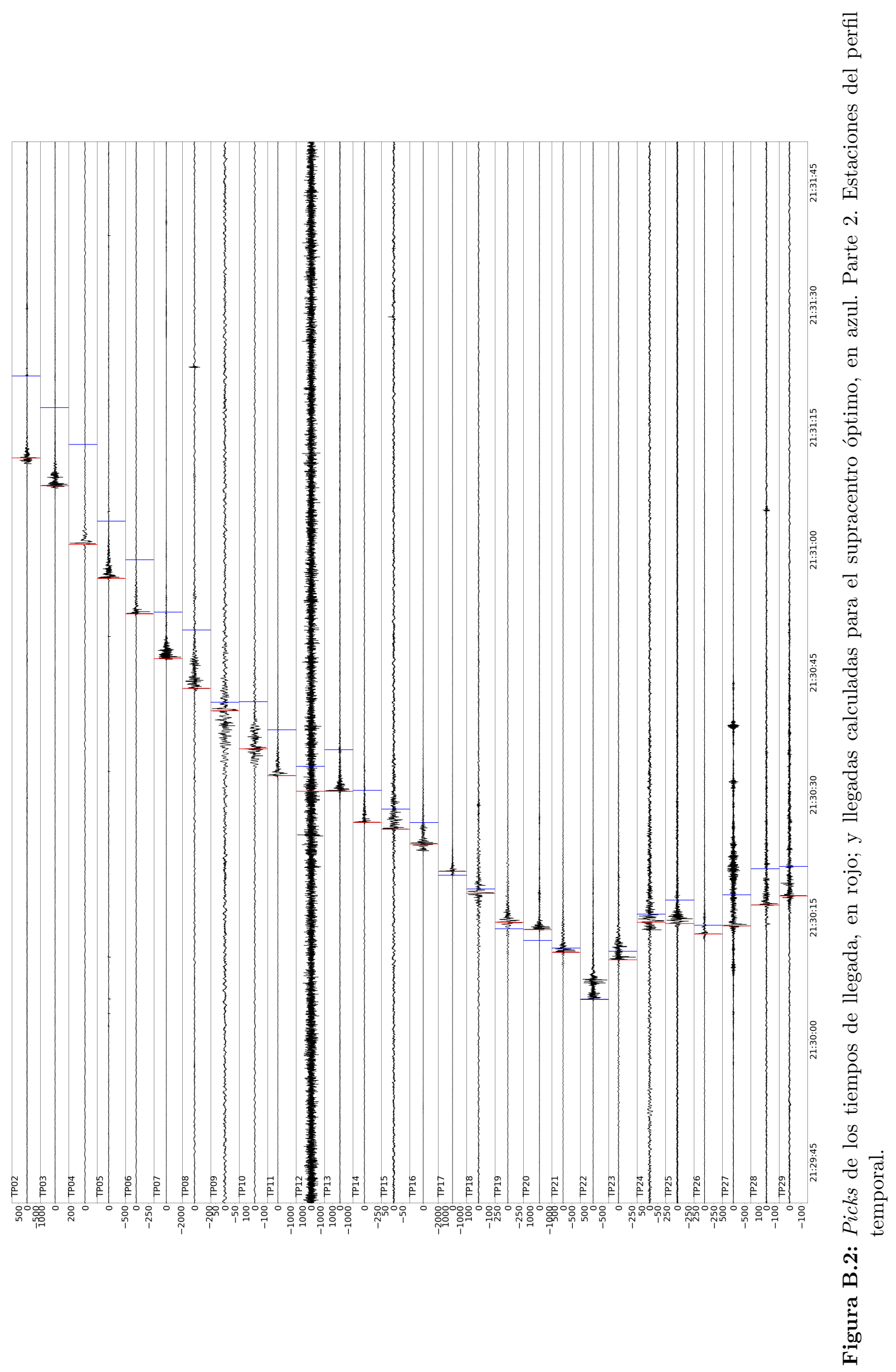





\section{Datos atmosféricos}

Algunas figuras más para mostrar la estructura de los vientos en varios niveles de presión.
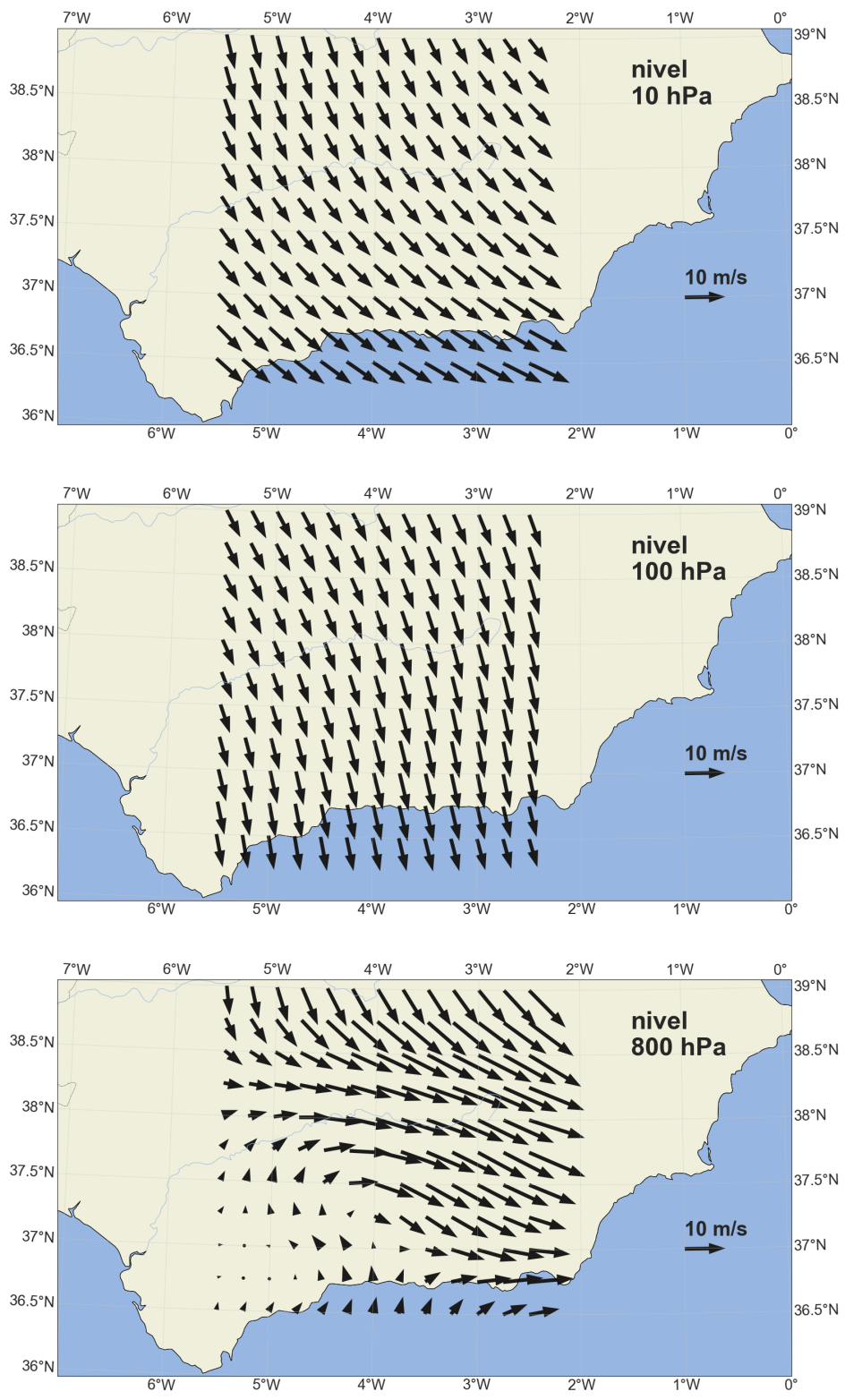

Figura C.1: Magnitud y dirección de los vientos en distintos niveles de presión. 



\section{Transformación vientos}

Aquí se muestra cómo pasar de la magnitud, $w$, y dirección del viento, $\psi$, a las componentes $u$ y $v$, paralela y perpendicular a una dirección dada por $\phi$. (figura D.1).

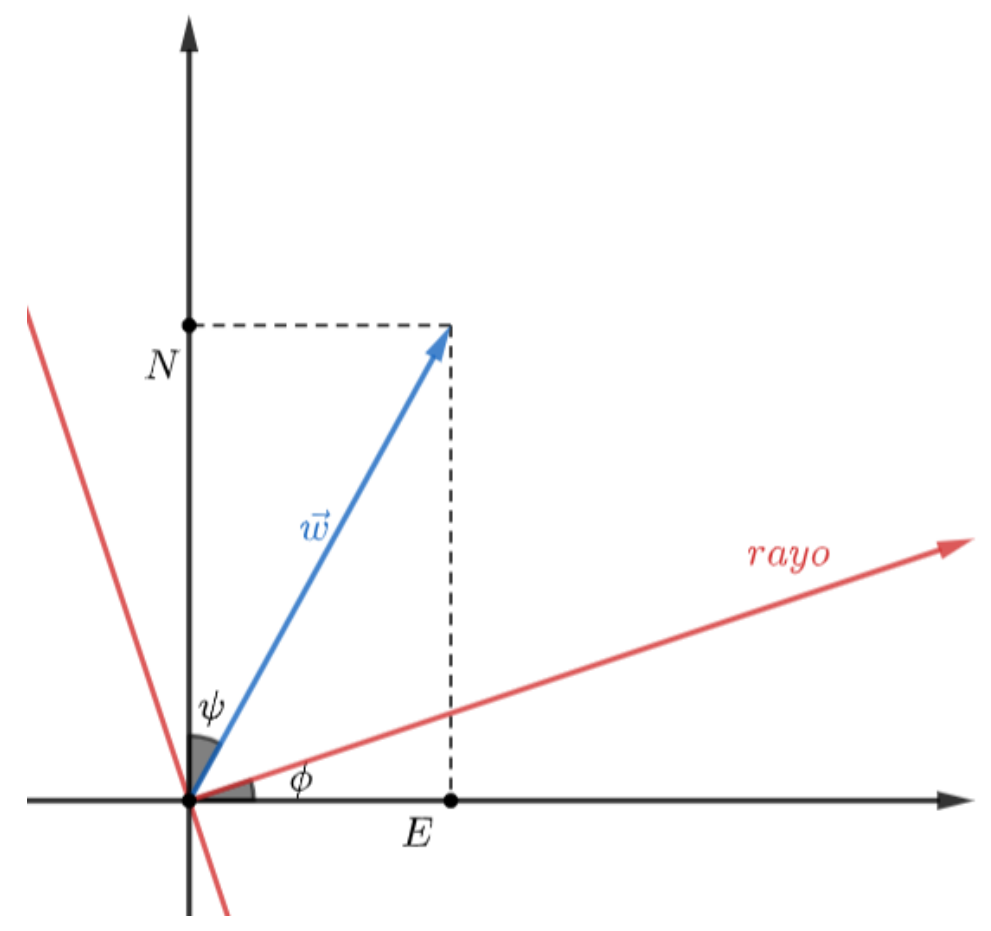

Figura D.1: Esquema con dirección del viento y proyecciones.

Primero, calculamos las componentes Este y Norte del viento:

$$
\begin{aligned}
& E=w \sin \psi \\
& N=w \cos \psi
\end{aligned}
$$

Y ahora hacemos una rotación según el ángulo $\phi$ para calcular las componentes en el sistema rotado:

$$
\left(\begin{array}{l}
u \\
v
\end{array}\right)=\left(\begin{array}{cc}
\cos \phi & \sin \phi \\
-\sin \phi & \cos \phi
\end{array}\right)=\left(\begin{array}{l}
E \\
N
\end{array}\right)
$$





\section{E. Particle Swarm Optimization}

Este algoritmo genético consigue encontrar el valor de las variables de una función para los cuales dicha función es un mínimo. En nuestro caso, la función a minimizar son los residuos de tiempos de viaje, y las variables son las coordenadas del supracentro. La bibliografía usada para esta sección ha sido Mirjalili (2021).

El funcionamiento de este método se suele explicar haciendo una analogía con el movimiento de una bandada de pájaros. Para determinar hacia dónde se mueve un pájaro en particular en cada paso de tiempo hay que tener en cuenta tanto el movimiento propio del pájaro como el movimiento de toda la bandada. La búsqueda que hace el método PSO del espacio de soluciones la realiza explorándolo, no sistemáticamente, si no usando una nube de "partículas" o buscadores. Cada buscador comienza en un lugar aleatorio del espacio de soluciones y en cada paso de su camino debe registrar cuál es el valor mínimo de la función que ha calculado hasta entonces. Es decir, para cada posición del supracentro en la que se encuentre, debe calcular los residuos de viaje para esa posición y decir si es un mínimo en su búsqueda o no. Todos los buscadores registran en cada paso si han encontrado un mínimo o no, y antes de dar el siguiente paso deben comunicarse para ver cual ha sido el valor mínimo del equipo en conjunto. Entonces la dirección del siguiente paso estará determinada por la localización del mínimo personal y del mínimo grupal.

Matemáticamente, la nueva posición de un buscador será la posición anterior más el camino que tiene que recorrer:

$$
\overrightarrow{\boldsymbol{X}}_{i}^{j+1}=\overrightarrow{\boldsymbol{X}}_{i}^{j}+\overrightarrow{\boldsymbol{V}}_{i}^{j+1}
$$

Donde $i$ indica el buscador y $j$ el número de iteración. Como hemos dicho, el recorrido que tiene que hacer para llegar a la siguiente posición depende de la propia inercia que lleva el buscador, el valor del mínimo grupal y el valor del mínimo personal. Es decir:

$$
\overrightarrow{\boldsymbol{V}}_{i}^{j+1}=w \overrightarrow{\boldsymbol{V}}_{i}^{j}+c_{1} r_{1}\left(\overrightarrow{\boldsymbol{P}}_{i}^{j}-\overrightarrow{\boldsymbol{X}}_{i}^{j}\right)+c_{2} r_{2}\left(\overrightarrow{\boldsymbol{G}}_{i}^{j}-\overrightarrow{\boldsymbol{X}}_{i}^{j}\right)
$$

El primer sumando es el término de inercia, cuyo peso lo controla el valor de la constante $w$. El segundo sumando es la llamada componente de cognición, controlado por una constante $c_{1}$ y un número aleatorio $r_{1} . \overrightarrow{\boldsymbol{P}}_{i}^{j}$ es la posición de su marca personal, y por tanto $\overrightarrow{\boldsymbol{P}}_{i}^{j}-\overrightarrow{\boldsymbol{X}}_{i}^{j}$ apunta en la dirección en la que se encuentra su marca personal. El tercer sumando se conoce como componente social, ya que tiene en cuenta la mejor marca del equipo en conjunto, $\overrightarrow{\boldsymbol{G}}_{i}^{j}$. También está controlado por un peso $c_{2}$ y un número aleatorio $r_{2}$.

Este proceso estocástico garantiza encontrar el mínimo de la función. En el caso de la búsqueda del supracentro, se ha dado el mismo peso a todas las componentes, haciendo $c_{1}=c_{2}=w=0.5$. El número de buscadores/partículas ha sido 200, y se ha hecho un máximo de 100 iteraciones. 



\section{F. Datos astrofísicos}

Gracias a las grabaciones de las estaciones de detección de meteoros del proyecto SMART, el profesor José María Madiedo ha calculado la trayectoria aproximada del meteoroide en la atmósfera, así como la curva fotométrica, de la cual nosotros tenemos los tiempos de los máximos de luminosidad, que se muestran en la tabla F.1. Como vemos en la figura, la parte luminosa de la trayectoria del meteoroide comienza sobre el norte de la ciudad de Granada y acaba sobre Alcaudete.

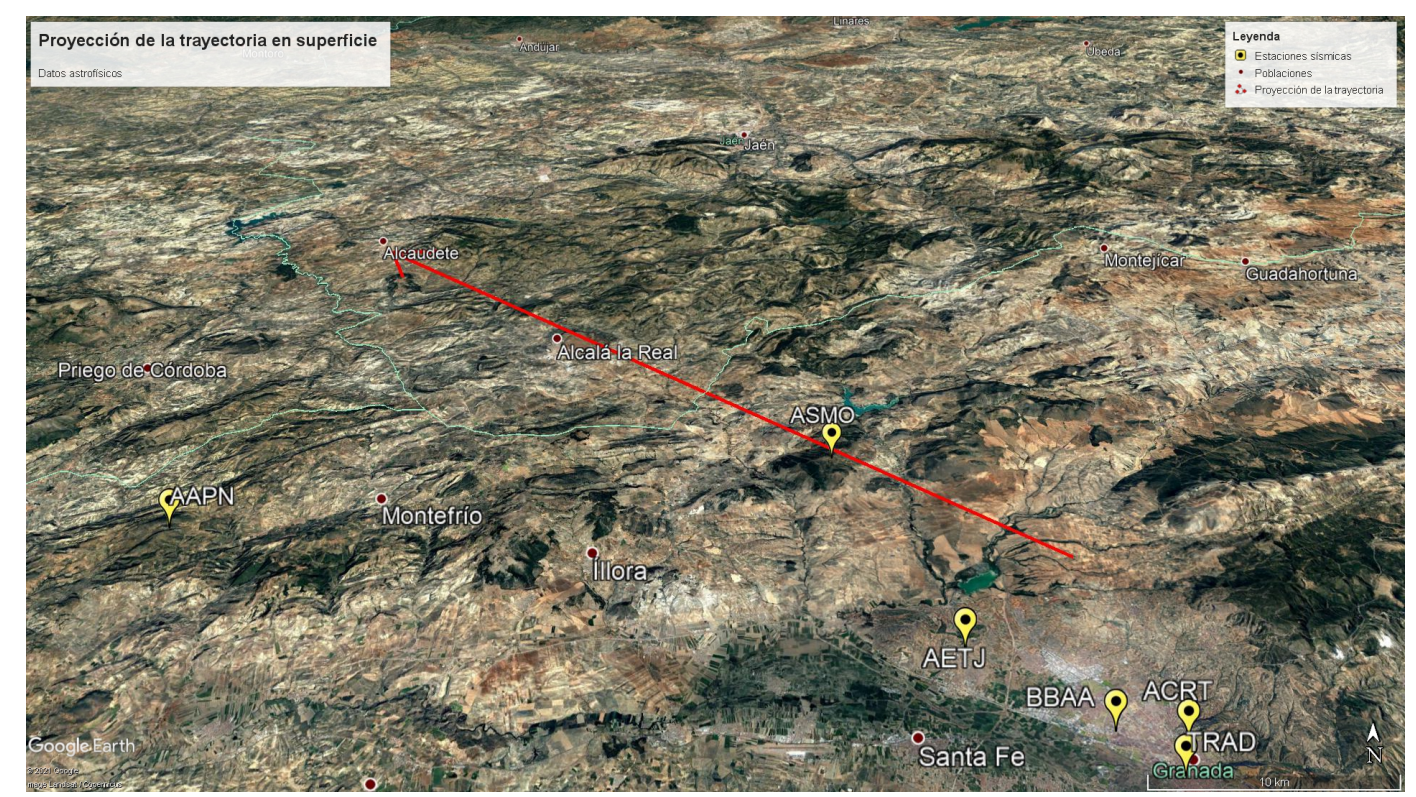

Figura F.1: Proyección de la trayectoria del meteoroide en la superficie terrestre.

\begin{tabular}{|c|c|l|}
\hline $\mathrm{i}$ & Hora UTC & Descripción \\
\hline 1 & $21: 25: 45.1$ & Primera explosión significativa \\
2 & $21: 25: 45.4$ & Intensidad lumínica aprox. igual a la del evento anterior \\
3 & $21: 25: 45.6$ & Intensidad lumínica aprox. igual a la del evento anterior \\
4 & $21: 25: 45.7$ & Intensidad lumínica aprox. igual a 2/3 de la del evento anterior \\
5 & $21: 25: 46.4$ & Intensidad lumínica aprox. igual a la del evento anterior \\
6 & $21: 25: 46.5$ & Intensidad lumínica aprox. igual a la del evento anterior \\
7 & $21: 25: 46.6$ & Intensidad lumínica aprox. igual a la del evento anterior \\
8 & $21: 25: 46.7$ & Intensidad lumínica aprox. igual a la del evento anterior \\
9 & $21: 25: 46.8$ & Intensidad lumínica aprox. igual a la del evento anterior \\
10 & $21: 25: 46.9$ & Intensidad lumínica aprox. igual a la del evento anterior \\
11 & $21: 25: 47.1$ & Intensidad lumínica aprox. igual a 1/2 de la del evento anterior \\
12 & $21: 25: 47.3$ & La explosión más intensa \\
13 & $21: 25: 47.6$ & Explosión final, no muy intensa \\
\hline
\end{tabular}

Tabla F.1: Información sobre los picos de luminosidad registrados por las cámaras. 